Prepared for the U.S. Department of Energy

under Contract DE-AC05-76RL01830

\title{
Literature Review of Spherical Resorcinol-Formaldehyde for Cesium Ion Exchange
}

\author{
GN Brown
}

September 2014

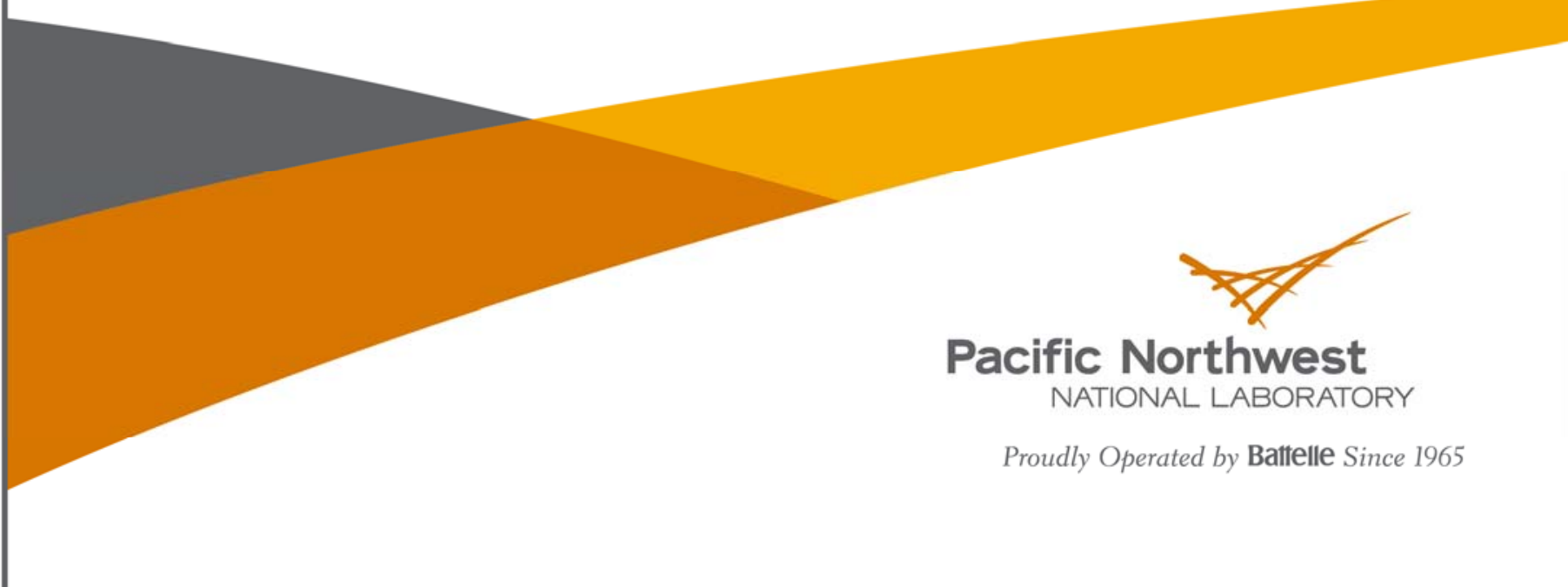




\title{
DISCIAIMER
}

This report was prepared as an account of work sponsored by an agency of the United States Government. Neither the United States Government nor any agency thereof, nor Battelle Memorial Institute, nor any of their employees, makes any warranty, express or implied, or assumes any legal liability or responsibility for the accuracy, completeness, or usefulness of any information, apparatus, product, or process disclosed, or represents that its use would not infringe privately owned rights. Reference herein to any specific commercial product, process, or service by trade name, trademark, manufacturer, or otherwise does not necessarily constitute or imply its endorsement, recommendation, or favoring by the United States Government or any agency thereof, or Battelle Memorial Institute. The views and opinions of authors expressed herein do not necessarily state or rellect those of the United States Government or any agency thereof.

\author{
PACIFIC NORTHWEST NATIONAI, I.ABORATORY \\ operated by \\ BAI"I'ELLE \\ for the \\ INITED STATES DFPARTMENT OF FNFRGY \\ under Contract DE-ACO5-76RL01830 \\ Printed in the United States of America \\ Available to DOE and DOE contractors from the \\ Office of Scientific and Technical Information, \\ P.O. Box 62, Oak Ridge, TN 37831-0062; \\ ph: (865) 576-8401 \\ fax: (865) 576-5728 \\ email: reports (a) adonis,osti.gov
}

\author{
Available to the public from the National Technical Information Service, \\ U.S. Department of Commerce, 5285 Port Royal Rd., Springfield, VA 22161 \\ ph: (800) 553-6847 \\ fax: (703) 605-6900 \\ email: orders $(a)$ ntis,fedworld.gov \\ online ordering: http://www.ntis.gov/ordering.htm
}

This document was printed on recycled paper.

(9/2003) 


\title{
Literature Review of Spherical Resorcinol-Formaldehyde for Cesium Ion Exchange
}

\author{
GN Brown
}

September 2014

Test Specification: 24590-PTF-TSP-RT-09-002 Rev 0

Test Plan: TP-WTPSP-002, Rev. 3.0

Test Exceptions: 24590-PTF-TEF-RT-10-00001, Rev. 0

24590-PTF-TEF-RT-10-00002, Rev. 1

24590-PTF-TEF-RT-11-00003, Rev 0

24590-PTF-TEF-RT-11-00004, Rev 0

R\&T Focus Area: Pretreatment

Test Scoping Statement: 24590-WTP-PL-RT-07-0002, Rev 0; M6-3

Prepared for the U.S. Department of Energy

Under Contract DE-AC05-76RL01830

Pacific Northwest National Laboratory

Richland, Washington 99352 


\section{COMPLETENESS OF TESTING}

This report describes the results of work and testing specified by Test Specification 24590-PTF-TSP-RT-09-002, Rev 0 "RF Resin Cesium Removal with Expanded Load and Elution Conditions," Test Exceptions 24590-PTF-TEF-RT-10-00001, Rev 0, 24590-PTF-TEF-RT-10-00002, Rev 1, 24590-PTF-TEF-RT-11-00003, Rev. 0, 24590-PTF-TEF-RT-11-00004, Rev 0, and Test Plan TP-WTPSP-002, Rev 3.0 "Cesium Ion Exchange Simulant Testing in Support of M-6." The work and any associated testing followed the quality assurance requirements outlined in the Test Specification and Test Plan. The descriptions provided in this test report are an accurate account of both the conduct of the work and the data collected. Test plan results are reported. Also reported are any unusual or anomalous occurrences that are different from expected results. The test results and this report have been reviewed and verified.

\section{Approved:}

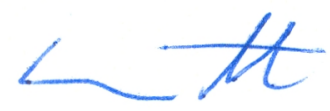

Reid A. Peterson, Manager WTP R\&T Support Project

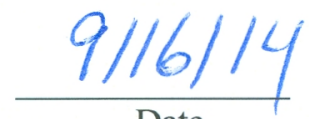

Date 


\section{Summary}

Ion exchange using the spherical resorcinol-formaldehyde (SRF) resin has been selected by the U.S. Department of Energy's Office of River Protection (DOE-ORP) for use in the pretreatment facility (PTF) of the Hanford Tank Waste Treatment and Immobilization Plant (WTP) and for potential application in an at-tank deployment. Over the past two decades, resorcinol-formaldehyde (RF), in original ground gel (GGRF) form and now in SRF form, has been evaluated for the removal of cesium $\left(\mathrm{Cs}^{+}\right)$from defense nuclear waste solutions. Numerous studies have shown that the SRF resin is effective for removing ${ }^{137} \mathrm{Cs}$ from a wide variety of actual and simulated tank waste supernatants (Adamson et al. 2006; Blanchard et al. 2008; Burgeson et al. 2004; Duignan and Nash 2009; Fiskum et al. 2006a, 2006b, 2006c, 2007; Hassan and Adu-Wusu 2003; King et al. 2004; Nash et al. 2006; Thorson and Gilbert 2007). A majority of the historic work presented in the literature, especially work performed at Pacific Northwest National Laboratory (PNNL), Savannah River National Laboratory (SRNL), and Oak Ridge National Laboratory (ORNL), has focused primarily on nominal conditions surrounding expected WTP flowsheet operations (e.g., loading with 4 to $6 \underline{\mathrm{M}}$ sodium $\left(\mathrm{Na}^{+}\right)$solutions at 25 to $45^{\circ} \mathrm{C}$ and eluting with $0.5 \underline{\mathrm{M}}$ $\mathrm{HNO}_{3}$ ). Many batch distribution equilibrium $\left(\mathrm{K}_{\mathrm{d}}\right)$ and kinetic tests have investigated $\mathrm{Cs}^{+}$uptake as a function of expanded concentrations of $\mathrm{Na}^{+}$(up to $8 \underline{\mathrm{M}}$ ), $\mathrm{K}^{+}$(0 to $0.8 \underline{\mathrm{M}}$ ), $\mathrm{Cs}^{+}$(5E-09 to $0.05 \underline{\mathrm{M}}$ ), free hydroxide $\left(\mathrm{OH}^{-}\right)$, and various organic components. Column loading and elution studies have targeted most major types of Hanford and Savannah River tank waste supernatant liquids using actual or simulated wastes and a variety of column dimensions from small-scale $(10 \mathrm{~mL})$ laboratory tests to large-scale operations.

The current report summarizes work performed throughout the scientific community and DOE complex as reported in the open literature and DOE-sponsored reports on the $\mathrm{Cs}^{+}$ion exchange (CIX) characteristics of SRF resin. King (2007) completed a similar literature review in support of material selection for the Small Column Ion Exchange (SCIX) project. Josephson et al. (2010) and Sams et al. (2009) provided a similar brief review of SRF CIX for the near-tank $\mathrm{Cs}^{+}$removal (NTCR) project.

Thorson (2008a) documented the basis for recommending SRF over SuperLig ${ }^{\mathrm{TM}} 644$ as the primary CIX resin in the WTP. The current review expands on previous work, summarizes additional work completed to date, and provides a broad view of the literature without focusing on a specific column system. Although the focus of the current review is the SRF resin, many cited references include multiple materials such as the non-spherical GGRF and SuperLig ${ }^{\mathrm{TM}} 644$ organic resins and crystalline silicotitanate (CST) IONSIV ${ }^{\mathrm{TM}}$ IE-911, a non-elutable inorganic material. This report summarizes relevant information provided in the literature. Unfortunately, some of the individual references contain hundreds of pages of raw data, technical analysis, computational input/output files, or detailed procedures. Due to the large volume of information compiled over the course of nearly 25 years, more complete details must be obtained directly from the cited references.

\section{S.1 Objective}

The objective of this report is to summarize the large amount of experimental and theoretical work and literature reports relating to the use of the SRF resin for the ion exchange separation of $\mathrm{Cs}^{+}$from defense-related nuclear waste materials.

Table S.1 provides the objectives that apply to this task. 
Table S.1. Summary of Test Objectives and Results

\begin{tabular}{lcl}
\hline \multicolumn{1}{c}{ Test Objective } & Objective & \multicolumn{1}{c}{ Discussion } \\
\hline $\begin{array}{l}\text { Review the known literature and } \\
\text { summarize the CIX work } \\
\begin{array}{l}\text { completed to date relating to the } \\
\text { SRF resin. }\end{array}\end{array}$ & Yes & $\begin{array}{l}\text { The report summarizes nearly a decade of literature reports related } \\
\text { to the SRF resin and presents information on synthesis, } \\
\text { characterization, use, flow sheet development, column load/elution, } \\
\text { equilibrium batch contacts, kinetics, modeling, spent resin } \\
\text { characterization, and testing with actual and simulated wastes. }\end{array}$ \\
\hline
\end{tabular}

\section{S.2 Test Exceptions}

Table S.2 shows that no test exceptions were applicable to this report.

Table S.2. Test Exceptions

\begin{tabular}{|c|c|}
\hline Test Exceptions & Description of Test Exceptions \\
\hline 24590-PTF-TEF-RT-10-00001, Rev 0 & $\begin{array}{l}\text { This test exception was received from Bechtel National, Inc. (BNI) on } \\
\text { September } 13,2010 \text {. The primary temperature selected for testing was } \\
45^{\circ} \mathrm{C} \text {. However, the operating temperatures have been changed in the } \\
\text { design of the ultra-filtration process (UFP) and Cs ion exchange } \\
\text { process. Temperatures were added and changed to include } 50^{\circ} \mathrm{C} \text { to } \\
\text { determine cesium removal performance impacts based on these design } \\
\text { updates. The test exception is addressed in Russell et al. (2012a) and } \\
\text { is not applicable to the current literature review report. }\end{array}$ \\
\hline 24590-PTF-TEF-RT-10-00002, Rev 1 & $\begin{array}{l}\text { This test exception was received from BNI on September } 25,2010 \text {. } \\
\text { The kinetics testing described in the test plan }{ }^{(\mathrm{a})} \text { had an elution flow rate } \\
\text { of } 1.4 \text { bed volumes (BV)/hour. It was determined that the lowest } \\
\text { accurate flow rate that the pumps can support was } 2.8 \mathrm{BV/hour.} \mathrm{It} \mathrm{was} \\
\text { determined that using } 2.8 \mathrm{BV} / \text { hour would not impact the test objective, } \\
\text { so it was changed. The test exception is addressed in Russell et al. } \\
\text { (2012a) and is not applicable to the current literature review report. }\end{array}$ \\
\hline 24590-PTF-TEF-RT-11-00003, Rev 0 & $\begin{array}{l}\text { This test exception was received from BNI on March } 11,2011 \text {. } \\
\text { Results for the testing of Cs kinetic load tests indicated that further } \\
\text { investigation was required. Further work was added to identify the } \\
\text { potential precipitates and particles observed during the } 65^{\circ} \mathrm{C} \text { and } 75^{\circ} \mathrm{C} \\
\text { long-duration runs. The highest temperature to complete the } 30 \text {-day } \\
\text { duration test without issues was } 50^{\circ} \mathrm{C} \text {. Therefore, tests at } 55^{\circ} \mathrm{C} \text { and } \\
60^{\circ} \mathrm{C} \text { were added also. The test exception is addressed in Russell et al. } \\
(2014) \text { and is not applicable to the current literature review report. }\end{array}$ \\
\hline 24590-PTF-TEF-RT-11-00004, Rev 0 & $\begin{array}{l}\text { This test exception was received from BNI on December 22, } 2011 . \\
\text { The test exception is addressed in Kim et al. (2012a, 2012b) and is not } \\
\text { applicable to the current literature review report. }\end{array}$ \\
\hline
\end{tabular}




\section{S.3 Results and Performance Against Success Criteria}

Table S.3 presents research and technology (R\&T) success criterion for achieving the test objective.

Table S.3. The Success Criterion for the SRF Resin Literature Review Task

Success Criterion

Summarize the open literature reports of the use of the SRF resin for the removal of $\mathrm{Cs}^{+}$from defense-related wastes by ion exchange.

\section{S.4 Quality Requirements}

The PNNL Quality Assurance (QA) Program is based upon the requirements defined in DOE Order 414.1D, Quality Assurance, and Title 10 of the Code of Federal Regulations Part 830, Energy/Nuclear Safety Management, and Subpart A-Quality Assurance Requirements (a.k.a. the Quality Rule). PNNL has chosen to implement the following consensus standards in a graded approach:

- ASME NQA-1-2000, Quality Assurance Requirements for Nuclear Facility Applications, Part 1, Requirements for Quality Assurance Programs for Nuclear Facilities.

- ASME NQA-1-2000, Part II, Subpart 2.7, Quality Assurance Requirements for Computer Software for Nuclear Facility Applications.

- ASME NQA-1-2000, Part IV, Subpart 4.2, Graded Approach Application of Quality Assurance Requirements for Research and Development.

The procedures necessary to implement the requirements are documented through PNNL's "How Do I...?” $\left(\mathrm{HDI}^{1}\right)$.

The Waste Treatment Plant Support Project (WTPSP) implements an NQA-1-2000 QA Program, graded on the approach presented in NQA-1-2000, Part IV, Subpart 4.2. The WTPSP Quality Assurance Manual (QA-WTPSP-0002) describes the technology life cycle stages under the WTPSP Quality Assurance Plan (QA-WTPSP-0001). The technology life cycle includes the progression of technology development, commercialization, and retirement in process phases of basic and applied research and development (R\&D), engineering and production, and operation until process completion. The life cycle is characterized by flexible and informal QA activities in basic research, which become more structured and formalized through the applied R\&D stages.

The work described in this report has been completed under the QA technology level of applied research. WTPSP addresses internal verification and validation activities by conducting an independent technical review of the final data report in accordance with WTPSP procedure QA-WTPSP-601, Document Preparation and Change. This review verifies that the reported results are traceable, that inferences and conclusions are soundly based, and that the reported work satisfies the test plan objectives.

${ }^{1}$ System for managing the delivery of PNNL policies, requirements, and procedures. 


\section{S.5 R\&T Test Conditions}

This report summarizes historical literature and government-sponsored reports that describe the ion exchange removal of $\mathrm{Cs}^{+}$from actual or simulated defense-related wastes. No experimental testing was required to complete this review.

Table S.4. Summary of R\&T Test Conditions

\begin{tabular}{cc}
\hline R\&T Test Condition & Discussion \\
\hline NA & NA \\
\hline
\end{tabular}

\section{S.6 Simulant Use}

No simulants were used in this literature review.

\section{S.7 Discrepancies and Follow-on Tests}

No discrepancies were found and no follow-on tests are required. 


\section{Acknowledgments}

The author would like to thank Jennifer Meehan and Fred Damerow of the Hanford Tank Waste Treatment and Immobilization Plant project and Murray Thorson of Washington River Protection Solutions for their technical insights, helpful discussions, and support. The author is grateful for the assistance of Pacific Northwest National Laboratory staff, including Mike Parker (editorial and document design support) and Dean Kurath, Reid Peterson, Renee Russell, and Sandy Fiskum (technical review and discussion) and Bill Wilmarth of Savannah River National Laboratory (support locating certain reports). 



\section{Acronyms and Abbreviations}

\begin{tabular}{|c|c|}
\hline ASME & American Society of Mechanical Engineers \\
\hline ASTM & American Society for Testing and Materials \\
\hline $\mathrm{BV}$ & bed volume \\
\hline CIX & cesium ion exchange \\
\hline CST & crystalline silicotitanate \\
\hline DIW & deionized water \\
\hline DF & decontamination factor \\
\hline DOE & U.S. Department of Energy \\
\hline GGRF & ground gel resorcinol-formaldehyde \\
\hline HDI & "How Do I," the standards-based management system for PNNL \\
\hline HLW & low-volume high-level waste \\
\hline LAW & high-volume low-activity waste \\
\hline NTCR & near-tank cesium removal \\
\hline ORNL & Oak Ridge National Laboratory \\
\hline ORP & DOE-Office of River Protection \\
\hline PNNL & Pacific Northwest National Laboratory \\
\hline PNWD & Battelle-Pacific Northwest Division \\
\hline PSD & particle size distribution \\
\hline PTF & pretreatment facility \\
\hline QA & Quality Assurance \\
\hline RCRA & Resource Conservation and Recovery Act \\
\hline $\mathrm{RF}$ & resorcinol-formaldehyde \\
\hline RPP-WTP & (River Protection Project) Waste Treatment Plant \\
\hline RV & resin volume \\
\hline $\mathrm{R} \& \mathrm{D}$ & Research and Development \\
\hline $\mathrm{R} \& \mathrm{~T}$ & Research and Technology \\
\hline SCIX & Small Column Ion Exchange \\
\hline SRF & spherical resorcinol-formaldehyde \\
\hline SRNL & Savannah River National Laboratory \\
\hline SRS & Savannah River Site \\
\hline TCLP & Toxicity Characteristic Leaching Procedure \\
\hline TGA & thermogravimetric analysis \\
\hline TRU & transuranic \\
\hline VERSE-LC & Modeling program for liquid chromatography \\
\hline WSRC & Westinghouse Savannah River Company \\
\hline WTP & Hanford Tank Waste Treatment and Immobilization Plant \\
\hline WTPSP & Waste Treatment Plant Support Project \\
\hline
\end{tabular}





\section{Contents}

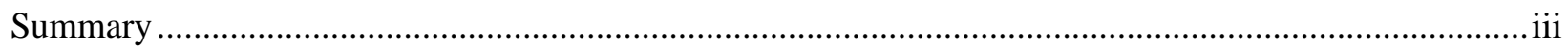

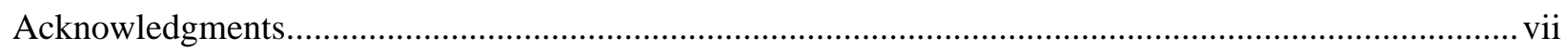

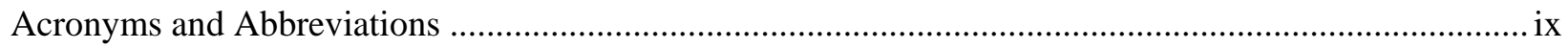

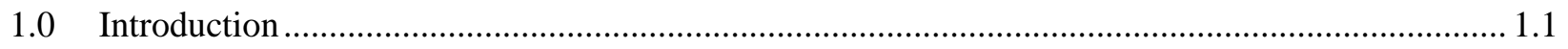

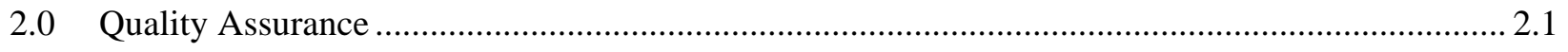

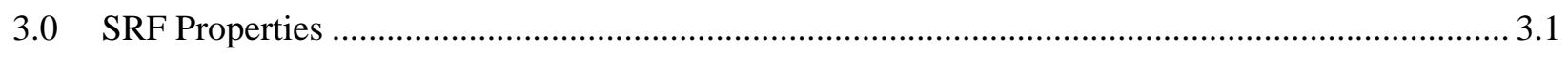

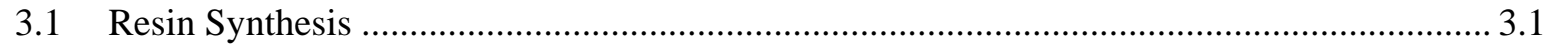

3.2 Resin Production Lot Evaluation..................................................................................... 3.1

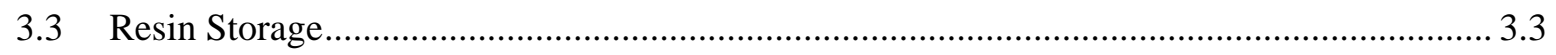

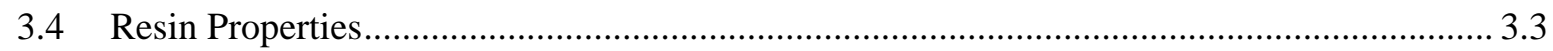

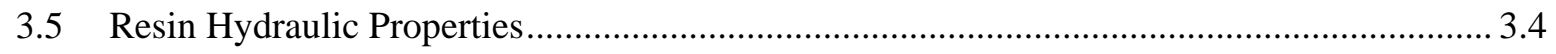

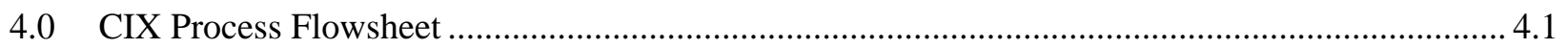

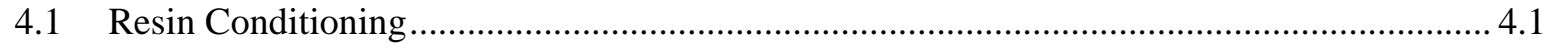

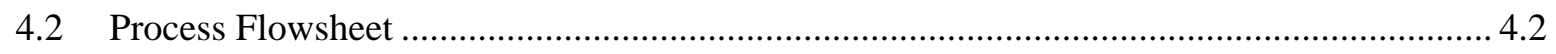

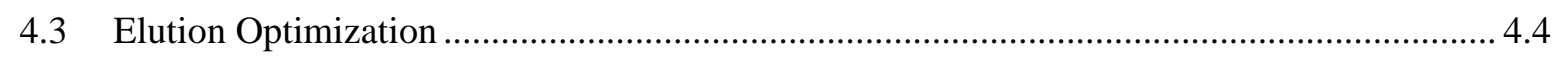

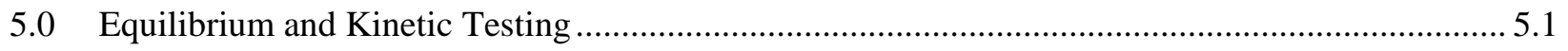

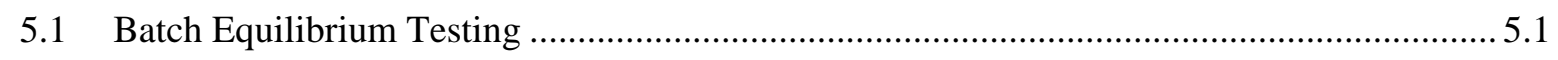

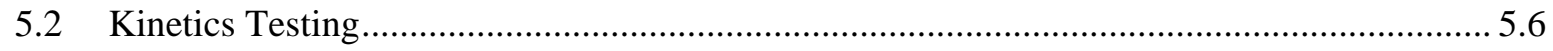

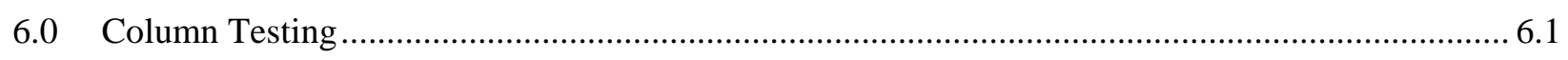

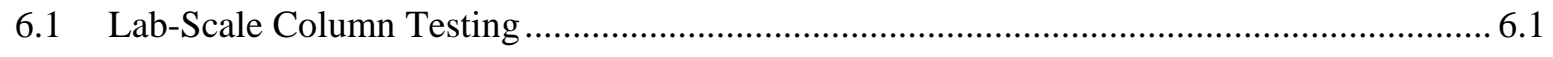

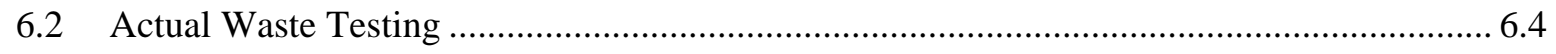

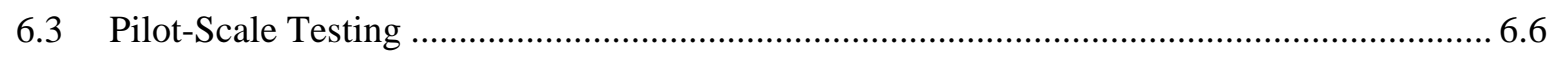

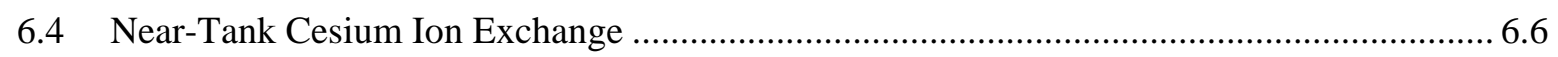

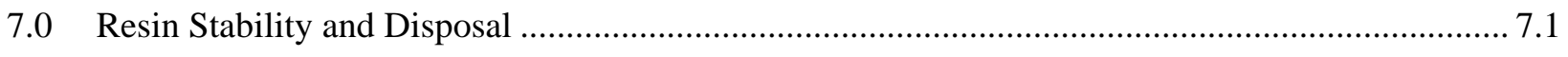

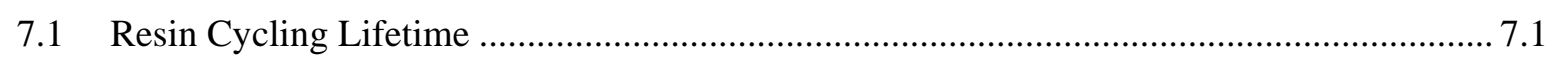

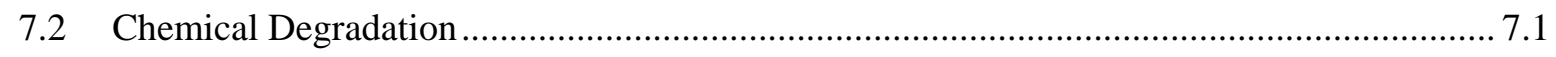

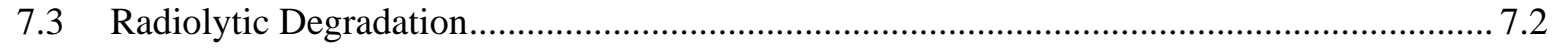

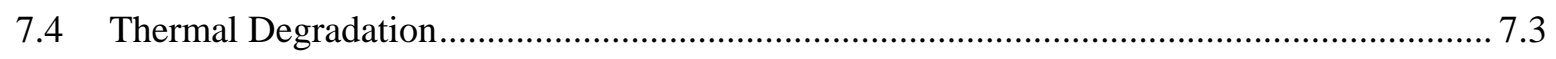

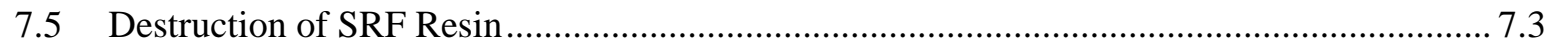

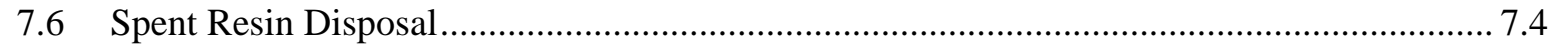

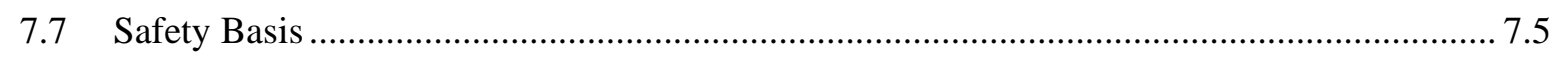

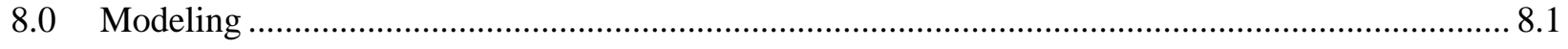

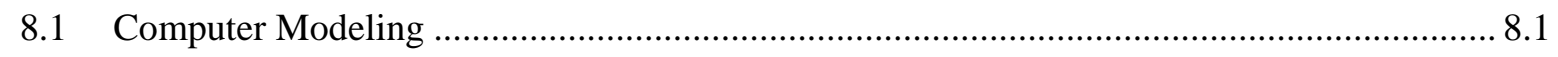

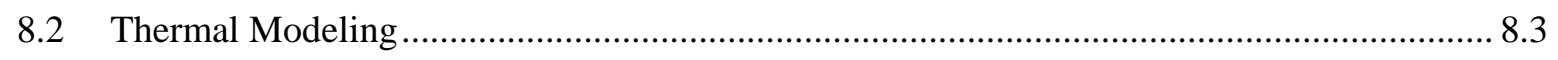

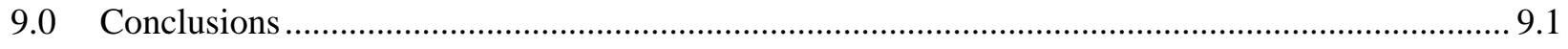

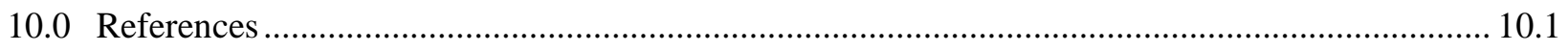

Appendix A - Literature Reviewed but Not Cited.............................................................................. A.1 


\section{Figures}

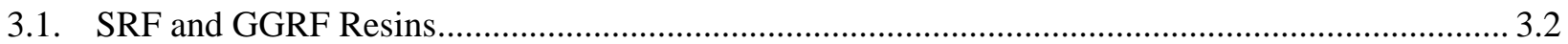

3.2. $\mathrm{Cs}^{+}$Loading Curves for Aged and Non-Aged SRF Resin ........................................................... 3.3

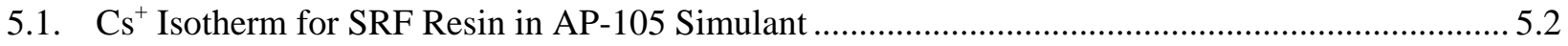

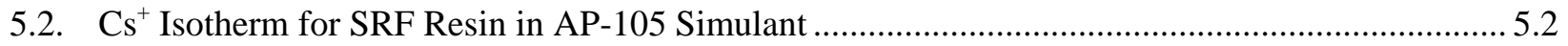

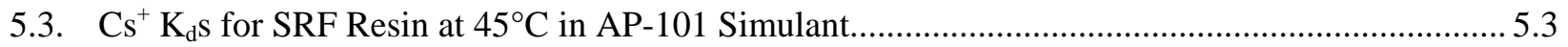

5.4. $\mathrm{Cs}^{+}$Isotherm for SRF Resin at $25^{\circ} \mathrm{C}$ in SRS Tank 2F Simulant ................................................. 5.4

5.5. $\mathrm{Cs}^{+}$Isotherm for SRF Resin at $50^{\circ} \mathrm{C}$ in Variable $\mathrm{Na}^{+}$Simulants .................................................. 5.5

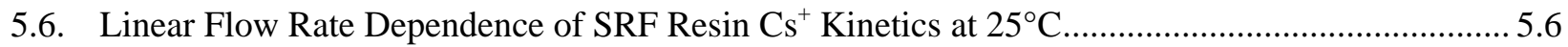

5.7. Temperature Dependence of SRF Resin $\mathrm{Cs}^{+}$Kinetics in AP-101 Simulant .................................. 5.7

6.1. Typical Laboratory-Scale Lead-Lag Ion Exchange Column System.............................................. 6.1

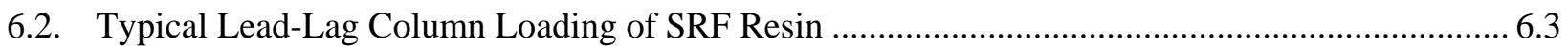

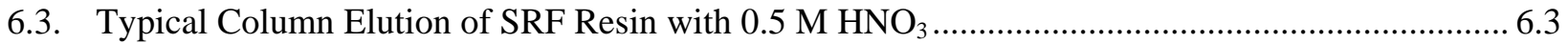

7.1. Cs+ Uptake by SRF Resin During Extended Flow Testing ........................................................ 7.2

\section{Tables}

4.1. Typical Ion Exchanger Laboratory Pre-Conditioning and Process Steps ...................................... 4.4

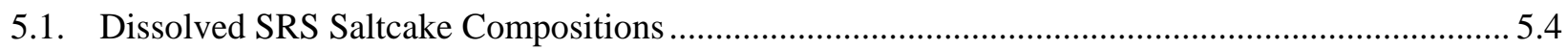




\subsection{Introduction}

The U.S. Department of Energy (DOE) Hanford Site contains more than 53 million gallons of legacy wastes generated as a byproduct of plutonium production and reprocessing operations. The wastes, stored in underground storage tanks, are a complex mixture composed predominantly of water-soluble sodium nitrate, nitrite, hydroxide, aluminate, phosphate, and sulfate; insoluble metal oxide sludge; a number of minor and trace metals; organics; and radionuclides. The DOE-Office of River Protection (ORP) contracted Bechtel National Incorporated to build a pretreatment facility (PTF) within the River Protection Project-Waste Treatment Plant (WTP) that will separate long-lived transuranics (TRU) and highly radioactive components (specifically ${ }^{137} \mathrm{Cs}$ and perhaps others such as ${ }^{90} \mathrm{Sr}$ or ${ }^{99} \mathrm{Tc}$ ) from the bulk (nonradioactive) constituents and immobilize the wastes by vitrification (Nash et al. 2004). The plant is designed to produce two waste streams: a high-volume low-activity waste (LAW) stream and a low-volume high-level waste (HLW) stream.

Ion exchange using the spherical resorcinol-formaldehyde (SRF) resin has been selected by Bechtel National Incorporated and approved by DOE-ORP for use in the PTF. The SRF resin is an engineered spherical form of the older ground gel resorcinol-formaldehyde (GGRF) resin, also known as resorcinol-formaldehyde (RF), which was developed and evaluated at the Westinghouse Savannah River Company (WSRC) and the Hanford Site in the 1980s (Ebra and Wallace 1983; Bibler et al. 1989; Bibler and Wallace 1995; Bray et al. 1996a, 1996b). Numerous historic studies at the Hanford Site and other DOE sites have shown the GGRF and SRF resins to be effective for removing ${ }^{137} \mathrm{Cs}$ from a wide variety of simulated and actual tank waste supernatants and for meeting the proposed spent waste classification criteria of $<100 \mathrm{nCi}$ per gram of TRU and $<60 \mu \mathrm{Ci}{ }^{137} \mathrm{Cs}$ per gram of spent resin (Adamson et al. 2006; Blanchard et al. 2008; Burgeson et al. 2004; Duignan and Nash 2009; Fiskum et al. 2006a, 2006b, 2006c, 2007; Hassan and Adu-Wusu 2003; King et al. 2004; Kurath et al. 1994; Nash et al. 2006).

Prior experimental and theoretical cesium ion exchange (CIX) work was previously reviewed by King (2007) in support of material selection for the Small Column Ion Exchange (SCIX) project. Thorson (2008a) documented the basis for recommending SRF over SuperLig ${ }^{\mathrm{TM}} 644$ as the primary CIX resin in the WTP. This current review expands on previous work, summarizes additional work completed to date, and provides a broad summary of the literature without focusing on a specific column system.

Section 1.0 provides a brief historical background for HLW, CIX, and the report design. Section 2.0 details the basis of the Pacific Northwest National Laboratory (PNNL) Quality Assurance (QA) Program as applied to the WTP quality requirements. Section 3.0 describes the synthesis and various properties of the SRF resin. Section 4.0 describes SRF resin conditioning and the CIX process flowsheet. Section 5.0 provides a summary of the equilibrium batch and kinetic testing completed on the SRF resin. Section 6.0 summarizes small-scale laboratory column, pilot-scale, near-tank, and actual waste testing. Section 7.0 reviews the chemical, radiolytic, and thermal stability of the SRF resin and analysis of spent resin for disposal. Section 8.0 describes computer modeling of the loading, elution, and thermal properties of the SRF in column operations. Section 9.0 provides a brief summary of this report and Section 10.0 lists the references cited. 



\subsection{Quality Assurance}

The PNNL QA Program is based upon the requirements defined in the DOE Order 414.1D, Quality Assurance, and Title 10 of the Code of Federal Regulations Part 830, Energy/Nuclear Safety Management, and Subpart A-Quality Assurance Requirements (a.k.a. the Quality Rule). PNNL has chosen to implement the following consensus standards in a graded approach:

- ASME NQA-1-2000, Quality Assurance Requirements for Nuclear Facility Applications, Part 1, Requirements for Quality Assurance Programs for Nuclear Facilities.

- ASME NQA-1-2000, Part II, Subpart 2.7, Quality Assurance Requirements for Computer Software for Nuclear Facility Applications.

- ASME NQA-1-2000, Part IV, Subpart 4.2, Graded Approach Application of Quality Assurance Requirements for Research and Development.

The procedures necessary to implement the requirements are documented through PNNL's "How Do I....? $\left(\mathrm{HDI}^{1}\right)$.

The Waste Treatment Plant Support Project (WTPSP) implements an NQA-1-2000 QA Program, graded on the approach presented in NQA-1-2000, Part IV, Subpart 4.2. The WTPSP Quality Assurance Manual (QA-WTPSP-0002) describes the technology life cycle stages under the WTPSP Quality Assurance Plan (QA-WTPSP-0001). The technology life cycle includes the progression of technology development, commercialization, and retirement in process phases of basic and applied research and development (R\&D), engineering and production, and operation until process completion. The life cycle is characterized by flexible and informal QA activities in basic research, which become more structured and formalized through the applied R\&D stages.

The work described in this report has been completed under the QA technology level of applied research. WTPSP addresses internal verification and validation activities by conducting an independent technical review of the final data report in accordance with WTPSP procedure QA-WTPSP-601, Document Preparation and Change. This review verifies that the reported results are traceable, that inferences and conclusions are soundly based, and that the reported work satisfies the test plan objectives.

${ }^{1}$ System for managing the delivery of PNNL policies, requirements, and procedures. 



\subsection{SRF Properties}

This section summarizes properties of the SRF resin, including generic synthesis methods, SRF product lot evaluations, storage conditions, particle size distribution (PSD), shrink-swell behavior, density, visual observations, and hydraulic characteristics.

\subsection{Resin Synthesis}

The RF cation exchange resin was developed for the selective removal of $\mathrm{Cs}^{+}$from highly alkaline supernates (Ebra and Wallace 1983; Bibler et al. 1989; Bibler and Wallace 1995). The resin is prepared by caustic condensation polymerization of resorcinol $\left(\mathrm{C}_{6} \mathrm{H}_{4}(\mathrm{OH})_{2}\right)$ and formaldehyde (HCHO). High Cs ${ }^{+}$ selectivity has been attributed to the two weakly acidic hydroxyl groups on the resorcinol ring, which ionize and become functional at high $\mathrm{pH}$. Due to its weak acid nature, the resin has strong preference for $\mathrm{H}^{+}$and can be eluted using strong acids to remove $\mathrm{Cs}^{+}$and other cations such as $\mathrm{Na}^{+}$or $\mathrm{K}^{+}$. The relative affinities are $\mathrm{H}^{+}>>\mathrm{Cs}^{+}>>\mathrm{K}^{+}>\mathrm{Na}^{+}$. Hubler et al. $(1995,1996)$ evaluated the chemical synthesis, structural characterization, and CIX performance of the parent RF polymer (GGRF) from which the SRF resin is based. Samanta et al. (1992) reported on the synthesis of the GGRF resin in addition to other phenolic resins. Ugelstad (1984) and Berge et al. (1997) described the preparation of highly monomodal, spherical beads of various polymers including RF using preformed polystyrene seed particles with light divinylbenzene crosslinking that contained an active ionic group. Favre-Réguillon et al. (2001) and Ray et al. (2005) also described the synthesis and characterization of RF resins. Dwivedi et al. (2012) reported the synthesis and evaluation of a spherical RF-based resin using commercially available divinylbenzene cross-linked polystyrene microspheres (XAD-4). Tests included optical and scanning electron microscopy images, thermogravimetric analysis (TGA), Brunauer-Emmett-Teller surface area, ion exchange uptake, sorption isotherms, sorption kinetics, and mechanical strength.

Thorson (2008a, 2008b) provided a detailed historical summary of the development and testing of the SRF resin for use in the PTF. The author included a production timeline, testing of over 100 different batches from multiple vendors, process optimization and scale up, and the large-scale production of six separate 100-gal lots. Thorson also provided a schematic of the conceptual SRF synthesis from seed to final form; however specific details of the proprietary process were not included.

\subsection{Resin Production Lot Evaluation}

The evaluation of multiple, small- and medium-sized production lots of SRF resin (as well as GGRF and SuperLig ${ }^{\mathrm{TM}}$ 644) from multiple vendors has been reported in a large series of research that support DOE’s legacy waste PTF (Fiskum et al. 2004, 2005, 2006a, 2006b, 2006c, 2006d, 2006e, 2007; Adamson et al. 2006; Duignan and Nash 2009, 2010a, 2010b; Nash and Duignan 2009, 2010). These works supplied supporting data necessary to evaluate and qualify resin formulations, production methods, and vendors and to develop a detailed material purchase specification for the WTP (Thorson 2008a). The earlier reports compared the SRF, GGRF, and SuperLig ${ }^{\mathrm{TM}} 644$ resins and the later reports focused specifically on the SRF resin. Resin samples were characterized by optical microscopy, PSD analysis, morphology, dry and skeletal density, shrink-swell characteristics, skeletal and bed density, porosity, permeability, compressibility, and $\mathrm{Cs}^{+}$batch distribution $\left(\mathrm{K}_{\mathrm{d}}\right)$ coefficients and/or column loading and elution profiles using Hanford tank AP-101, AZ-102, or AN-102 simulants and, in some cases, actual 
wastes. The cesium batch distribution coefficient $\left(\mathrm{K}_{\mathrm{d}}\right)$ is defined as the ratio of Cs adsorbed on a resin material to the Cs remaining in the contacting solution at equilibrium as follows:

$$
K_{d}=\frac{\left(C_{0}-C_{1}\right)}{C_{1}} \times \frac{V}{M \times F}
$$

where

$\mathrm{C}_{0}=$ the initial cesium concentration in the solution

$\mathrm{C}_{1}=$ the final, equilibrium cesium concentration in the solution

$\mathrm{V}=$ the volume of the liquid sample, typically expressed in $\mathrm{mL}$

$\mathrm{M}=$ the mass of the ion exchange resin used during the contact

$\mathrm{F}=$ the mass of a separately dried resin sample divided by its mass before drying.

Resin samples were exposed to oxidative solutions and oxygen uptake was quantified. Resin samples were exposed to acids and bases and shrinkage and swelling was measured. In addition, the speed of resin neutralization was tested, formaldehyde generation was monitored, and expanded resin pretreatment conditions were evaluated. The resulting dataset is too large to easily summarize, but it does demonstrate that the SRF resin will meet the WTP plant CIX processing requirements for a range of tank waste conditions and, for certain defining characteristics, is superior to the SuperLig ${ }^{\mathrm{TM}} 644$ and GGRF resins. Pertinent results from these reports are summarized in the following sections. Figure 3.1 displays visible light microscopy images of samples of the SRF and GGRF resins (Fiskum et al. 2004).

The SRF resin selected by the WTP for future use is represented by a 100-gal production lot manufactured in May 2005 (lot number 5E-370/641) by Microbeads (Skedsmokorset, Norway) ${ }^{1}$ that is currently stored at various DOE site locations in the $\mathrm{H}^{+}$-form underwater and in an inert atmosphere.

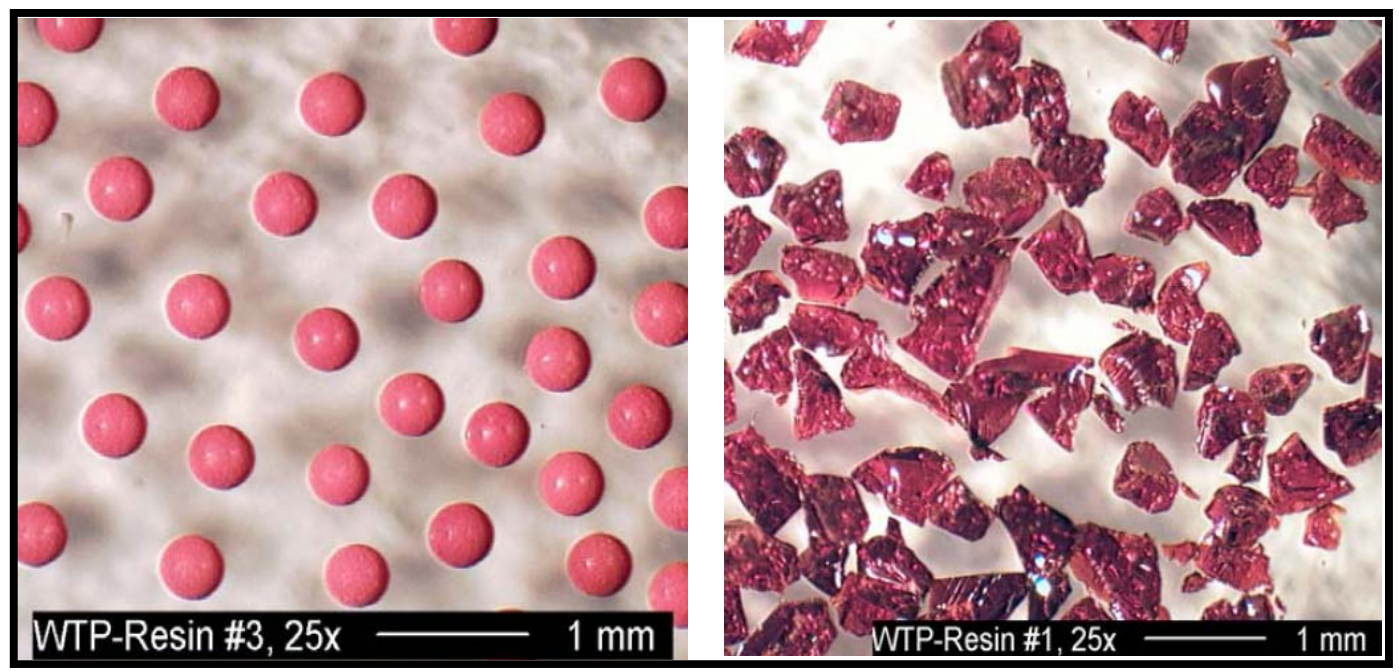

Figure 3.1. SRF and GGRF Resins (Fiskum et al. 2004)

\footnotetext{
${ }^{1}$ Technical Data Sheet for Dynoseeds ${ }^{\circledR}$ RF 380, June 2009. http://www.micro-beads.com. Microbeads AS, Skedsmokorset, Norway.
} 


\subsection{Resin Storage}

Fiskum et al. (2007) evaluated the effect of storage conditions $\left(\mathrm{N}_{2}\right.$ inert atmosphere; wet or dry; $22^{\circ} \mathrm{C}$, $35^{\circ} \mathrm{C}, 45^{\circ} \mathrm{C}$; three material lots; and 1-year duration) on loading and elution characteristics of the SRF resin using $20 \mathrm{~mL}, 2 \mathrm{~cm}$ diameter columns, AP-101 simulant $\left(4.9 \underline{\mathrm{M} \mathrm{Na}}{ }^{+}, 0.68 \underline{\mathrm{M} \mathrm{K}} \mathrm{K}^{+}, 4.4 \mathrm{E}-05 \underline{\mathrm{M} \mathrm{Cs}}{ }^{+}\right)$, and standard flowsheet conditions. Fiskum et al. reported 130 to $150 \mathrm{BV}$ to $50 \% \mathrm{Cs}^{+} \mathrm{C} / \mathrm{C}_{0}$ breakthrough (Figure 3.2). Wet versus dry storage at $45^{\circ} \mathrm{C}$ resulted in no significant difference in $\mathrm{Cs}^{+}$loading. The resins stored at $35^{\circ} \mathrm{C}$ and $45^{\circ} \mathrm{C}$ exhibited slightly more loading to $50 \% \mathrm{Cs}^{+} \mathrm{C} / \mathrm{C}_{0}$ breakthrough than the $22^{\circ} \mathrm{C}$ control ( $+4.6 \%$ and $+15 \%$, respectively). Furthermore, the resins exposed to higher temperatures exhibited a slightly delayed elution, which was attributed to increased polymeric crosslinking during storage. The differences were deemed insignificant and all WTP contract-based performance metrics were determined to be easily achieved. Fiskum et al. (2007) also reported shrink/swell volumes, resin storage masses, and visual observations. They reported that the SRF resin reacts with dissolved oxygen and the upper surface darkens over time as a manifestation of this reaction. This effect was observed on past archived resin samples during storage and during the ion exchange process. In the absence of oxygen they observed virtually no dark band after 1-year storage, indicating that the resin was well protected from oxygen exposure. After more than four years in storage, Brown et al. (2011) reported similar visual darkening of the SRF resin, which suggests that much longer storage may be possible with only minimal oxidative degradation.

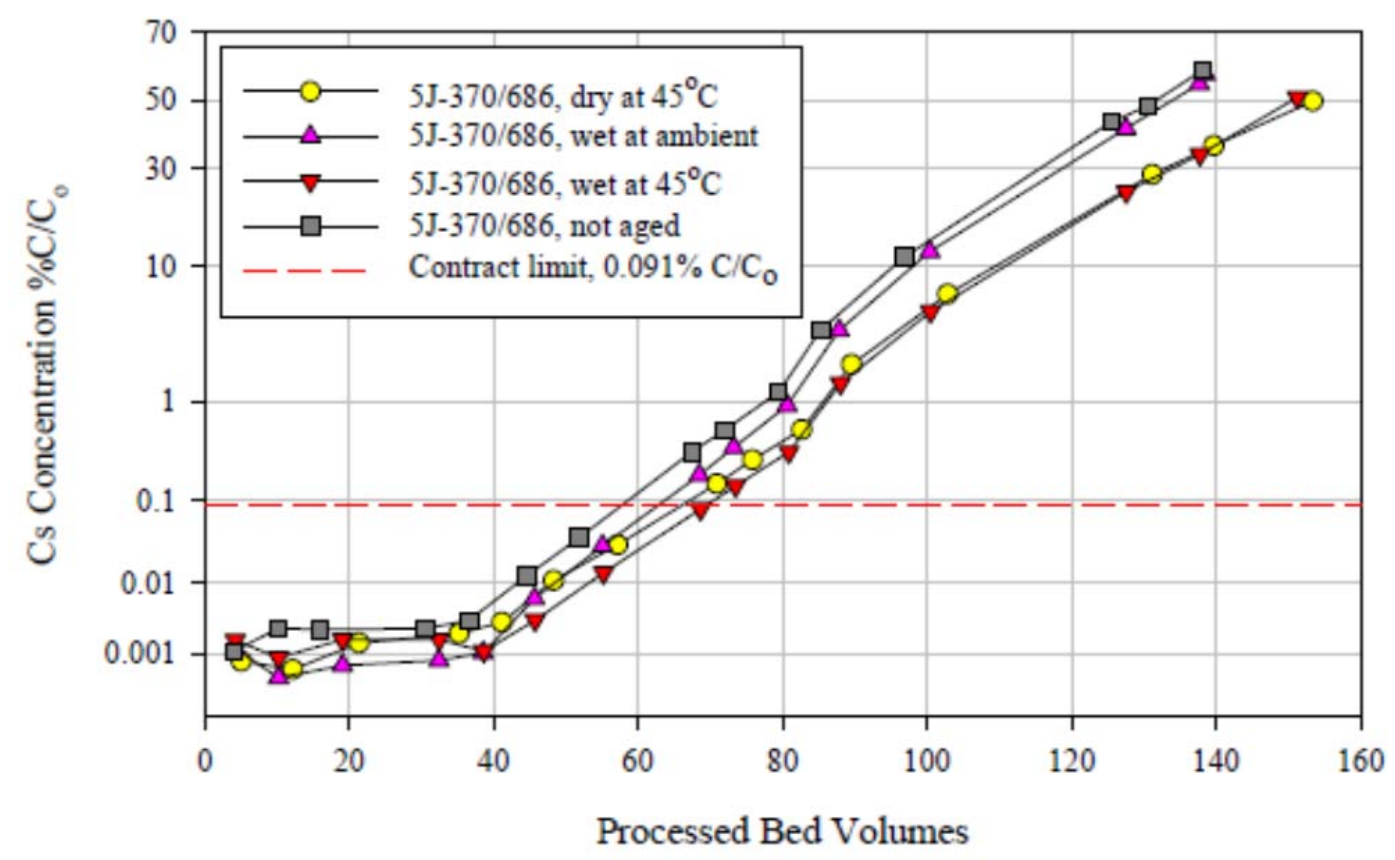

Figure 3.2. Cs $^{+}$Loading Curves for Aged and Non-Aged SRF Resin (Fiskum et al. 2007)

\subsection{Resin Properties}

The SRF resin batch 5E-370/641 was characterized in both $\mathrm{H}^{+}$and $\mathrm{Na}^{+}$forms at Battelle-Pacific Northwest Division (PNWD) by Fiskum et al. (2006a) and at the Savannah River National Laboratory (SRNL) by Adamson et al. (2006). It was manufactured in a 100-gal production lot in May 2005 and stored in the $\mathrm{H}^{+}$-form underwater and in an inert atmosphere prior to testing. The PSD of the $\mathrm{Na}^{+}$-form 
ranged from 400 to $600 \mu \mathrm{m}$ with Fiskum et al. (2006a) reporting an average particle diameter of $421 \mu \mathrm{m}$ ( $\mathrm{H}^{+}$-form) and $452 \mu \mathrm{m}\left(\mathrm{Na}^{+}\right.$-form) and Adamson et al. (2006) reporting $461 \mu \mathrm{m}\left(\mathrm{Na}^{+}\right.$-form) in AP-101 simulant. Nash et al. (2006) reported an average diameter of $421 \mu \mathrm{m}\left(\mathrm{H}^{+}\right.$-form) and $460 \mu \mathrm{m}\left(\mathrm{Na}^{+}\right.$-form) in $5 \underline{\mathrm{M}} \mathrm{Na}^{+}$with $2 \underline{\mathrm{M}} \mathrm{OH}^{-}$.

The CIX loading and elution performance of an SRF column are influenced by the total amount of ion exchange sites that can be packed into a specific column volume. This is related to the density of ion exchange sites (meq/g) and the total resin mass in the column. Further, this is a function of the column packing method (i.e., loaded into the column as a slurry and possibly vibrated to further settle) and resin chemical form. Due to historical manufacturing processes, the resin often arrived from the manufacturer containing residual $\mathrm{K}^{+}$. Future purchases may specify that the resin be pretreated to remove this residual $\mathrm{K}^{+}$and delivered in either the $\mathrm{Na}^{+}$- or $\mathrm{H}^{+}$-forms. Furthermore, as is common for organic-based ion exchange resins, the resin may be received partially dry, containing variable moisture content, or in water. Thus, a portion of the as-received material should be dried to achieve a constant mass, thereby eliminating the variability that might be expected when weighing undried materials throughout the DOE complex under widely different ambient temperatures and humidities. When reviewing the literature, direct comparisons should only be made where forms, drying, and loading methods are identical. Specifically, drying methods (F-factor corrections) used over the past two decades vary in temperature, pressure, and time. After receiving the SRF resin in water, Fiskum et al. (2006a) removed excess water, dried a portion under vacuum at $50^{\circ} \mathrm{C}$ until the mass change was $<0.5 \%$ over a 7 -hour period, and reported a $0.5851 \pm 0.0016 \mathrm{~F}$-factor. Brown et al. (2011) reported that the average density was $0.456 \mathrm{~g} / \mathrm{mL}$ (mass of dried $\mathrm{H}^{+}$-form resin per $\mathrm{mL}$ of settled $\mathrm{H}^{+}$-form resin underwater in a 25 -mL graduated cylinder that had been tap-vibrated several times with a rubber dowel to achieve a maximum density). Other researchers reported densities ranging from 0.36 to $0.38 \mathrm{~g} / \mathrm{mL}$ when normalized to the $\mathrm{Na}^{+}$-form volume (Fiskum et al. 2006b, 2006c). Because the $\mathrm{Na}^{+}$-form volume is approximately $25 \%$ greater than the $\mathrm{H}^{+}$-form; the two reported values are essentially the same.

In the $\mathrm{Na}^{+}$-form, the SRF resin is a dark brown/black color and has near maximum volume when compared to the $\mathrm{H}^{+}$-form. Depending upon the loading solution (e.g., density and ionic strength), the resin may compress slightly during the $\mathrm{Cs}^{+}$loading cycle. However, most literature from the past 10 years normalizes the resin bed volume (BV) in a standard $1 \underline{\mathrm{M} \mathrm{NaOH}}$ solution (Hassan and Adu-Wusu 2003; King et al. 2004; Adamson et al. 2006; Fiskum et al. 2006a, 2006b, 2006c, 2007; Nash et al. 2006; Duignan and Nash 2009). Older reports describing the GGRF resin used $2 \underline{\mathrm{M}} \mathrm{NaOH}$ to normalize the BV (Bray et al. 1990, 1996a; Brown et al. 1995). During acid elution, the SRF resin becomes a lighter orange color and compresses dramatically ( 25\%). Historically, the GGRF resin agglomerated and pulled away from the column walls during elution (Bray et al. 1990, 1996a; Brown et al. 1995), which created channels that allowed the acid to bypass the GGRF resin bulk, thereby reducing elution efficiency and generating significant tailing. The SRF resin geometry was developed to ameliorate this situation. Even in small diameter columns $(<2 \mathrm{~cm})$, the SRF resin does not generate observable channeling during acid elution (King et al. 2004; Adamson et al. 2006; Fiskum et al. 2006a, 2006b, 2006c; Nash et al. 2006; Duignan and Nash 2009).

\subsection{Resin Hydraulic Properties}

Brooks et al. (2006) developed an approach to simulate hydraulic conditions experienced in a full-scale column using high flow rates in a geometrically similar bench-scale column. This was done by 
increasing the superficial velocity in the column by the ratio of the full-scale and bench-scale column heights. By doing so, the testing time and expense could be reduced and the hydraulic characteristics of GGRF, SRF, and SuperLig ${ }^{\mathrm{TM}} 644$ could be compared. Brooks et al. reported bed permeability vs. cycle

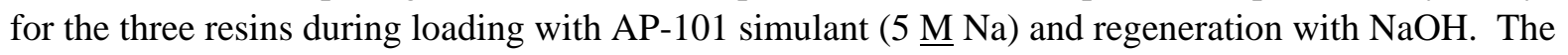
SRF resin had the highest bed permeability. They also reported differential, radial and axial pressures as well as PSD before and after testing for the three resins. The SRF PSD did not change appreciably while the PSD of the other two materials decreased significantly. The resin compressibility was measured five times from 0 to 20 psi. The SRF resin showed less compressibility than either of the other two resins. Further, Brooks et al. noted that the SRF resin appeared to be more durable than the granular materials; thus, the SRF resin demonstrated less compressibility and little particle breakage. Instead of fracturing, the SRF resin tended to develop high axial and radial pressures within the column. In contrast, SuperLig ${ }^{\mathrm{TM}} 644$ did not develop high pressures; rather, it tended to fracture or compress under the load arising from its expansion during regeneration. The significant compressibility and particle size reduction for the SuperLig ${ }^{\mathrm{TM}} 644$ resin could be a concern in a full-scale column.

Arm et al. (2005, 2006) characterized the hydraulic properties of several test and production batches of the SRF resin under a range of upflow and downflow conditions in columns that were nominally $76 \mathrm{~mm}$ in diameter by $124 \mathrm{~mm}$ high. Bed void, permeability, axial and radial pressure, fluidization, resin capacity, and PSD were monitored. The SRF resins experienced no significant particle breakage or deterioration in their hydraulic characteristics throughout multiple cycles. One resin produced in a 100-gal batch (5E-370/641) and representative of that expected for the WTP, experienced 14 cycles and exhibited no significant change in bed void. Regeneration was typically conducted upflow, with radial and axial pressures comparable to the differential pressure (i.e., no residual stresses because the bed underwent free expansion). The single downflow regeneration test yielded a permeability of $2.4 \times 10^{-10} \mathrm{~m}^{2}$, with radial and axial pressures indicative of residual stresses from constrained bed expansion. Bed pressures were three times the differential pressure when downflow LAW processing immediately followed downflow regeneration. The SRF resin exhibited radial and axial pressures higher than expected when considering only the action of the hydraulic drag during downflow regeneration because the bed retained the stresses induced by its constrained expansion. However, as expected from theory, bed pressures were proportional to the differential pressure during regeneration. In contrast, following upflow regeneration, radial and axial pressures were comparable to the differential pressure, indicating unconstrained expansion.

Researchers at SRNL performed a series of hydraulic and chemical testing on the SRF resin using $1 / 4-$ and 1/2-scale WTP columns (Adamson et al. 2006; Adamson 2007, 2009). A total of 23 hydraulic/chemical cycles were completed, including 16 in the $1 / 2$-scale column ( $0.59 \mathrm{~m}$ diameter). The overall column height was $2.18 \mathrm{~m}$, with the area capable of holding resin approximately $1.25 \mathrm{~m}$. The column was fully instrumented with diaphragm pressure transducers at seven locations. Radial bed pressures were measured at two locations on the resin support screen and radial bed pressures were measured at two locations above the screen $(15.2$, and $45.7 \mathrm{~cm}$ ). The standard WTP flowsheet (see Section 4.0 of this report) was evaluated and included upflow regeneration $(12.4 \mathrm{~cm} / \mathrm{min}$ for $3 \mathrm{~min}$ to

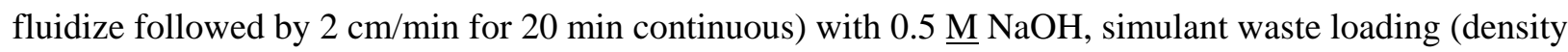
$1.25 \mathrm{~g} / \mathrm{mL}$ and viscosity $2.9 \mathrm{cP}, 72 \mathrm{BV}$ at $26.9 \mathrm{~cm} / \mathrm{min}$ ), feed displacement (3 BV at $8.8 \mathrm{~cm} / \mathrm{min}$ ) with $0.1 \underline{\mathrm{M} \mathrm{NaOH}}$, water rinse (2.5 BV at $13.3 \mathrm{~cm} / \mathrm{min})$, elution (15 BV at $6.1 \mathrm{~cm} / \mathrm{min}$ ) with $0.5 \underline{\mathrm{M} \mathrm{HNO}}$, and water rinse (1.2 BV at $13.3 \mathrm{~cm} / \mathrm{min})$. Certain tests loaded the simulant at higher superficial velocities to achieve a 9.7 psig pressure drop across the resin bed which would simulate the maximum differential bed 
pressure in the full-scale WTP column. Hydraulic testing showed that the permeability of the RF resin remained essentially constant (3.40E-06 $\mathrm{cm}^{2}$ ), with no observed reduction in the permeability as the number of cycles increased. Permeability was 2.5 times greater than the WTP design requirements, the SRF bed showed no tendency to form fissures or pack more densely as the number of cycles increased, the resin PSD did not change with cycling, and essentially no resin fines were formed. Negligible radial pressures to the column walls were observed during upflow regeneration. No degradation in $\mathrm{Cs}^{+}$uptake was observed and the test solutions remained clear over all 16 loading and elution cycles. The resin bed exhibited a slight $(<5 \%)$ increase in height (either $\mathrm{H}^{+}$- or $\mathrm{Na}^{+}$-forms) with a definite trend over the 16 cycles. The SRF resin flowed well in $\mathrm{H}^{+}$- and $\mathrm{Na}^{+}$-forms and was easily sluiced out of the ion exchange column with $>99 \%$ removal.

Thorson (2008a) used the SRNL work (Adamson et al. 2006; Adamson 2007, 2009), to recommend flow rates and methods to minimize chemical consumption and to describe the superior hydraulic properties of SRF over SuperLig ${ }^{\mathrm{TM}} 644$. The theoretical stationary bed height closely matched the SRNL experimental data collected from 2 to $20 \mathrm{~cm} / \mathrm{min}$ superficial velocity.

Duignan et al. (2007, 2008) used previous work (Arm et al. 2006; Adamson et al. 2006; Adamson 2007, 2009) to expand on the understanding of SRF hydraulic properties as applied to high aspect ratios (10:1) for the SCIX configuration. The full-scale SCIX column was planned at $0.69 \mathrm{~m}$ inner diameter with $4 \mathrm{~m}$ height of SRF resin and $0.3 \mathrm{~m}$ freeboard. In addition, some configurations included a $0.17 \mathrm{~m}$ diameter central cooling tube. Using an average Savannah River Site (SRS) waste feed simulant (nominal $6 \underline{\mathrm{M} \mathrm{Na}}{ }^{+}$) recirculated at $25^{\circ} \mathrm{C}$ through a $72 \mathrm{~mm}$ inside diameter (i.d.) column with a central core to represent the SCIX cooling tube, Duignan et al. $(2007,2008)$ evaluated three scaled bed heights $(0.32$, 0.48 , and $0.80 \mathrm{~m}$ ). While the small-scale SCIX hydraulic test did not fully replicate the absolute pressures expected in the full-scale resin bed, the authors stated that "previous studies indicate that the pressure drop through the linearly scaled bed will be prototypic of the full-scale unit when using a prototypic feed superficial velocity because the bed void fraction and permeability are not significantly affected.” Average pressure losses of 12, 38, and $66 \mathrm{kPa} / \mathrm{m}$ were measured for prototypic downflow superficial feed velocities of 5.6, 16.1, and $27.4 \mathrm{~cm} / \mathrm{min}$, respectively. The pressure loss in the resin bed per unit height was independent of the resin height. The downflow introduction of $1.28 \mathrm{~g} / \mathrm{mL}$ simulant into the $1.0 \mathrm{~g} / \mathrm{mL}$ caustic regeneration solution did not disturb the resin bed. The freeboard significantly dampened turbulence in the dense simulant before it reached the resin. Allowing the column to stagnate overnight in water caused a fine white precipitate to form at the top of the $\mathrm{H}^{+}$-form of the SRF resin. The precipitate redissolved as fluid flow resumed and was switched from water to the caustic feed. As has been reported by nearly all investigators, color changes from red/black to orange and significant ( 20\%) volume reduction were observed when converting from the $\mathrm{Na}^{+}$form to the acid form resin. Upflow regeneration fluidized the resin bed to a volume approximately $50 \%$ larger than the settled $\mathrm{Na}^{+}$form resin. Duignan et al. $(2007,2008)$ reported no significant particle degradation, fines generation, or other operational problems with the SRF resin during the hydraulic testing.

Taylor (2009) used a test loop, containing 500-mL of Na-form SRF resin and recirculating AP-101 simulant solution, to measure permeability and void fraction of a packed bed as a function of oxygen uptake and radiation exposure. The flow rate (2.6 to $4.3 \mathrm{gpm}$ ) and superficial fluid velocity (3.4 to $5.7 \mathrm{~cm} / \mathrm{s}$ ) was varied to generate the maximum pressure $(9.7 \mathrm{psig})$ expected at the WTP. The frictional drag from this high-velocity solution flow produced forces on the resin in the laboratory-scale tests that matched the design basis of the full-scale WTP column. Three hydraulic test runs were completed (fresh resin at $25^{\circ} \mathrm{C}$ and $177 \mathrm{MRad}$ irradiated resin tested at $25^{\circ} \mathrm{C}$ or $45^{\circ} \mathrm{C}$ ), known amounts of oxygen (1.44 to 
$7.02 \mathrm{mmol} \mathrm{O}_{2} / \mathrm{g}$ resin) were introduced, and oxygen uptake was measured. Flow rate and pressure drop data indicated that irradiation reduces the void fraction and permeability of the resin bed. The mechanism for these reductions was unclear because irradiation was also observed to increase SRF resin particle size and reduce bead deformation under pressure. Microscopic examination of the resin beads showed that they were all smooth regular spheres and that irradiation or oxygen uptake did not change their shape. Mean SRF resin particle size ranged from 0.455 to $0.485 \mathrm{~mm}$, increasing with $\mathrm{O}_{2}$ uptake for all experiments, with the largest sizes observed for the samples that underwent $50^{\circ} \mathrm{C}$ irradiation. The data showed that the resin reacted rapidly with dissolved oxygen, reducing the bed permeability and bead crush strength. As other investigators have reported, $\mathrm{Cs}^{+}$uptake was decreased by resin exposure to oxygen, irradiation, and higher temperatures (Duffey and Walker 2006; Fiskum et al. 2006a; Russell et al. 2014). Chemical degradation of the SRF resin is further summarized in Section 7.2. 



\subsection{Process Flowsheet}

This section summarizes development and optimization of the CIX process, including SRF resin conditioning, the CIX flowsheet, and elution optimization. Complete details of the current WTP flowsheet have been previously published (Jenkins et al. 2013).

\subsection{Resin Conditioning}

Prior to development of the SRF resin, several investigators evaluated pre-conditioning the GGRF resin prior to use in CIX column or batch systems. Typically, Bray et al. (1990) and Brown et al. (1995) placed the as-received GGRF resin into a container of $2 \underline{\mathrm{M}} \mathrm{NaOH}$ to allow unconstrained expansion, loaded the slurry into the column, and then rinsed with an additional $3 \mathrm{BV}$ of $2 \underline{\mathrm{M}} \mathrm{NaOH}$. Hassan and Adu-Wusu (2005) introduced the GGRF resin as a slurry into the CIX column using $1 \underline{\mathrm{M}} \mathrm{NaOH}$. Unlike more recent studies, early studies did not cycle as-received resin with multiple acid/base contacts. Fiskum et al. (2004) rinsed the GGRF resin with $6 \mathrm{BV}$ of $0.25 \underline{\mathrm{M}} \mathrm{NaOH}$ and noted bubble formation before increasing to $6 \mathrm{BV}$ of $1 \underline{\mathrm{M}} \mathrm{NaOH}$. Arm and Blanchard (2004) investigated pre-conditioning and regeneration requirements for the GGRF resin. Although only tangentially related to the SRF resin, the GGRF resin pretreatment conditions included rinsing the as-received resin with deionized water (DIW), $0.5 \underline{\mathrm{M}} \mathrm{HNO}_{3}, 1 \underline{\mathrm{M}} \mathrm{HNO}_{3}, 0.25 \underline{\mathrm{M} \mathrm{NaOH}}$, and/or $1 \underline{\mathrm{M}} \mathrm{NaOH}$ in various combinations, including single or double cycles. Performance was evaluated by $\mathrm{Cs}^{+}$uptake, $\mathrm{Na}^{+} / \mathrm{H}^{+}$consumption, $\mathrm{K}^{+}$and organic leaching, and resin PSD for various column and batch equilibrium tests. Arm and Blanchard reported that pre-conditioning improved initial loading, but not elution or overall performance, presumably due to the removal of residual $\mathrm{K}^{+}$remaining in the resin from the manufacturing process. Their preferred pre-conditioning method used a single cycle of more dilute reagents, thereby reducing overall chemical consumption and resin degradation but with a concomitant increase in process duration.

Over the years, other investigators have used slightly different concentrations, solid-liquid contact phase ratios, various batch pretreatment processes outside of the column, and/or column flow rates to complete resin conditioning and column operations. Eventually, the pre-conditioning and column process flowsheet for the SRF resin were standardized in laboratory operations (Fiskum et al. 2004; Nash 2004; Nash et al. 2006). However, due to the inherent difference in scale, the resin-to-volume ratio chosen for the laboratory work may vary slightly from the ratio chosen for eventual plant-scale operations.

As has been previously described (Fiskum et al. 2004; Nash 2004; Nash et al. 2006), the as-received resin is first gently agitated with 5 resin volumes (RV) DIW for 30 minutes in an open vessel (e.g., laboratory beaker) to allow unconstrained expansion and contraction. The liquid is drained from the resin and $5 \mathrm{RV}$ of $1 \underline{\mathrm{M} \mathrm{NaOH}}$ is added. At this point the resin expands significantly as it is converted to the $\mathrm{Na}^{+}$-form. The resin is agitated gently several times and allowed to soak in this solution overnight. After the alkaline solution is removed, the resin is washed three times with $3 \mathrm{RV} \mathrm{DIW}$, to a $\mathrm{pH}$ of $<12.5$. The bulk resin is then converted back to the $\mathrm{H}^{+}$-form with $10 \mathrm{RV}$ of $0.5 \underline{\mathrm{M}} \mathrm{HNO}_{3}$ for 2 hours. The solution $\mathrm{pH}$ is reduced to $<1$ and then the resin is washed three times with 3 RV DIW. At this point, most of the residual $\mathrm{K}^{+}$from the manufacturing process has been removed from the resin and the resin can be stored, long-term, underwater with an inert gas (typically nitrogen) headspace. Conversion back to the $\mathrm{Na}^{+}$-form is accomplished by swirling the unconstrained resin in $10 \mathrm{RV}$ of $1 \underline{\mathrm{M} \mathrm{NaOH}}$ for 1 hour. At this point, the expanded resin beads and caustic solution can easily be transferred into the process column. However, for 
safe laboratory operations, the residual caustic is typically removed and the resin is contacted with $10 \mathrm{RV}$ DIW. Finally, the water-resin slurry is transferred into the column to finish the pre-conditioning process.

\subsection{Process Flowsheet}

Collins et al. (1980) described a multi-column carousel system containing the inorganic zeolite IONSIV $^{\mathrm{TM}}$ IE-95 for treatment of $\mathrm{Cs}^{+}$-tainted wastewaters from the Three Mile Island nuclear plant. Ernest et al. (1997) described a similar system, but containing the GGRF resin, for efficient ion exchange loading of $\mathrm{Cs}^{+}$from alkaline nuclear waste solutions. The multi-column carousel system, with lead-lag-polishing columns during loading, offline elution of the lead column, and counter current positioning of ion exchange columns after elution, has now become the industry standard and is the planned configuration of the WTP CIX system ${ }^{1}$ (Thorson and Gilbert 2007).

Hassan et al. (2003) reported a series of SuperLig ${ }^{\mathrm{TM}} 644$ batch distribution contacts, $\mathrm{Cs}^{+}$isotherm data, and column flow rate studies using simulated AZ-102 and AN-107 wastes in support of WTP flowsheet development. Although not the SRF resin, they used a $100 \mathrm{~mL}$ column $(2.7 \mathrm{~cm}$ i.d.) and concluded that loading at 1.5 to $3 \mathrm{BV} / \mathrm{hr}$ was adequate, marginally better below $1.5 \mathrm{BV} / \mathrm{hr}$, and significantly worse above $3 \mathrm{BV} / \mathrm{hr}$. They also reported effective elution, to below $0.01 \mathrm{Cs}^{+} \mathrm{C} / \mathrm{C}_{0}$ in the stock solution, with $15 \mathrm{BV} 0.5 \underline{\mathrm{M}} \mathrm{HNO}_{3}$. Numerous investigators have reported a wide range of column loading and elution process flowsheets that were eventually standardized (Fiskum et al. 2004; Nash 2004; Nash et al. 2006).

The following two paragraphs provide a brief summary of the CIX process flowsheet, as presented by PNNL and WSRC (Fiskum et al. 2004; Nash 2004; Nash et al. 2006; Brown et al. 2011). This summary reflects the expected CIX process in the WTP pretreatment facility as described in Figure 2.5-55 of the WTP flowsheet (Jenkins et al. 2013). The $\mathrm{Na}^{+}$-form of the SRF resin previously conditioned from Section 4.1 is loaded into the column as a slurry and allowed to settle (using tapping to slightly vibrate the column). The resin is rinsed with 7.5 BV DIW at $3 \mathrm{BV} / \mathrm{h}$ for 2.5 hours, followed by in-column elution

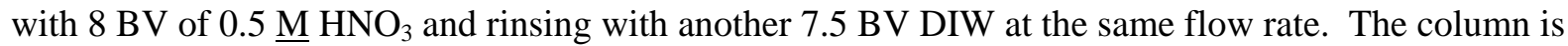

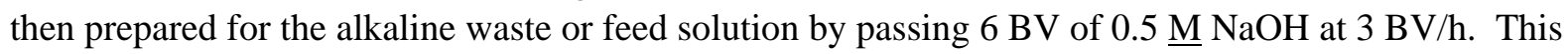
last "regeneration" step is performed to convert the resin into the $\mathrm{Na}^{+}$-form, raise the interstitial solution $\mathrm{pH}$ above 12, and eliminate the possibility that dissolved aluminum in the feed solution might precipitate in the column. An additional solution density adjustment (e.g., $3 \mathrm{BV}$ of $1 \underline{\mathrm{M}} \mathrm{NaOH}$ and $6 \underline{\mathrm{M}} \mathrm{NaNO}_{3}$ ) has been proposed and tested by other investigators (e.g., Blanchard et al. 2008). The regeneration and density adjustment solutions may be passed upflow, as needed, to release stress within the column. The target waste solution (typically $5 \underline{\mathrm{M} \mathrm{Na}}{ }^{+}$) is then passed downflow through the column at $1.5 \mathrm{BV} / \mathrm{h}$ and the $\mathrm{Cs}^{+}$is loaded on the SRF resin. The loading step is continued until sufficient $\mathrm{Cs}^{+}$breakthrough is measured or predicted, typically when $50 \% \mathrm{Cs}^{+} \mathrm{C} / \mathrm{C}_{0}$ breakthrough is measured for the leading column or an initial breakthrough $\left(<1 \% \mathrm{Cs}^{+} \mathrm{C} / \mathrm{C}_{0}\right)$ is measured on the lag or second column. At this point the lead column is considered fully loaded. Depending upon the $\mathrm{Na}^{+}, \mathrm{Cs}^{+}$, and $\mathrm{K}^{+}$content of the feed solution, $50 \% \mathrm{Cs}^{+} \mathrm{C} / \mathrm{C}_{0}$ breakthrough may occur as early as $50 \mathrm{BV}$ or as late as $500 \mathrm{BV}$ (Smith et al. 2008a, 2008b, 2009; Aleman et al. 2011).

Following loading, the lead column is flushed downflow with $7.5 \mathrm{BV}$ of $0.1 \underline{\mathrm{M}} \mathrm{NaOH}$ for 2.5 hours at $3 \mathrm{BV} / \mathrm{h}$ to displace the feed solution, thereby eliminating the possibility of aluminum precipitation in

\footnotetext{
${ }^{1}$ 24590-PTF-3YD-CXP-00001, Rev 0, System Description for the Cesium Ion Exchange Process - System CXP.
} 
subsequent steps. Then the column is flushed downflow with $7.5 \mathrm{BV}$ of DIW for 2.5 hours at $3 \mathrm{BV} / \mathrm{h}$ to reduce the $\mathrm{pH}$ (Brown et al. 2011). Neutralization and elution may be accomplished in either upflow or

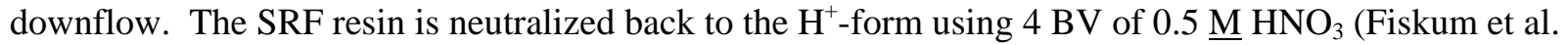
2004; Nash 2004; Nash et al. 2006). At this point very little $\mathrm{Cs}^{+}$and most $\mathrm{Na}^{+}$and $\mathrm{K}^{+}$will have been removed from the column (Aleman et al. 2011). Shunting the DIW rinse and first 4 BV neutralization solutions to the LLW stream may help reduce the total amount of $\mathrm{Na}^{+}$passing to the HLW. Elution of the high-level $\mathrm{Cs}^{+}$can then be accomplished by passing additional acid through the column until the specific elution target concentrations have been met. The elution of $\mathrm{Cs}^{+}$beyond 6-8 $\mathrm{BV}$ is diffusion-limited and requires very little additional acid (Taylor and Johnson 2009a, 2009b; Brown et al. 2011; Aleman et al. 2011). Therefore, after passing the initial 4-8 BV of $0.5 \underline{\mathrm{M} \mathrm{HNO}}$, anticipated WTP operations may reduce the subsequent acid concentration to as low as $0.1 \underline{\mathrm{M}} \mathrm{HNO}_{3}$, until an additional 20-30 BV of acid has been processed to minimize total nitrate sent to downstream waste processes (Thorson 2008a; Gilbert 2007; Taylor and Johnson 2009a, 2009b). Following elution, $3 \mathrm{BV}$ of DIW at $1.4 \mathrm{BV} / \mathrm{h}$ is used to raise the $\mathrm{pH}$ prior to regenerating the resin with $6 \mathrm{BV}$ of $0.5 \mathrm{M} \mathrm{NaOH}$. At this point, the proposed density adjustment may be used to further prepare the resin for the next loading cycle (Blanchard et al. 2008). The specific steps, solutions, volumes, time, mixing methods, and flow rates for bulk resin and column pre-conditioning are summarized in Table 4.1 (Brown et al. 2011). 
Table 4.1. Typical Ion Exchanger Laboratory Pre-Conditioning and Process Steps

\begin{tabular}{|c|c|c|c|c|c|}
\hline Process Step & Solution & Volume & Time & Mixing & Flow Rate \\
\hline \multicolumn{6}{|c|}{ Bulk Pre-Conditioning } \\
\hline Water Rinse & DI Water & $5 \mathrm{RV}$ & $30 \mathrm{~min}$ & Swirl $^{(\mathrm{a})}$ & NA \\
\hline Resin Expansion & $1 \underline{\mathrm{M} \mathrm{NaOH}}$ & $5 \mathrm{RV}$ & $1 \mathrm{~h}$ & Swirl & NA \\
\hline Resin Expansion & $1 \underline{\mathrm{M}} \mathrm{NaOH}$ & $5 \mathrm{RV}$ & $>12 \mathrm{~h}$ & Soak & NA \\
\hline Water Rinse $-1^{\text {st }}$ & $\overline{\text { DI Water }}$ & $3 R V$ & $30 \mathrm{~min}$ & Swirl & NA \\
\hline Water Rinse $-2^{\text {nd }}$ & DI Water & $3 R V$ & $30 \mathrm{~min}$ & Swirl & NA \\
\hline Water Rinse $-3^{\text {rd }}$ & DI Water & $3 R V$ & $30 \mathrm{~min}$ & Swirl & NA \\
\hline Resin Conversion & $0.5 \underline{\mathrm{M}} \mathrm{HNO}_{3}$ & $10 \mathrm{RV}$ & $2 \mathrm{~h}$ & Swirl & NA \\
\hline Water Rinse $-4^{\text {th }}$ & DI Water & $3 \mathrm{RV}$ & $1 \mathrm{~min}$ & Swirl & NA \\
\hline Resin Expansion & $1 \underline{\mathrm{M}} \mathrm{NaOH}$ & $10 \mathrm{RV}$ & $1 \mathrm{~h}$ & Swirl & NA \\
\hline Water Rinse $-5^{\text {th }}$ & DI Water & $10 \mathrm{RV}$ & $1 \mathrm{~min}$ & Swirl & NA \\
\hline \multicolumn{6}{|c|}{ Column Pre-Conditioning } \\
\hline Water Rinse & DI Water & $7.5 \mathrm{BV}$ & $2.5 \mathrm{~h}$ & Flow & $3 \mathrm{BV} / \mathrm{h}$ \\
\hline Acid Rinse & $0.5 \underline{\mathrm{M}} \mathrm{HNO}_{3}$ & $8 \mathrm{BV}$ & $2.7 \mathrm{~h}$ & Flow & $3 \mathrm{BV} / \mathrm{h}$ \\
\hline Water Rinse & DI Water & $3 \mathrm{BV}$ & $1 \mathrm{~h}$ & Flow & $3 \mathrm{BV} / \mathrm{h}$ \\
\hline Feed Prep & $0.5 \underline{\mathrm{M}} \mathrm{NaOH}$ & 3-6 BV & $1-2 \mathrm{~h}$ & Flow & $3 \mathrm{BV} / \mathrm{h}$ \\
\hline Density Adjustment ${ }^{(b)}$ & $1 \mathrm{M} \mathrm{NaOH} \& 6 \mathrm{M} \mathrm{NaNO}_{3}$ & $0-3 \mathrm{BV}$ & $0-1 \mathrm{~h}$ & Flow & $3 \mathrm{BV} / \mathrm{h}$ \\
\hline \multicolumn{6}{|c|}{ Column Loading/Elute } \\
\hline Simulant & Simulant & $50-500 \mathrm{BV}$ & Variable & Flow & $1.5 \mathrm{BV} / \mathrm{h}$ \\
\hline Feed Displaced & $0.1 \underline{\mathrm{M}} \mathrm{NaOH}$ & $7.5 \mathrm{BV}$ & $2.5 \mathrm{~h}$ & Flow & $3 \mathrm{BV} / \mathrm{h}$ \\
\hline Water Rinse & DI Water & $7.5 \mathrm{BV}$ & $2.5 \mathrm{~h}$ & Flow & $3 \mathrm{BV} / \mathrm{h}$ \\
\hline Neutralization & $0.5 \underline{\mathrm{M}} \mathrm{HNO}_{3}$ & $4 \mathrm{BV}$ & $2.9 \mathrm{~h}$ & Flow & $1.4 \mathrm{BV} / \mathrm{h}$ \\
\hline Acid Elution & $0.5 \underline{\overline{\mathrm{M}}} \mathrm{HNO}_{3}$ & $15 \mathrm{BV}$ & $10.7 \mathrm{~h}$ & Flow & $1.4 \mathrm{BV} / \mathrm{h}$ \\
\hline Water Rinse & DI Water & $3 \mathrm{BV}$ & $2.1 \mathrm{~h}$ & Flow & $1.4 \mathrm{BV} / \mathrm{h}$ \\
\hline Regeneration & $0.5 \underline{\mathrm{M}} \mathrm{NaOH}$ & 3-6 BV & $1-2 \mathrm{~h}$ & Flow & $3 \mathrm{BV} / \mathrm{h}$ \\
\hline Density Adjustment ${ }^{(b)}$ & $1 \mathrm{M} \mathrm{NaOH} \& 6 \mathrm{M} \mathrm{NaNO}_{3}$ & $0-3 \mathrm{BV}$ & $0-1 \mathrm{~h}$ & Flow & $3 \mathrm{BV} / \mathrm{h}$ \\
\hline
\end{tabular}

\subsection{Elution Optimization}

Although a range of concentrations and alternate chemicals have been evaluated (Burgeson et al. 2004, 2006; Taylor and Johnson 2009a, 2009b; Brown et al. 2011), the current WTP flowsheet

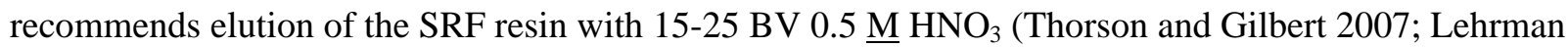
2010). As mentioned previously, a reduction in acid concentration after eluting with 4-8 BV of $0.5 \underline{\mathrm{M}}$ $\mathrm{HNO}_{3}$ is being considered. Adu-Wusu and Pennebaker (2009) conducted a literature review of potential non-acid compounds for the elution of $\mathrm{Cs}^{+}$from the SRF resin. Using batch contact sorption-desorption tests, Adu-Wusu and Pennebaker (2010) evaluated a range of compounds, including salts of $\mathrm{NH}_{4}{ }^{+} \mathrm{Ca}^{+2}$, $\mathrm{Li}^{+}, \mathrm{Mg}^{+2}, \mathrm{~K}^{+}, \mathrm{Rb}^{+}$and $\mathrm{Na}^{+}$. The highest performing material was nitric acid followed by ammonium carbonate and acetate. These results were subsequently confirmed with additional batch and quasi-column operations (Adu-Wusu et al. 2010) and small (4.2 mL) column operations with concentrations ranging from 1 to $3 \underline{\mathrm{M}}$ in ammonium carbonate, acetate, and mixtures thereof (Adu-Wusu et al. 2011, 2012). The highest $\mathrm{NH}_{4}{ }^{+}$concentrations resulted in the fastest elution to remove only $80 \%$ of 
the loaded $\mathrm{Cs}^{+}$. Elution of $100 \%$ of the $\mathrm{Cs}^{+}$required substantially more solution and additional time (i.e., overnight).

Burgeson et al. (2004) compared the elution properties of the GGRF and SRF resins with 0.5 to $1.5 \underline{\mathrm{M}}$ $\mathrm{HNO}_{3}$ and at 25 to $45^{\circ} \mathrm{C}$. Tests were conducted with $11 \mathrm{~mL} \mathrm{BV}$ columns and loaded at $25^{\circ} \mathrm{C}$ with

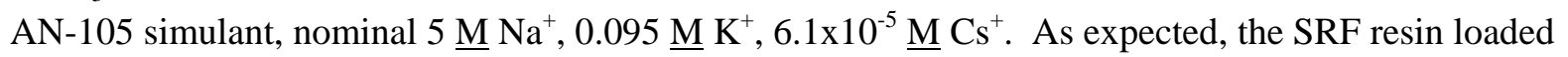
significantly less $\mathrm{Cs}^{+}$than the GGRF resin due to the inactive binder required to form the spherical bead of the SRF resin. Higher acid concentrations reduced the acid volume required to reach the $\mathrm{Cs}^{+}$elution peak concentration but did not improve tailing. In contrast, higher temperature elutions improved the tailing (e.g., reduced the $\mathrm{Cs}^{+}$effluent concentration) beyond $13 \mathrm{BV}$. The SRF resin showed dramatically improved elution vs. the GGRF resin. Burgeson, et al. (2006) continued this analysis under similar conditions and comparing elution of SRF and SuperLig ${ }^{\mathrm{TM}} 644$ resins. Conclusions were similar to the previous testing with improved elution at higher temperature $\left(45^{\circ} \mathrm{C}\right)$ and lower flow rate $(1 \mathrm{BV} / \mathrm{hr})$. However, the SuperLig ${ }^{\mathrm{TM}} 644$ resin appeared to degrade more than the SRF resin at these conditions.

Taylor and Johnson (2009a, 2009b) reported that $4 \mathrm{BV}$ of $0.5 \mathrm{M} \mathrm{HNO}_{3}$ is required to remove (titrate or neutralize) most of the $\mathrm{Na}^{+}$and $\mathrm{K}^{+}$from the SRF resin. An additional 4-8 $\mathrm{BV}$ is required to remove $>99 \%$ of the $\mathrm{Cs}^{+}$, and any additional acid (e.g., 10 to $15 \mathrm{BV}$ ) passes through the column with little additional incremental $\mathrm{Cs}^{+}$removal. To reduce overall acid consumption, Taylor and Johnson evaluated several alternative elution strategies: $0.5 \underline{\mathrm{M}} \mathrm{HCOOH}$ (formic acid) at $1 \mathrm{BV} / \mathrm{hr}, 0.8 \underline{\mathrm{M} \mathrm{H}} \mathrm{BO}_{3}$ (boric acid) at $1 \mathrm{BV} / \mathrm{hr}, 0.2 \underline{\mathrm{M}} \mathrm{HNO}_{3}$ at $1 \mathrm{BV} / \mathrm{hr}, 0.1 \underline{\mathrm{M}} \mathrm{HNO}_{3}$ at $1 \mathrm{BV} / \mathrm{hr}, 0.5 \underline{\mathrm{M}} \mathrm{HNO}_{3}$ at $0.56 \mathrm{BV} / \mathrm{hr}, 0.5 \underline{\mathrm{M}} \mathrm{HNO}_{3}$ at $2 \mathrm{BV} / \mathrm{hr}$, and finally $4 \mathrm{BV}$ of $0.5 \underline{\mathrm{M}} \mathrm{HNO}_{3}$ at $1 \mathrm{BV} / \mathrm{hr}$ followed by either $0.05 \underline{\mathrm{M}} \mathrm{HNO}_{3}$ at $1 \mathrm{BV} / \mathrm{hr}$, recirculated $0.5 \underline{\mathrm{M}} \mathrm{HNO}_{3}$ at $1 \mathrm{BV} / \mathrm{hr}$, or $0.5 \underline{\mathrm{M}} \mathrm{HNO}_{3}$ with a staccato flow of 1 hour on followed by 3 hours off. Using a small column $(1.5 \mathrm{~cm}$ i.d. $\times 10 \mathrm{~cm})$, they loaded $9.5 \mathrm{~g} \mathrm{Cs} / \mathrm{L}$ (maximum expected loading) on the SRF resin with a SRS dissolved salt simulant $\left(6.2 \underline{\mathrm{M} \mathrm{Na}}{ }^{+}\right)$containing $\mathrm{Cs}^{+}$increased to $1.8 \mathrm{E}-03 \underline{\mathrm{M}}$. The baseline method eluted $>99.9999 \%$ of the $\mathrm{Cs}^{+}$but required $465 \mathrm{~g}$ nitrate while $4 \mathrm{BV}$ of

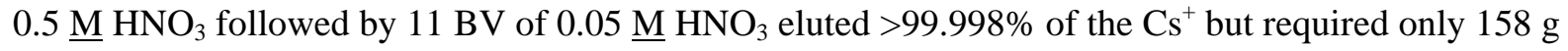
nitrate (i.e., 66\% less). The staccato method eluted $>99.9998 \%$ of the $\mathrm{Cs}^{+}$with a $20 \%$ reduction in nitrate. Taylor and Johnson also reported that more than $99 \%$ of the $\mathrm{Cs}^{+}$is typically present in the solution collected between 3 and 5 BV. While these data are encouraging, they do not quantify the critical parameter (e.g., the level of ${ }^{137} \mathrm{Cs}$ present in the column effluent during subsequent loading cycles).

Brown et al. (2011) conducted a multi-concentration $\mathrm{HNO}_{3}$ elution study that also evaluated $\mathrm{Cs}^{+}$ impurity content in the eluting acid (from proposed WTP acid recycle streams). They loaded multiple SRF columns to minimum breakthrough $\left(<5 \% \mathrm{Cs}^{+} \mathrm{C} / \mathrm{C}_{0}\right)$ with a simple simulant $\left(5 \underline{\mathrm{M} \mathrm{Na}}{ }^{+}, 2.4 \mathrm{E}-04 \underline{\mathrm{M}}\right.$ $\mathrm{Cs}^{+}$), neutralized the columns with a fixed volume (3 BV) of $0.5 \underline{\mathrm{M}} \mathrm{HNO}_{3}$, and then eluted the columns with variable strength acid $\left(0.02,0.07,0.15,0.23\right.$, or $0.28 \underline{\mathrm{M}}$ ) containing variable $\mathrm{Cs}^{+}$impurities (5.0E-09, 1.9E-08, 5.0E-08, 1.4E-07, or 5.0E-07 $\underline{\mathrm{M}}$ ). The loading solution was spiked with ${ }^{134} \mathrm{Cs}$ and eluting solutions were spiked with ${ }^{137} \mathrm{Cs}$ in order to independently evaluate the effect of impurity $\mathrm{Cs}^{+}$in the acid recycle streams. Following the initial resin neutralization with $3 \mathrm{BV}$ of $0.5 \underline{\mathrm{M}} \mathrm{HNO}_{3}$, acid concentrations greater than $0.07 \underline{\mathrm{M}}$ were sufficient to elute the SRF resin. Furthermore, results suggested that although ${ }^{137} \mathrm{Cs}$ impurities in the recycled eluting acid may impact the eventual decontamination that can be achieved during the elution process, this $\mathrm{Cs}^{+}$appears to remain "fixed" to the resin during subsequent loading cycles and does not significantly affect the $\mathrm{Cs}^{+}$"bleed” or carry over. 



\subsection{Equilibrium and Kinetic Testing}

This section summarizes SRF resin batch contact equilibrium and kinetics testing.

\subsection{Batch Equilibrium Testing}

Nearly all of the investigators referenced in this paper have used one or more equilibrium batch contact experiments to evaluate the SRF resin for CIX. The method is a simple and quick way of estimating the amount of $\mathrm{Cs}^{+}$that can be loaded on the resin under the specific ionic conditions that exist at equilibrium. The resulting data are used to estimate the volume of solution that could be processed to achieve $50 \% \mathrm{Cs}^{+} \mathrm{C} / \mathrm{C}_{0}$ breakthrough in a column experiment. Most investigators contact the resin with a known solution at constant temperature for enough time to achieve equilibrium (e.g., 24 to 72 hours) and at a phase ratio of approximately 100 (e.g., $10 \mathrm{~mL}$ of solution to 0.1 gram of resin). Unfortunately, direct comparison of the various results discussed in this section is difficult because of the wide range of experimental conditions that affect the batch equilibrium CIX (e.g., the final or equilibrium concentration of $\mathrm{Na}^{+}, \mathrm{K}^{+}, \mathrm{Cs}^{+}, \mathrm{Rb}^{+}$, and $\mathrm{OH}^{-}$; temperature; liquid-resin contact phase ratio; and contact duration). Often experimental conditions were determined by a combination of actual waste solution availability, limited funding, a requirement to test previous baseline materials (e.g., GGRF and SuperLig ${ }^{\mathrm{TM}} 644$ resins), or the need to backfill gaps in the knowledge base.

Hassan et al. (2003) reported a series of SuperLig ${ }^{\mathrm{TM}} 644$ batch contacts as a function of time at 25, 35 , and $45^{\circ} \mathrm{C}$ using simulated wastes spiked with small quantities of metals (i.e., $\mathrm{Cd}, \mathrm{Cr}, \mathrm{Fe}, \mathrm{Pb}$ ) to evaluate each metal's competitiveness with $\mathrm{Cs}^{+}$. Cesium uptake was not impacted by the metals. Although not specific to the SRF resin, these results demonstrate expanded understanding of metal uptake by CIX resins. Hassan and Adu-Wusu (2003) and Hassan et al. (2004) reported $\mathrm{Cs}^{+}$batch distribution testing using the GGRF resin with actual Hanford 101-AW tank waste at $25^{\circ} \mathrm{C}$ and a phase ratio of $100 \mathrm{~mL} / \mathrm{g}$. Cesium isotherms were obtained by adding variable amounts of nonradioactive ${ }^{133} \mathrm{Cs}$ into several waste solution aliquots. These authors reported $\mathrm{Cs}^{+} \mathrm{K}_{\mathrm{d}} \mathrm{S}$ of 948 and $1039 \mathrm{~mL} / \mathrm{g}$ and a maximum sorption capacity of $1.17 \mathrm{mmol} \mathrm{Cs}^{+}$per gram dry resin.

King et al. (2004) evaluated batch equilibrium loading of $1.000 \mathrm{~g}$ SRF resin in $100 \mathrm{~mL}$ batches of

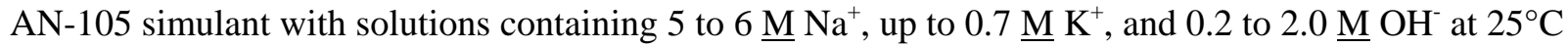
and $45^{\circ} \mathrm{C}$. The simulant solutions were chosen from known extreme concentrations for these species in the Hanford waste tanks and, therefore, were believed to bracket compositions that might be experienced in the plant operation. Isotherms obtained using two $\mathrm{Cs}^{+}$concentrations are shown in Figure 5.1. Burgeson et al. (2004) compared the GGRF and SRF resins batch distributions in AN-105 simulant as a function of time. The GGRF resin exhibited two to three times the $\mathrm{K}_{\mathrm{d}} \mathrm{S}$ of the SRF resin. The $\mathrm{K}_{\mathrm{d}} \mathrm{s}$ for the SRF resin ranged from $890 \mathrm{~mL} / \mathrm{g}$ at 3 hours to $2050 \mathrm{~mL} / \mathrm{g}$ at 19 hours for equilibrium concentrations of $1.0 \mathrm{E}-10 \underline{\mathrm{M}}$ to $2.0 \mathrm{E}-10 \underline{\mathrm{M}} \mathrm{Cs}^{+}$. Linear isotherms were as expected at these low concentrations (Figure 5.2). Further, King et al. (2004) reported that the SRF resin showed increased $\mathrm{K}_{\mathrm{d}} \mathrm{s}$ after being loaded and eluted in a series of column tests. This may be due to removal of the residual $\mathrm{K}^{+}$from the manufacturing process (Arm and Blanchard 2004). Burgeson, et al. (2006) reported similar batch distribution testing of SuperLig ${ }^{\mathrm{TM}} 644$ and SRF resins with AN-105 simulant (0.5 g, $50 \mathrm{~mL}$, 48 hours, $25^{\circ} \mathrm{C}$ ) in preparation for multiple column tests. Unfortunately, limited $\mathrm{K}_{\mathrm{d}}$ data were presented. 


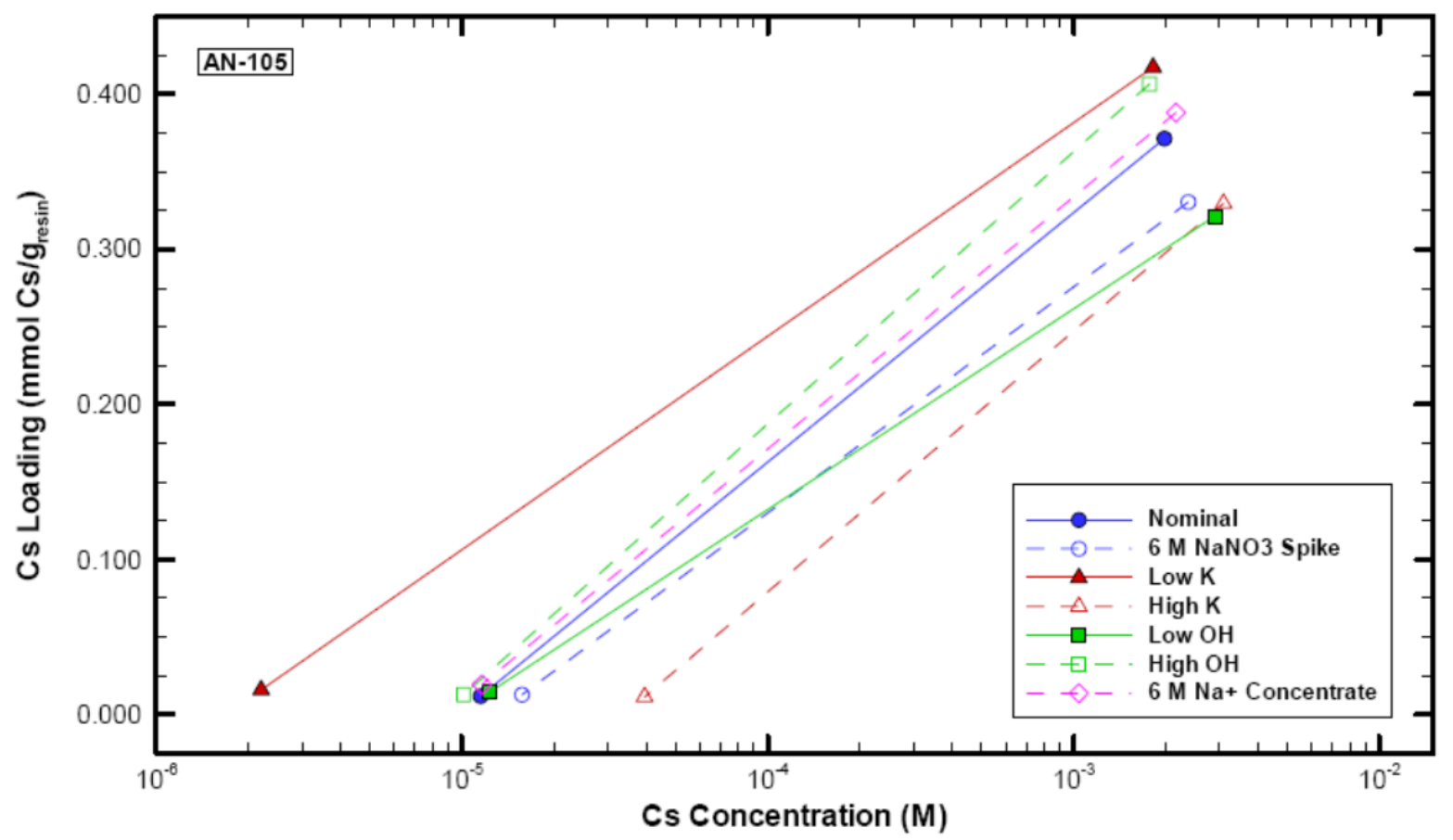

Figure 5.1. $\mathrm{Cs}^{+}$Isotherm for SRF Resin in AP-105 Simulant (King et al. 2004)

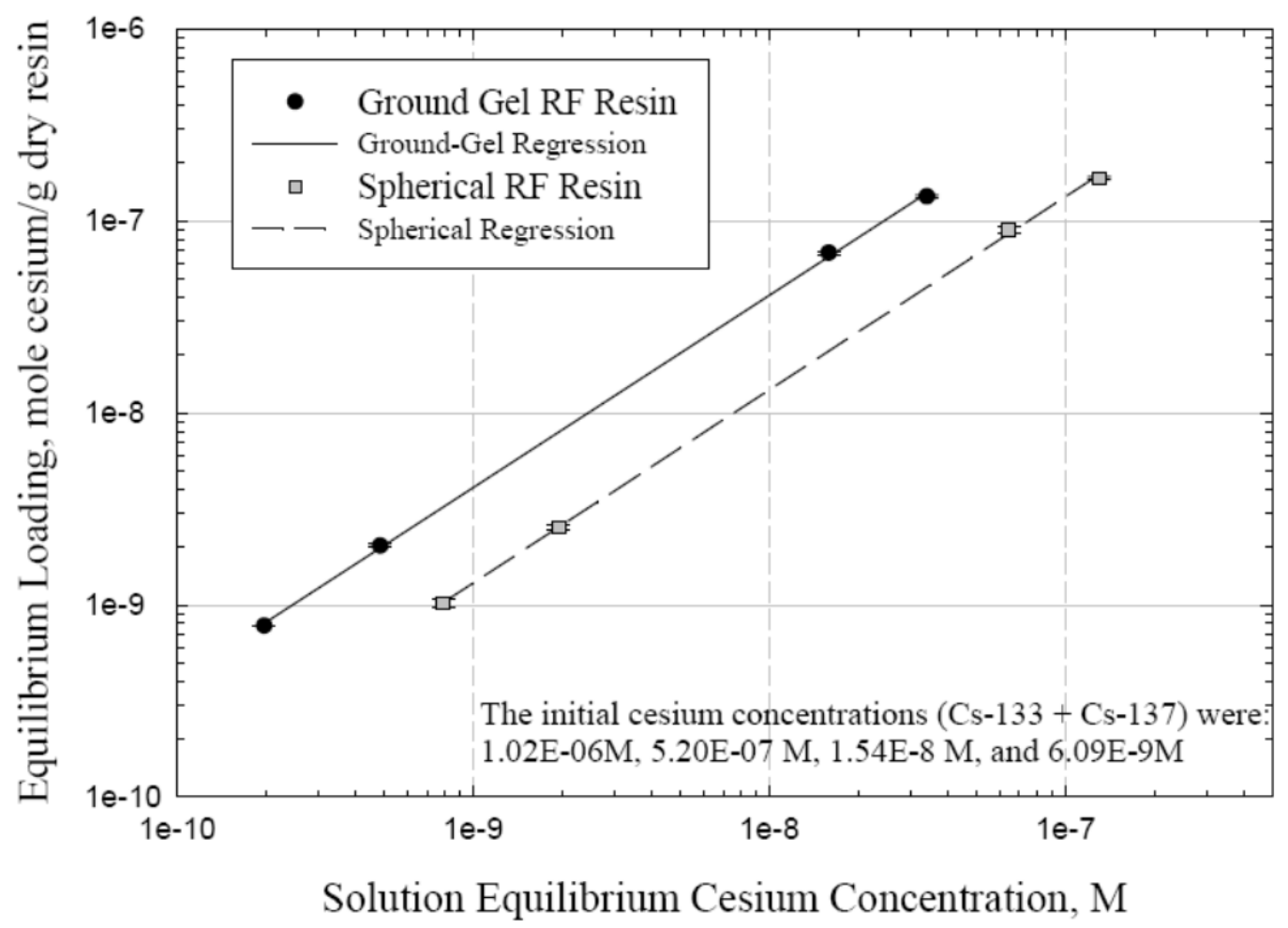

Figure 5.2. $\mathrm{Cs}^{+}$Isotherm for SRF Resin in AP-105 Simulant (Burgeson et al. 2004) 
Nash et al. (2006, 2007) expanded on the work of King et al. (2004) and presented a series of SRF batch contact data using a simplified AP-101 simulant (no aluminate present) as a function of temperature (i.e., 15, 25, and $45^{\circ} \mathrm{C}$ ) and various ions and competitors (e.g., $\mathrm{Na}^{+}, \mathrm{Cs}^{+}, \mathrm{K}^{+}, \mathrm{Rb}^{+}$, and free $\mathrm{OH}^{-}$). $\mathrm{Nash}^{2}$ al. (2006) reported kinetics and column tests as well as batch contact $\mathrm{Cs}^{+}$isotherms (Figure 5.3). They reported a theoretical ion exchange capacity of $6 \pm 0.8 \mathrm{meq} / \mathrm{g}$. Furthermore, Nash et al. (2006) reported batch, kinetics, and column data for AP-101 simulant (Russell et al. 2003) and AN-105 and AN-107 simulants (Eibling et al. 2001). In the report, they evaluated a series of ten simulants, with variations in temperature, $\mathrm{Na}^{+}, \mathrm{K}^{+}, \mathrm{Cs}^{+}, \mathrm{Rb}^{+}$, and free $\mathrm{OH}^{-}$. As expected based on previous literature tests (Bray et al. 1996a, 1996b; Kurath et al. 1994, 1996; King et al. 2004), Nash et al. (2006) reported increasing $\mathrm{Cs}^{+}$ uptake with lower temperature, lower $\mathrm{Na}^{+}$, lower $\mathrm{K}^{+}$, and higher $\mathrm{Cs}^{+}$concentrations. A small increase in $\mathrm{Cs}^{+}$uptake was noted with increasing free hydroxide $\left(\mathrm{OH}^{-}\right)$. At the $\mathrm{Rb}^{+}$levels tested, Nash et al. (2006) reported no difference in uptake as a function of $\mathrm{Rb}^{+}$concentration.

Duignan and Nash (2009, 2010b) and Nash and Duignan (2009) completed a series of equilibrium batch distribution experiments at $25^{\circ} \mathrm{C}$ in support of actual waste column loading and elution tests for SRS tank 2F (see Section 6.2). Nash and Duignan (2009) provided a comparison of the several SRS tank compositions as shown in Table 5.1. Using a variable liquid-solid phase ratio (24 to 100), they reported $\mathrm{K}_{\mathrm{d}} \mathrm{s}$ between 1560 and $6480 \mathrm{~mL} / \mathrm{g}$ for the SRF resin and a Cs ${ }^{+}$isotherm (Figure 5.4) that over-predicted the expected column loading by $11 \%(4.0 \mathrm{E}-02 \mathrm{mmol} / \mathrm{g})$ at $2.51 \mathrm{E}-05 \underline{\mathrm{M} \mathrm{Cs}}{ }^{+}$.

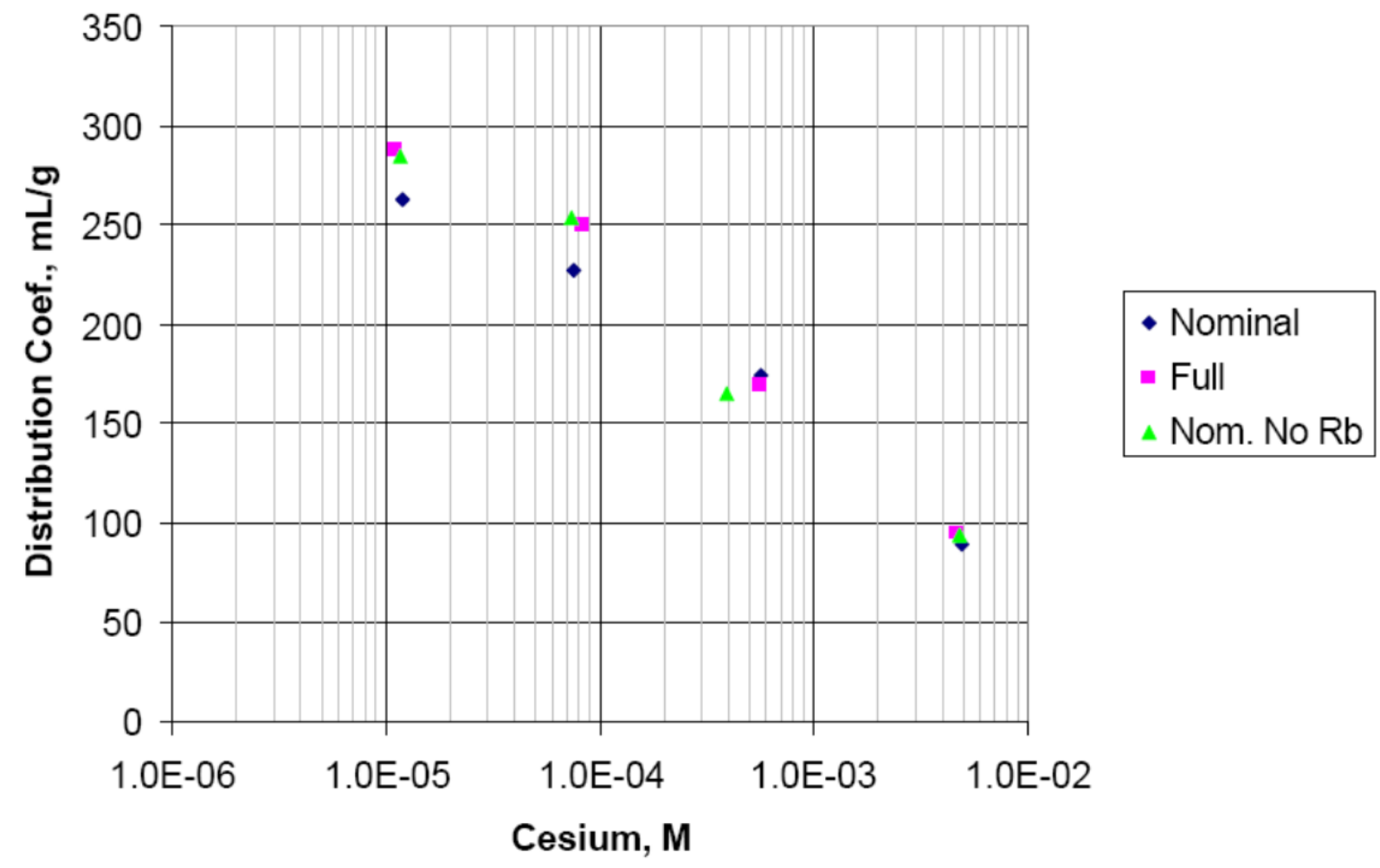

Figure 5.3. $\mathrm{Cs}^{+} \mathrm{K}_{\mathrm{d}} \mathrm{s}$ for SRF Resin at $45^{\circ} \mathrm{C}$ in AP-101 Simulant (Nash et al. 2006) 
Table 5.1. Dissolved SRS Saltcake Compositions (Duignan and Nash 2009)

\begin{tabular}{|c|c|c|c|c|c|c|}
\hline Species & Unit & Tank 1F & Tank 2F & Tank 3F & Tank 37H & Tank 41H \\
\hline $\mathrm{Na}^{+1}$ & $M$ & 6 & 6 & 6 & 6 & 6 \\
\hline $\mathrm{K}^{+1}$ & M & 0.02 & 0.007 & 0.002 & 0.01 & 0.01 \\
\hline $\mathrm{Cs}^{+1}$ & M & $1.81 \mathrm{E}-04$ & $1.70 \mathrm{E}-05$ & $6.35 \mathrm{E}-05$ & $1.08 \mathrm{E}-04$ & 7.5E-06 \\
\hline $\mathrm{Sr}^{+2}$ & M & $3.08 \mathrm{E}-04$ & $3.08 \mathrm{E}-04$ & $1.64 \mathrm{E}-04$ & $3.0 \mathrm{E}-06$ & 3.0E-06 \\
\hline $\mathrm{Rb}^{+1}$ & M & 2.19E-05 & 6.3E-06 & 2.19E-05 & $1.18 \mathrm{E}-05$ & 2.6E-06 \\
\hline $\mathrm{NO}_{3}^{-1}$ & M & 3.07 & 4.19 & 4.60 & 2.26 & 2.42 \\
\hline $\mathrm{NO}_{2}^{-1}$ & M & 0.30 & 0.15 & 0.29 & 0.74 & 0.69 \\
\hline $\mathrm{OH}^{-1}$ & M & 1.41 & 0.76 & 0.55 & 1.97 & 1.81 \\
\hline $\mathrm{AlO}_{2}^{-1}$ & M & 0.30 & 0.29 & 0.06 & 0.35 & 0.34 \\
\hline $\mathrm{CO}_{3}^{-2}$ & M & 0.18 & 0.13 & 0.08 & 0.11 & 0.13 \\
\hline $\mathrm{SO}_{4}^{-2}$ & M & 0.25 & 0.03 & 0.10 & 0.15 & 0.15 \\
\hline $\mathrm{PO}_{4}^{-3}$ & M & 0.003 & 0.005 & 0.003 & 0.01 & 0.01 \\
\hline $\mathrm{Cl}^{-1}$ & M & 0.03 & 0.003 & 0.01 & 0.03 & 0.03 \\
\hline $\mathrm{F}^{-1}$ & M & 0.06 & 0.003 & 0.025 & 0.03 & 0.03 \\
\hline \multicolumn{7}{|c|}{ Physical Properties at $25^{\circ} \mathrm{C}$} \\
\hline Density & $\mathrm{g} / \mathrm{mL}$ & 1.240 & 1.246 & 1.245 & 1.232 & 1.234 \\
\hline Viscosity & сP & 2.39 & 2.14 & 1.83 & 2.59 & 2.54 \\
\hline
\end{tabular}

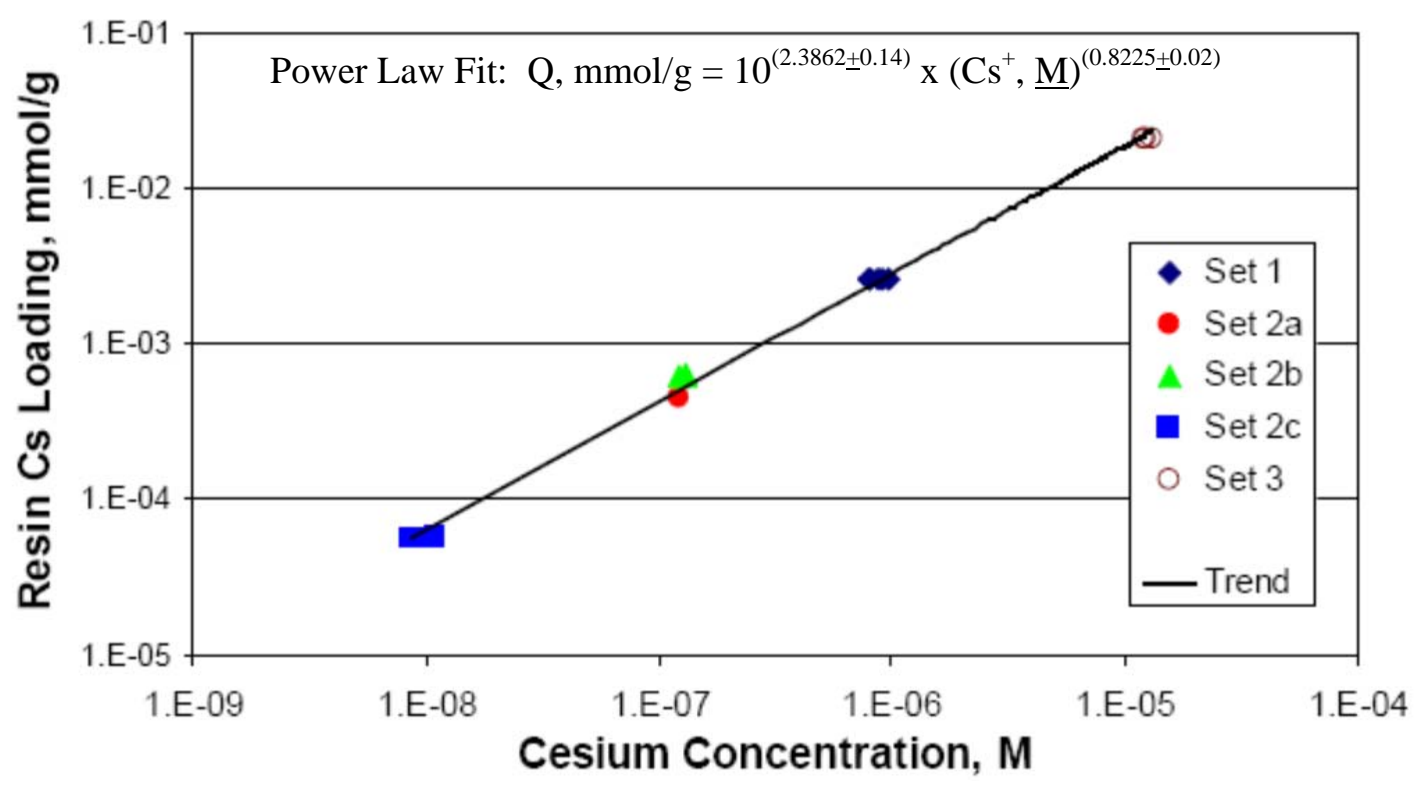

Figure 5.4. $\mathrm{Cs}^{+}$Isotherm for SRF Resin at $25^{\circ} \mathrm{C}$ in SRS Tank 2F Simulant (Duignan and Nash 2009)

In support of a ${ }^{60} \mathrm{Co}$ irradiation study, Birdwell et al. (2010) completed a series of batch distribution tests, with simple $\mathrm{NaOH} / \mathrm{NaNO}_{3}$, AP-101, and SRS Tank 1, 2, 3 simulants (200 mL, 2 g SRF resin, 25 and $45^{\circ} \mathrm{C}, 72$ hours, and $3 \mathrm{E}-08$ to $5 \mathrm{E}-02 \underline{\mathrm{M} \mathrm{Cs}}{ }^{+}$). They reported that the data were consistently above the existing isotherm model but offered no explanation. A series of extended contacts ( 3 weeks) at 25, 45, 
and $65^{\circ} \mathrm{C}$ was also reported. Higher temperatures resulted in reduced $\mathrm{Cs}^{+}$uptake, as demonstrated in previous reports (i.e., Bray et al. 1996a, 1996b; Kurath et al. 1994, 1996; King et al. 2004; Nash et al. 2006, 2007). Extended contact time did not appear to alter the SRF resin equilibrium $\mathrm{Cs}^{+}$uptake.

Nash and Isom (2010) reported batch equilibrium loading of the SRF resin under a variety of conditions (48 or 72 hour contact, $25^{\circ} \mathrm{C}, 0.2$ g resin, $20 \mathrm{~mL}$ test solutions, Tank $2 \mathrm{~F}$ simulant, 5 to $6 \underline{\mathrm{M}}$ $\mathrm{Na}^{+}$, up to $0.7 \underline{\mathrm{M} \mathrm{K}}{ }^{+}, 1 \mathrm{E}-03$ to $1 \mathrm{E}-05 \underline{\mathrm{M} \mathrm{Cs}}{ }^{+}$). At higher $\mathrm{Cs}^{+}$concentrations (i.e., $>1 \mathrm{E}-03 \underline{\mathrm{M} \mathrm{Cs}}{ }^{+}$), an unexpected reduced competition was observed with increasing $\mathrm{K}^{+}$as had been reported previously for the GGRF resin (Bray et al. 1996b). In addition, Nash and Isom (2010) reported that the dimethylamine, and to some extent, trimethylamine cations appeared to compete strongly with $\mathrm{Na}^{+}$, but not $\mathrm{Cs}^{+}$. Banerjee et al. (2013) reported $\mathrm{Cs}^{+}$exchange isotherms for a range of simple simulants $\left(0.6\right.$ to $3 \underline{\mathrm{M} \mathrm{Na}}{ }^{+}, 1 \mathrm{E}-04$ to $\left.1 \mathrm{E}-01 \mathrm{M} \mathrm{Cs}^{+}\right)$using standard batch contact conditions $\left(0.1 \mathrm{~g}, 10 \mathrm{~mL}, 24\right.$ hours, $\left.25^{\circ} \mathrm{C}\right)$ for the GGRF resin. They reported particle sizes ranging from 0.3 to $0.85 \mathrm{~mm}$, a theoretical capacity of $5.98 \mathrm{meq} / \mathrm{g}$, and a batch equilibrium $\mathrm{K}_{\mathrm{d}}$ of $10,500 \mathrm{~mL} / \mathrm{g}$ in a test solution of $3.8 \underline{\mathrm{M} \mathrm{Na}}{ }^{+}, 1 \underline{\mathrm{M}} \mathrm{OH}^{-}$, and 7.52E-06 $\underline{\mathrm{M}} \mathrm{Cs}^{+}$.

Russell et al. (2014) recently reported an extensive series of batch equilibrium, kinetic, and SRF resin degradation tests over a wide range of temperatures and solution conditions. For the batch distribution tests, a series of 72 nonradioactive simulant solutions were prepared containing variable $\mathrm{Na}^{+}(0.1$ to $5 \underline{\mathrm{M}})$, $\mathrm{K}^{+}$(0.005 to $0.05 \underline{\mathrm{M}}$ ), $\mathrm{Cs}^{+}$(5E-06 to $5 \mathrm{E}-03 \underline{\mathrm{M}}$ ), and either 0.1 or $1.0 \underline{\mathrm{M}} \mathrm{OH}^{-}$. The simulants did not contain aluminum and were not selected to represent any particular tank waste. SRF resin ( $\sim 0.1 \mathrm{~g})$ was contacted with $\sim 25 \mathrm{~mL}$ of simulant for 72 hours at 25,35 , and $50^{\circ} \mathrm{C}$. Numerous $\mathrm{Cs}^{+}$isotherms were reported at the various conditions, similar to those shown in Figure 5.5.

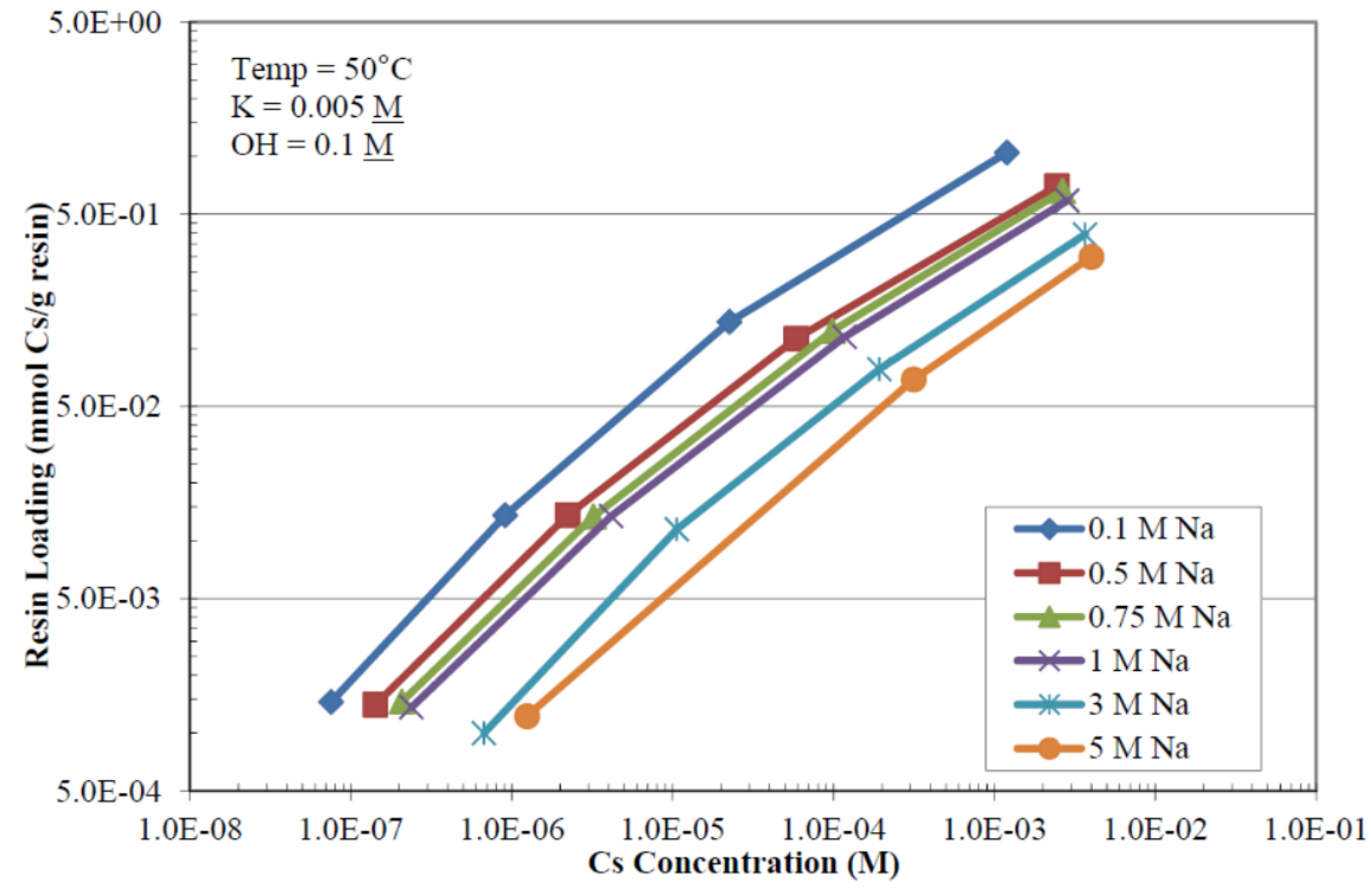

Figure 5.5. $\mathrm{Cs}^{+}$Isotherm for SRF Resin at $50^{\circ} \mathrm{C}$ in Variable $\mathrm{Na}^{+}$Simulants (Russell et al. 2014) 


\subsection{Kinetics Testing}

Various kinetic flow tests have been performed and reported. Those experiments generated data that can be used to predict column loading and elution performance through computer modeling.

Using a thin resin bed and recirculating AN-105 simulant, King et al. (2004) evaluated loading kinetics of SRF, GGRF, and SuperLig ${ }^{\mathrm{TM}} 644$ resins at $0.208,12.5$, and $37.5 \mathrm{~cm} / \mathrm{min}$ each at 25 and $45^{\circ} \mathrm{C}$. They reported faster kinetics for the SRF resin than GGRF or SuperLig ${ }^{\mathrm{TM}} 644$. At $25^{\circ} \mathrm{C}$ there was no difference between the two highest linear flow rates, while the lowest linear flow rate $(0.208 \mathrm{~cm} / \mathrm{min})$ demonstrated substantial delay in $\mathrm{Cs}^{+}$uptake, especially between 0.25 and 20 hours (Figure 5.6). Loading kinetics improved at the higher temperatures while the equilibrium $\mathrm{Cs}^{+}$loading decreased.

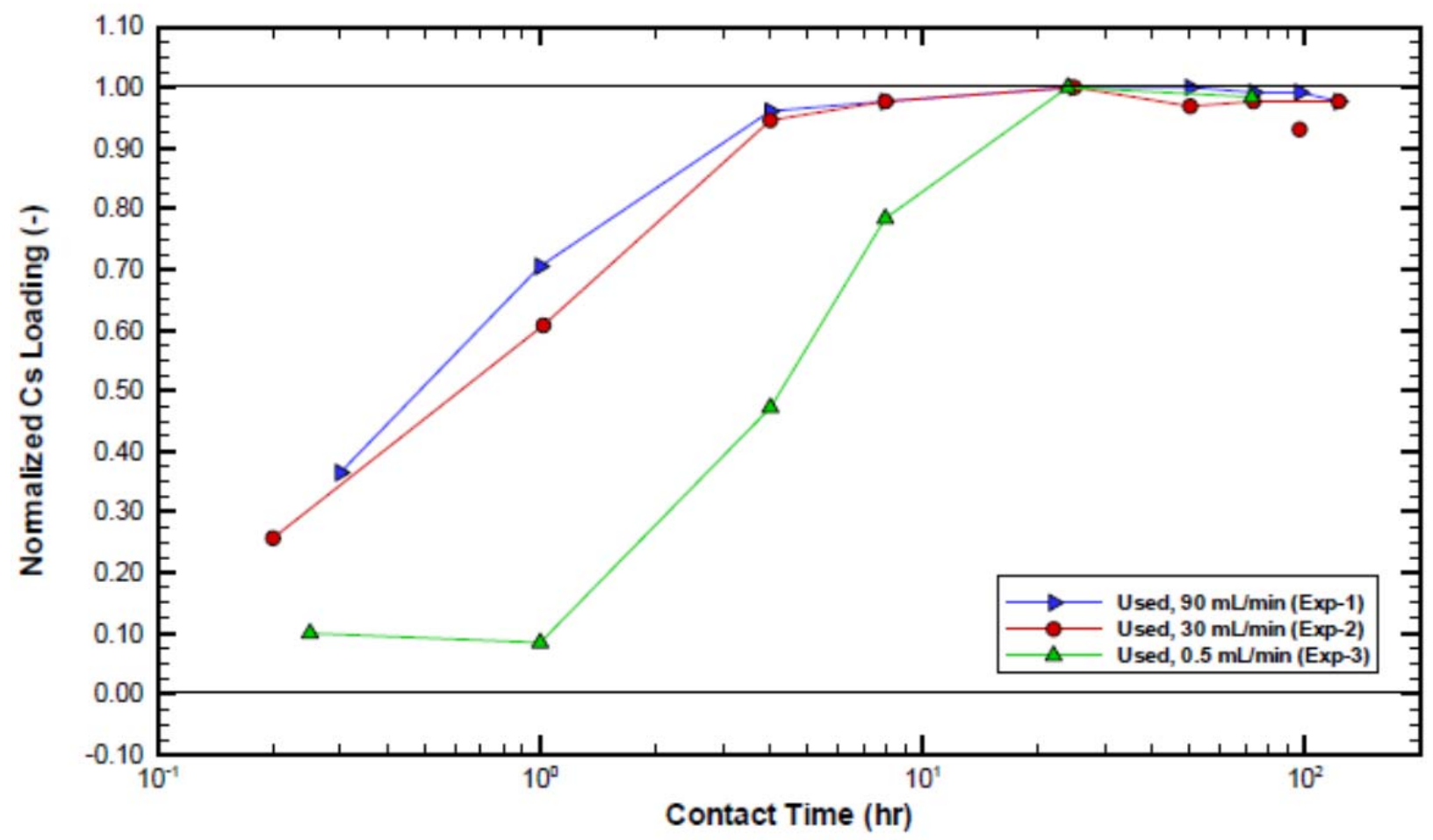

Figure 5.6. Linear Flow Rate Dependence of SRF Resin $\mathrm{Cs}^{+}$Kinetics at $25^{\circ} \mathrm{C}$ (King et al. 2004)

In conjunction with a series of batch equilibrium (see Section 5.1) and column loading and elution tests (see Section 6.1), Nash et al. (2006) reported a number of kinetic experiments at 15,25 , and $45^{\circ} \mathrm{C}$ in AP-101 and AN-105 simulants using a system similar to that described by King et al. (2004). As expected, the equilibrium $\mathrm{Cs}^{+}$loading decreased with increasing $\mathrm{Na}^{+}$and $\mathrm{K}^{+}$in the simulants. The kinetics of $\mathrm{Cs}^{+}$uptake, however, were very similar between the various solutions and essentially identical to previous work (King et al. 2004). More importantly, the kinetics of $\mathrm{Cs}^{+}$uptake were markedly faster at higher temperatures (Figure 5.7). In addition, the $45^{\circ} \mathrm{C}$ data indicated that $\mathrm{Cs}^{+}$was released at contact times greater than 4 hours. While the kinetic uptake profiles are similar between King et al. (2004) and Nash et al. (2006), the two experiments used different simulants (e.g., AN-105 vs. AP-101, respectively) and different batches of SRF resin from different vendors (e.g., BSC-187 vs. 3E-370/641, respectively). The higher $\mathrm{K}^{+}$level $(0.71 \underline{\mathrm{M}})$ in the AP-101 simulant may have contributed to reduced $\mathrm{Cs}^{+}$loading at times exceeding $4 \mathrm{~h}$ due to kinetic differences in ion exchange. 


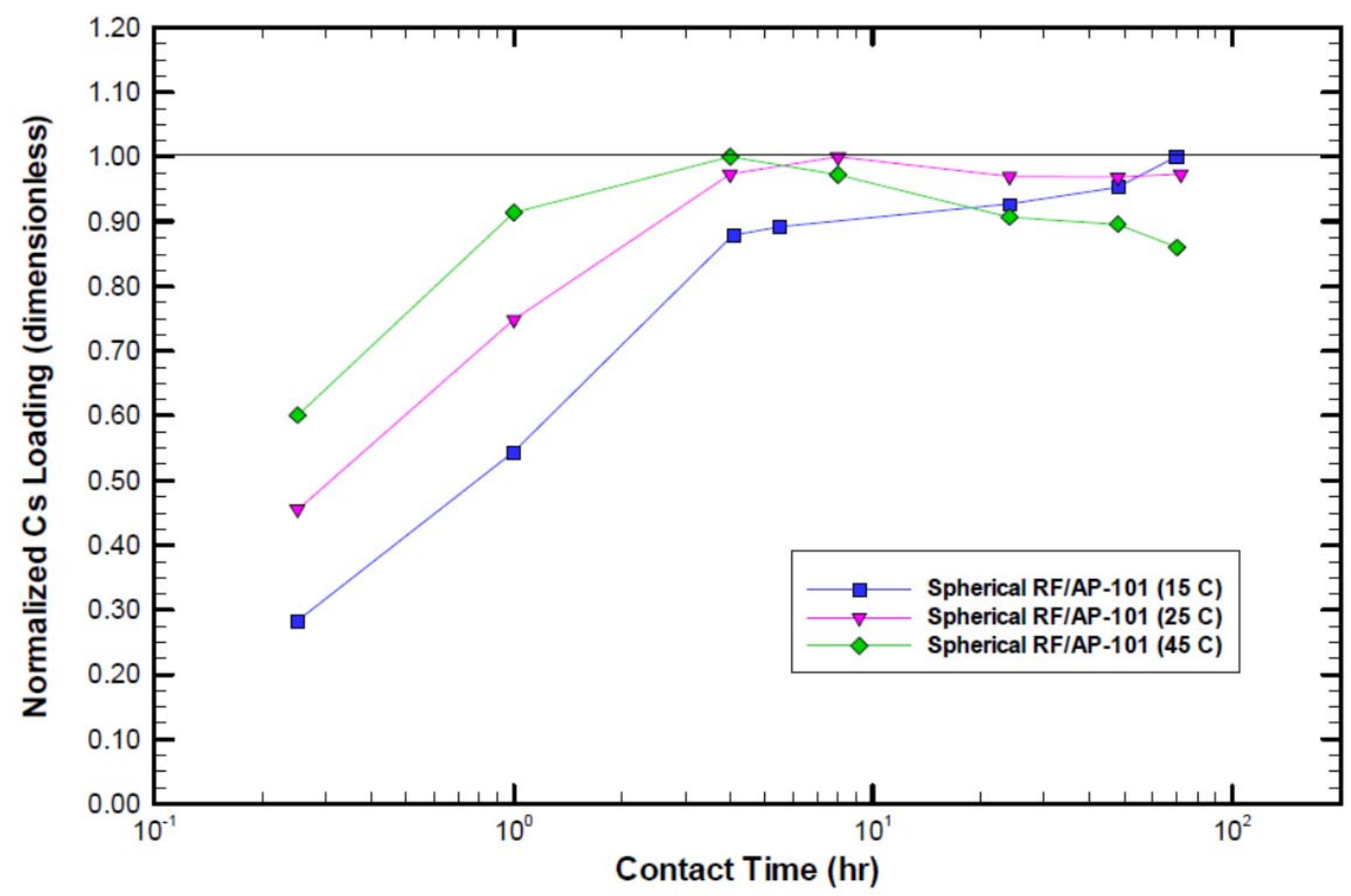

Figure 5.7. Temperature Dependence of SRF Resin Cs ${ }^{+}$Kinetics in AP-101 Simulant (Nash et al. 2006)

Using a similar system, Russell et al. (2012a, 2012b, 2014) examined $\mathrm{Cs}^{+}$ion exchange kinetics in a 2-mL SRF column by evaluating linear load velocity $(4,6,8 \mathrm{~cm} / \mathrm{min})$, initial $\mathrm{Na}^{+}$(2, 5, $8 \underline{\mathrm{M}}$ ), initial $\mathrm{Na}^{+} / \mathrm{Cs}^{+}$ratio $(1.4 \mathrm{E}+05,2.1 \mathrm{E}+05,2.8 \mathrm{E}+05 \mathrm{~mol} / \mathrm{mol})$, initial $\mathrm{Na}^{+} / \mathrm{OH}^{-}$ratio $(2.0,3.0,4.0 \mathrm{~mol} / \mathrm{mol})$, and various temperature $\left(25,30,40,45,50,55,60,65,75^{\circ} \mathrm{C}\right)$. Loading kinetics were not significantly impacted by $\mathrm{Na}^{+}$concentration but increased with the linear velocity similar to King et al. (2004) and Nash et al. (2006). These kinetics testing results indicated that $\mathrm{Cs}^{+}$adsorption is strongly dependent on film mass transfer and not significantly impacted by interparticle diffusion. In addition, Russell et al. (2012a, 2012b, 2014) reported reduced loading capacity during extended, low flow testing at temperatures above $50^{\circ} \mathrm{C}$, with significant reduction above $55^{\circ} \mathrm{C}$. This corroborates the $45^{\circ}$ data shown in Figure 5.7 and supports the hypothesis that $\mathrm{Cs}^{+}$may be released at higher temperatures. No full kinetic loading tests were completed above $45^{\circ} \mathrm{C}$, only low flow extended exposure tests. These tests were designed primarily to evaluate $\mathrm{Cs}^{+}$uptake kinetics, especially at $\mathrm{Na}^{+}$concentrations above $5 \underline{\mathrm{M}}$, using recirculated solutions and very small $(1 \mathrm{~mL})$ SRF columns. While these data demonstrate reduced $\mathrm{Cs}^{+}$uptake at elevated temperatures, extrapolation to systems with large SRF columns and single pass load-elution cycles would be extremely difficult and speculative at best. Additional discussion of these results is provided in Section 7.2. 



\subsection{Column Testing}

This section summarizes SRF resin column testing, including laboratory- and pilot-scale testing and experiments using actual wastes.

\subsection{Lab-Scale Column Testing}

In conjunction with batch equilibrium (see Section 5.1) and kinetics (see Section 5.2) testing, Nash et al. (2006) reported a series of small, $11 \mathrm{~mL}$ column loading and elution tests using AP-101 and AN-107 simulants at $45^{\circ} \mathrm{C}$. The AP- 101 simulant contained high levels of $\mathrm{K}^{+}$and, along with tank AW-101, is considered to be challenging for CIX processing. Tank AN-107, while lower in $\mathrm{K}^{+}$, contains significant ${ }^{90} \mathrm{Sr}$, TRU, and total organic carbon, and provides different processing challenges. Nash et al. (2006) reported $50 \% \mathrm{Cs}^{+} \mathrm{C} / \mathrm{C}_{0}$ breakthrough at $76 \mathrm{BV}$ for tank AP-101 while loading at $1.36 \mathrm{BV} / \mathrm{hr}$. They were not able to reach $50 \% \mathrm{Cs}^{+} \mathrm{C} / \mathrm{C}_{0}$ breakthrough for tank $\mathrm{AN}-107$, achieving only $7 \% \mathrm{Cs}^{+} \mathrm{C} / \mathrm{C}_{0}$ breakthrough at $235 \mathrm{BV}$, due to the relatively low $\mathrm{K}^{+}$level in the feed solution. In addition, Nash et al. (2006) showed elution curves for both solutions and calculated the $\mathrm{Cs}^{+}$mass balance, indicating over four orders of magnitude less $\mathrm{Cs}^{+}$remained on the column after elution. Further loading and elution data were shown that indicated, in addition to $\mathrm{Cs}^{+}$, an uptake of $\mathrm{Ca}, \mathrm{Cd}, \mathrm{Fe}, \mathrm{Pb}$, and $\mathrm{Sr}$ by the SRF resin. Finally, the eluted spent resin was analyzed for residual metals. Elements remaining on the resin included Fe, Sr, and Zn (all much higher for AN-107) and Cr (higher for AP-101). Figure 6.1 shows a typical laboratory-scale CIX column system.

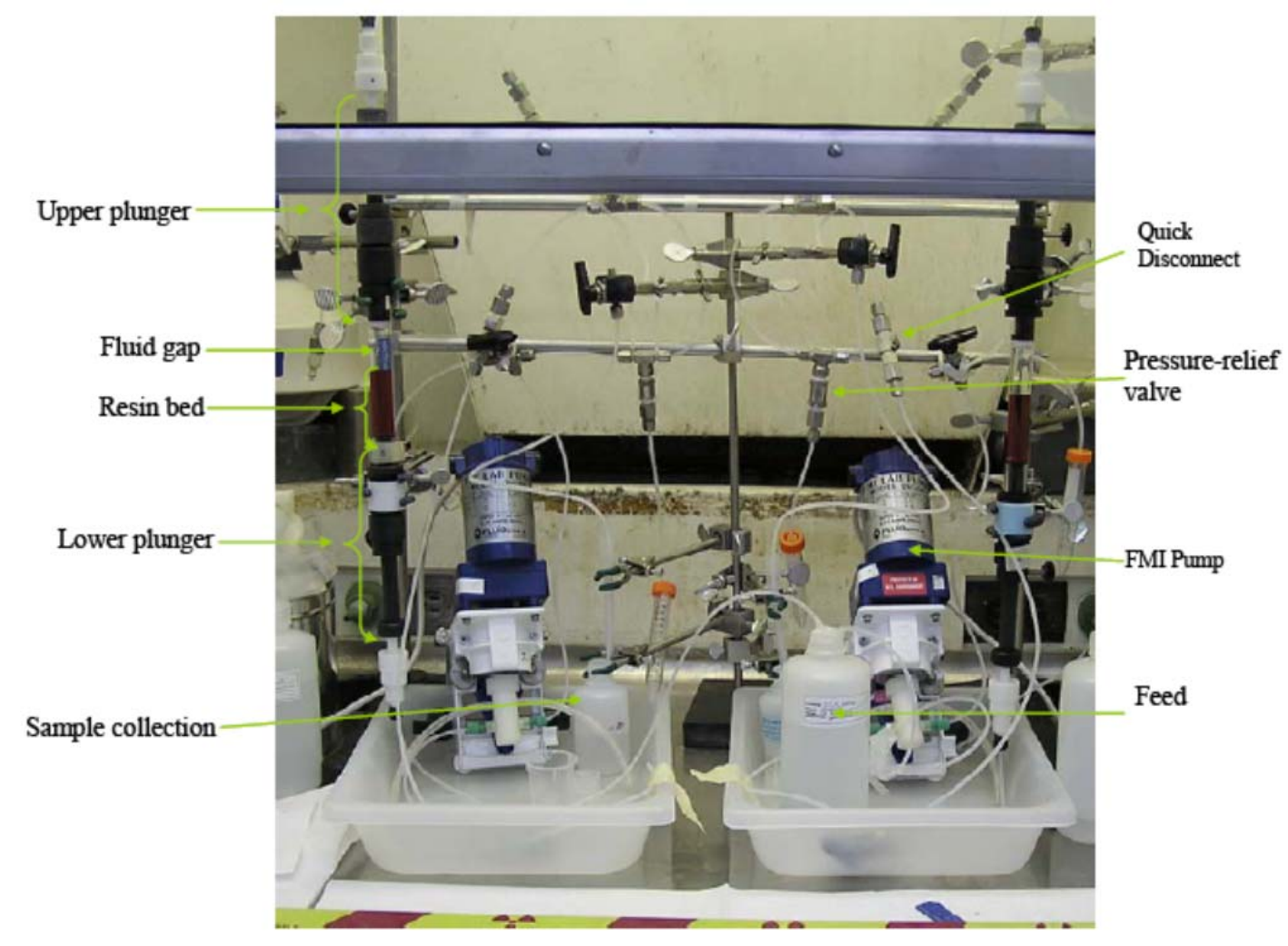

Figure 6.1. Typical Laboratory-Scale Lead-Lag Ion Exchange Column System (Blanchard et al. 2008) 
As described in Sections 3.2 and 5.1, Fiskum et al. (2004, 2006a, 2006b, 2006c) completed a series of column tests similar to Nash et al. (2006). Using small, $20 \mathrm{~mL}$ columns in the lead-lag configuration, Fiskum et al. (2006a) evaluated multiple small- and medium-sized production lots of SRF resin from multiple vendors with the objective to supply supporting data necessary to evaluate and qualify resin formulations, production methods, and vendors and develop a detailed material purchase specification. They reported column loading and elution profiles using AP-101, AN-102, and AZ-102 tank simulants. The resulting dataset is too large to easily summarize but does demonstrate that the SRF resin will meet the WTP plant CIX processing requirements for simulants evaluated and, for certain defining characteristics, is superior to both the GGRF and SuperLig ${ }^{\mathrm{TM}} 644$ resins (Thorson 2007).

Burgeson et al. (2006) compared the CIX column loading and elution characteristics of SRF, GGRF, and SuperLig ${ }^{\mathrm{TM}} 644$ resins using AN-105 simulant $\left(5.0 \underline{\mathrm{M} \mathrm{Na}}{ }^{+}, 0.09 \underline{\mathrm{M} \mathrm{K}}{ }^{+}, \mathrm{Cs}^{+}\right.$varied from $3.76 \mathrm{E}-05 \underline{\mathrm{M}}$ to $3.76 \mathrm{E}-04 \mathrm{M}$ ). They loaded the $1.5 \mathrm{~cm}$ diameter columns at 2 to $7 \mathrm{BV} / \mathrm{hr}$ and ambient temperature to $\geq 90 \% \mathrm{Cs}^{+} \mathrm{C} / \mathrm{C}_{0}$ breakthrough and then varied the $\mathrm{HNO}_{3}$ eluent concentration, flow rate, and temperature to determine optimal elution conditions. Using a partial factorial experimental design, they reported column $\mathrm{Cs}^{+}$loading under the various solution conditions, elution efficiency, and residual $\mathrm{Cs}^{+}$on the

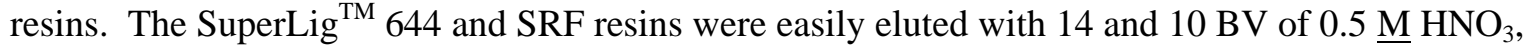
respectively, to meet the WTP design basis for spent resin $(60 \mu \mathrm{Ci} / \mathrm{g})$. The GGRF resin required more aggressive elution conditions to meet the design basis. Elevated temperatures and lower flow rates improved the elution, while concentration did not have a significant effect. Unfortunately, these conditions are likely to increase chemical and radiolytic degradation of the resin (see Section 7.0).

Blanchard et al. $(2008,2009)$ completed a series of $10 \mathrm{~mL}$ lead-lag column loading (Figure 6.2) and elution (Figure 6.3) experiments in support of the pilot-scale near-tank cesium removal (NTCR) project.

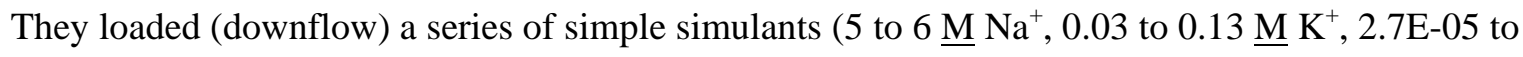
9.4E-05 $\underline{\mathrm{M} \mathrm{Cs}}{ }^{+}$) at 3 to $6 \mathrm{BV} / \mathrm{hr}$ and $25^{\circ} \mathrm{C}$ while eluting upflow with $0.5 \underline{\mathrm{M} \mathrm{HNO}} \mathrm{HN}_{3}$ at 1.5 to $2 \mathrm{BV} / \mathrm{hr}$ and 10 to $22^{\circ} \mathrm{C}$. They regenerated the SRF resin upflow with $1 \underline{\mathrm{M}} \mathrm{NaOH}$ followed by upflow density adjustment with a mixture of $2 \underline{\mathrm{M} N a O H}$ and $3 \underline{\mathrm{M}} \mathrm{NaNO}_{3}$. Interestingly, in an attempt to simplify the flowsheet and minimize secondary waste generation, they did not rinse with DIW after the $0.1 \underline{\mathrm{M}} \mathrm{NaOH}$ feed displacement or after the $0.5 \underline{\mathrm{M}} \mathrm{HNO}_{3}$ elution. This was made possible by eliminating $\mathrm{NaNO}_{2}$ from the density adjustment solution. Bubble formation and "fingering" was observed at the start of elution attributed to an insufficient (1.5 BV) feed displacement. Blanchard et al. (2008, 2009) reported delayed loading breakthrough at lower flowrates, $\mathrm{Na}^{+}$and $\mathrm{Cs}^{+}$concentrations, sufficient elution after $\sim 8 \mathrm{BV}$ of $0.5 \mathrm{M} \mathrm{HNO}_{3}$ (for the lead column only, the lag column required $>9 \mathrm{BV}$ ), excellent elution with $15 \mathrm{BV}$ of $0.5 \mathrm{M} \mathrm{HNO}_{3}$, and did not observe significant improvement in the elution profile with either increasing temperature or flowrate. Uneven conversion fronts were observed for all elutions and to a lesser extent for the regenerations. Elution performance did not seem to be seriously degraded as a result. Blanchard et al. (2008, 2009) emphasized the importance of stopping the loading process as soon as the $\mathrm{Cs}^{+} \mathrm{C} / \mathrm{C}_{0}$ values of the lag column (or polishing if more than two are used) begin to rise. Further, they emphasized the need to minimize the fluid volume above resin during elution (0.3 to $0.5 \mathrm{BV}$ ) to help minimize mixing and improve efficiency.

Duignan and Nash (2009, 2010a, 2010b) and Nash and Duignan (2009, 2010) completed a series of batch distribution (see Sections 5.1) and $10 \mathrm{~mL}$ lead-lag column loading and elution experiments in support of actual waste testing (see Section 6.2). They loaded (downflow) simulated and actual SRS tank wastes $\left(6 \underline{\mathrm{M} \mathrm{Na}}{ }^{+}, 0.01 \underline{\mathrm{M} \mathrm{K}}+2.5 \mathrm{E}-05 \underline{\mathrm{M} \mathrm{Cs}}{ }^{+}\right)$at $1.4 \mathrm{BV} / \mathrm{hr}$ and $25^{\circ} \mathrm{C}$ while eluting with up to $30 \mathrm{BV}$ of $0.5 \mathrm{M} \mathrm{HNO}_{3}$ at $1.4 \mathrm{BV} / \mathrm{hr}$. They reported $\mathrm{Cs}^{+}$isotherms and loading curves (200 to $300 \mathrm{BV}$ to 50\% 


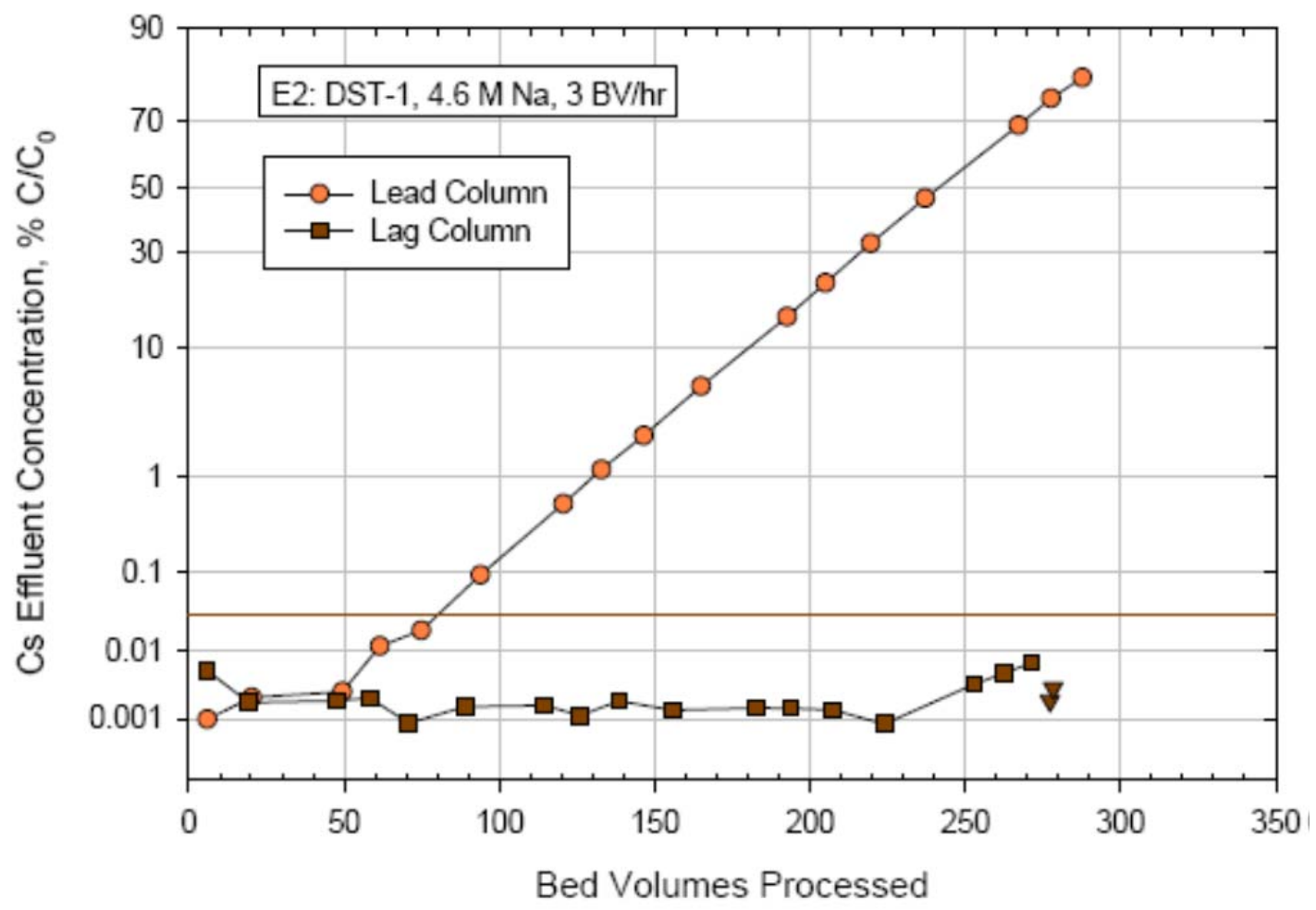

Figure 6.2. Typical Lead-Lag Column Loading of SRF Resin (Blanchard et al. 2008)

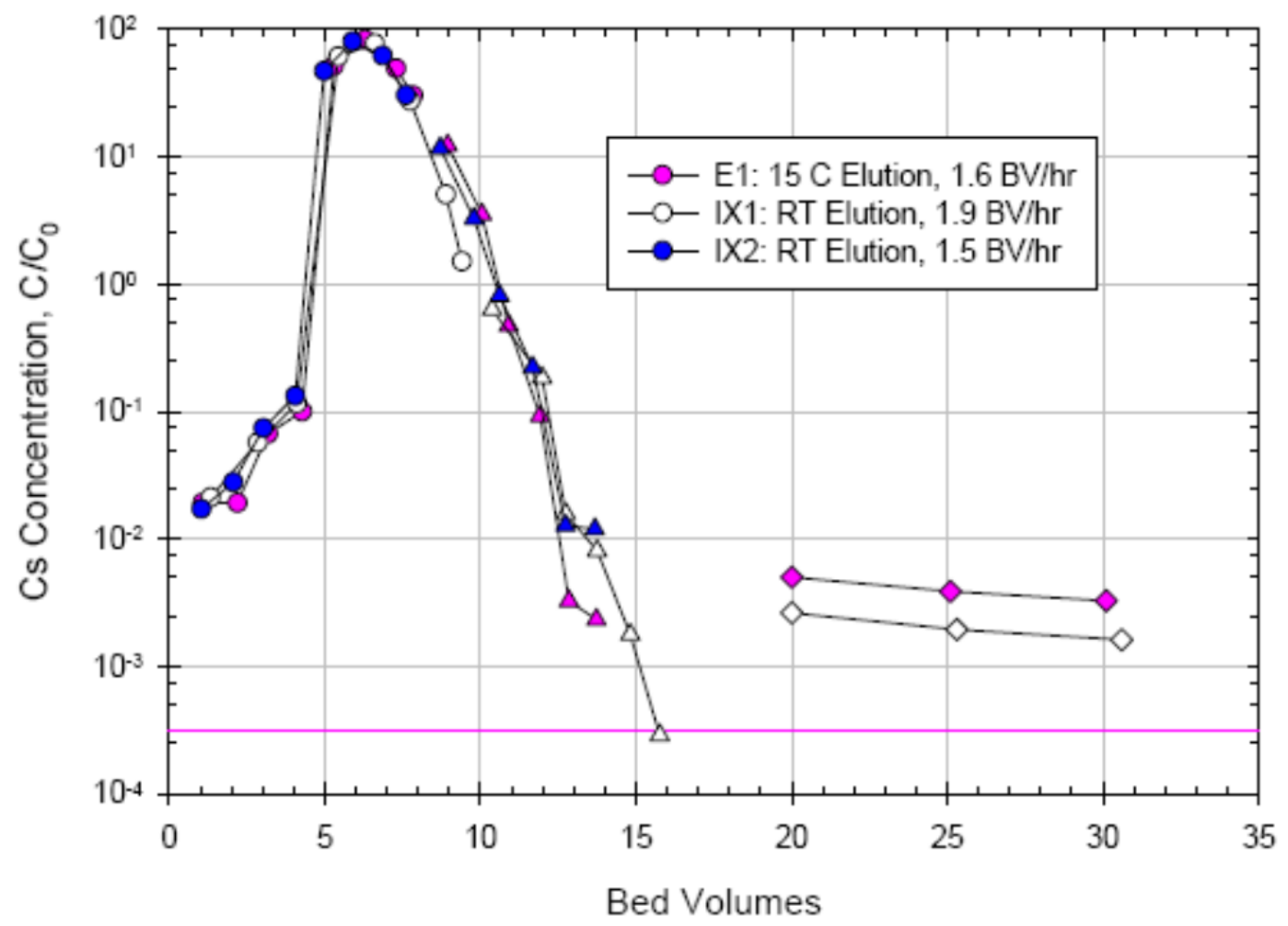

Figure 6.3. Typical Column Elution of SRF Resin with $0.5 \underline{\mathrm{M}} \mathrm{HNO}_{3}$ (Blanchard et al. 2008) 
$\mathrm{Cs}^{+} \mathrm{C} / \mathrm{C}_{0}$ breakthrough). The elution curves demonstrated that a majority of the $\mathrm{Cs}^{+}$was eluted between 4 and $6 \mathrm{BV}$ of $0.5 \mathrm{M} \mathrm{HNO}_{3}$. Furthermore, the batch tests over-predicted column loading by $11 \%$, which was within experimental uncertainty.

\subsection{Actual Waste Testing}

Various investigators have reported CIX testing using actual radioactive tank wastes, often in conjunction with simulated waste tests that confirm the validity of prior simulant evaluations. For specific testing details (e.g., sample traceability), the reader is directed to the individual references.

Fiskum et al. (2005) and Peterson et al. (2006) reported a significant series of actual waste tests from Hanford Tanks AW-101, AP-101, AP-104, AN-102, AZ-101, AZ-102, although for SuperLig ${ }^{\mathrm{TM}} 644$ and not the SRF resin. The investigators evaluated the effective mass transfer zone in the column for the three waste types and demonstrated effective elution for the WTP baseline. Similarly, Hassan et al. (2004) reported a series of six load/elute cycles with actual AW-101 tank waste diluted to $5.09 \underline{\mathrm{M}} \mathrm{Na}^{+}$using a $15 \mathrm{~mL}$ column of SuperLig ${ }^{\mathrm{TM}} 644$ resin. They reported that the resin performance degraded gradually from 225 to $160 \mathrm{BV}$ to $50 \% \mathrm{Cs}^{+} \mathrm{C} / \mathrm{C}_{0}$ breakthrough during an estimated $2 \mathrm{E}+07$ Rad cumulative irradiation. The $\mathrm{Cs}^{+}$decontamination factor (DF) exceeded $1 \mathrm{E}+04$ during loading while $>99 \%$ elution was achieved with less than $15 \mathrm{BV}$ of $0.5 \underline{\mathrm{M}} \mathrm{HNO}_{3}$. One important result from this work was the observation of significant $\mathrm{Cs}^{+}$"bleed" during second cycle loading for the previously loaded and eluted column subsequently placed in the lag position. The authors were able to show that insufficient elution of the lead column resulted in failure to meet the WTP ${ }^{137} \mathrm{Cs}$ decontamination specification. Conversely, by doubling the acid used to elute the SuperLig ${ }^{\mathrm{TM}} 644$ resin, the decontamination specification was met.

Fiskum et al. (2006b) reported small (1.5 cm diameter by $6.3 \mathrm{~cm}$ height, $11 \mathrm{~mL}$ nominal volume), lead-lag column loading (2.9 BV/hr) and elution ( $0.5 \underline{\mathrm{M}} \mathrm{HNO}_{3}$ at $\left.1.4 \mathrm{BV} / \mathrm{hr}\right)$ results for actual and simulated AP-101 supernate that had been diluted to a nominal $5 \underline{\mathrm{M} \mathrm{Na}}{ }^{+}$and $0.7 \underline{\mathrm{M}} \mathrm{K}^{+}$. They reported visual observations of resin expansion and analytical measurement of various metals and radionuclides. The testing used the large production batch of SRF resin (Microbeads lot number 5E-370/641). During the loading phase, the ${ }^{137} \mathrm{Cs}$ effluent concentration exceeded the WTP contract limits at 25 BV while $50 \% \mathrm{Cs}^{+} \mathrm{C} / \mathrm{C}_{0}$ breakthrough occurred after $92 \mathrm{BV}$ for the actual waste and $123 \mathrm{BV}$ for the simulant. It is possible that the discrepancy may have been related to a 5 and $7 \%$ increase in $\mathrm{Na}^{+}$and $\mathrm{K}^{+}$concentration, respectively, in the actual waste as compared to the simulant. The CIX column system was not water-jacketed for temperature control and both experiments were completed at ambient temperatures. They reported 20 to $25^{\circ} \mathrm{C}$ for the simulants and 25 to $27^{\circ} \mathrm{C}$ inside the hot cell for actual waste tests. In addition, because the same column and resin material was used sequentially for both the simulant and actual waste testing, it is possible that the nonradioactive $\mathrm{Cs}^{+}$from the first loading cycle was not completely eluted from SRF resin. Another possibility was the presence of channeling in the resin bed after the simulant testing, or chemical degradation of the SRF resin during the 24-day storage between the tests. Fiskum et al. (2006b) reported $>120,000{ }^{137} \mathrm{Cs}$ DF after loading $60 \mathrm{BV}$ and nearly complete elution after $10 \mathrm{BV}$ acid. For comparison, Nash et al. (2006) reported loading $76 \mathrm{BV}$ to $50 \% \mathrm{Cs}^{+} \mathrm{C} / \mathrm{C}_{0}$ for simulated AP- 101 at $45^{\circ} \mathrm{C}$. The difference between the two results is likely due to the temperature difference (see Section 5.1).

Fiskum et al. (2008) reported a similar series of three small $(1.5 \mathrm{~cm}$ diameter by $6.3 \mathrm{~cm}$ height, $11 \mathrm{~mL}$ nominal volume), lead-lag column loading and elution tests for the SRF resin using simulated and actual 
Hanford tank AP-101 (high $\mathrm{K}^{+}$) and AN-102 (organic complexant concentrate). As anticipated, due to the large difference in $\mathrm{K}^{+}$content of the two wastes, approximately 92 and $>200 \mathrm{BV}$ could be processed before reaching $50 \% \mathrm{Cs}^{+} \mathrm{C} / \mathrm{C}_{0}$ breakthrough for AP-101 and AN-102, respectively. In addition, an $8 \%$ difference in the $\mathrm{K}^{+}$content of the simulated and actual AP-101 wastes may explain the different loading profiles. The AP-101 mass transfer zone suggests that $\mathrm{Cs}^{+}$leakage could exceed specifications during actual WTP operations unless the lead column is taken offline prior to full loading or the solution is blended with lower $\mathrm{K}^{+}$feedstock. For AP-101, the composite effluent through the lead-lag columns maintained a Cs ${ }^{+}$DF of 1,000 through $110 \mathrm{BV}$. In contrast, the DF for the AN-102 effluent composite was 111,000 for the entire $202 \mathrm{BVs}$ processed. Although evaluated to $30 \mathrm{BV}$, most $\mathrm{Cs}^{+}$elution occurred between 3 and $10 \mathrm{BV}$ of $0.5 \mathrm{M} \mathrm{HNO}_{3}$ with diminishing effectiveness beyond $12 \mathrm{BV}$. Percent recovery in the treated effluent and acid eluate was reported for a large number of metals and radionuclides. In addition to $\mathrm{Cs}, \mathrm{Cu}, \mathrm{Pb}, \mathrm{U}, \mathrm{Pu}$, and perhaps $\mathrm{Ba}$ appeared to load onto and elute off of the SRF resin. Following elution, the spent resin was dissolved and analyzed for residual metals and radionuclides. In addition to those previously mentioned, ${ }^{99} \mathrm{Tc}$ and ${ }^{60} \mathrm{Co}$ appeared to remain on the spent resin. Finally, Toxicity Characteristic Leaching Procedure (TCLP) and Resource Conservation and Recovery Act (RCRA) metals were analyzed and the results reported. In a similar fashion, Nash et al. (2006, 2007) found that $\mathrm{Cd}$ and $\mathrm{Pb}$ loaded on the SRF resin but could be subsequently eluted with $0.5 \underline{\mathrm{M}} \mathrm{HNO}_{3}$. Certain amounts of other elements (i.e., $\mathrm{Al}, \mathrm{Cr}, \mathrm{Fe}, \mathrm{S}, \mathrm{Sr}$, and $\mathrm{Zn}$ ) appeared to remain on the resin even after elution.

Duignan and Nash (2009, 2010b, 2010b) and Nash and Duignan (2009, 2010) have reported a series of experiments involving small (1.4 cm diameter by $6.5 \mathrm{~cm}$ height, $10 \mathrm{~mL}$ nominal volume), lead-lag column loading and elution results for the SRF resin using simulated SRS tank 2F supernate and actual dissolved salt solution from tanks 25 and 41 that had been diluted to $6 \underline{\mathrm{M} \mathrm{Na}}{ }^{+}, 0.007 \underline{\mathrm{M}} \mathrm{K}^{+}$, and 1.7E-05 $\underline{\mathrm{M} \mathrm{Cs}}{ }^{+}$. The testing used the same batch of SRF resin (Microbeads lot number 5E-370/641), and similar column dimensions and process operations as reported by previous investigators (Adamson et al. 2006; Fiskum et al. 2006b; Smith 2007). Batch $\mathrm{K}_{\mathrm{d}}$ testing with simulants over-predicted column loading by approximately $11 \%$ which was considered inconsequential, likely within analytical error, and perhaps related to small differences in the composition. In addition, the low $\mathrm{K}^{+}$concentration in this testing resulted in much higher $\mathrm{Cs}^{+}$loading (250 BV to initial breakthrough and $325 \mathrm{BV}$ to $50 \% \mathrm{Cs}^{+} \mathrm{C}^{-} \mathrm{C}_{0}$ breakthrough) than the Hanford waste with a much higher $\mathrm{K}^{+}$concentration. The results confirm that approximately 75 to $80 \%$ of the resin in the column becomes loaded with $\mathrm{Cs}^{+}$as the initial breakthrough $\left(\mathrm{Cs}^{+} \mathrm{C} / \mathrm{C}_{0} \sim 5 \%\right)$ is measured at the column exit. The results also imply that even after the lead column effluent is at $100 \%$ breakthrough, sufficient capacity remains on the lag column to maintain effective $\mathrm{Cs}^{+}$ removal. This suggests that column switching after observing either initial or total breakthrough on the

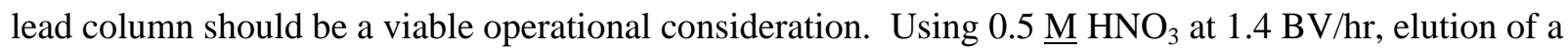
majority $\mathrm{Cs}^{+}$was demonstrated in the first $6 \mathrm{BV}$, as was the majority of the resin shrinkage. Exponential tailing was observed in the elution between 6 and $30 \mathrm{BV}$. Analytical results are provided for various metals and radionuclides, confirming that ${ }^{126} \mathrm{Sb}$ did not load onto the resin while $\mathrm{Al}, \mathrm{Cr}, \mathrm{K}, \mathrm{Na}$, and $\mathrm{Pu}$ showed an affinity for the SRF resin and partially loaded.

From an historical perspective several investigators have reported actual waste results for non-SRF materials. For example Hendrickson et al. (1996) evaluated removing ${ }^{137}$ Cs from actual AW-101 waste using GGRF resin. Lee et al. (1998) tested GGRF, SuperLig ${ }^{\mathrm{TM}}$ 644, crystalline silicotitanate (CST), CS-100, and several $\mathrm{KCoFe}(\mathrm{CN})_{6}$ configurations using supernatant liquids from the Melton Valley Storage Tanks at Oak Ridge National Laboratory (ORNL). Hassan and Adu-Wusu (2005) reported batch 
contact distribution testing and column loading and elution of GGRF resin using a small $12 \mathrm{~mL}$ column

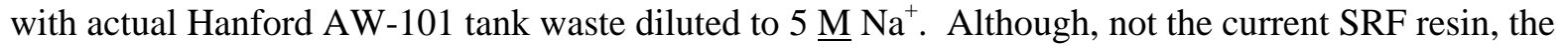
results demonstrated $\sim 208 \mathrm{BV}$ could be loaded to $50 \% \mathrm{Cs}^{+} \mathrm{C} / \mathrm{C}_{0}$ breakthrough at $3 \mathrm{BV} / \mathrm{hr}$. Effective $\mathrm{Cs}^{+}$ elution (>99\%) with $16.5 \mathrm{BV}$ of $0.5 \underline{\mathrm{M}} \mathrm{HNO}_{3}$ at $1.5 \mathrm{BV} / \mathrm{hr}$ was also reported. The analytical results suggested possible retention of $\mathrm{Al}, \mathrm{Ba}, \mathrm{Ca}, \mathrm{Cs}, \mathrm{Si}, \mathrm{Pu}$, and $\mathrm{U}$ on the GGRF resin. Hassan et al. (2004a, 2004b) reported a similar series of batch equilibrium tests using actual AW-101 waste at $5 \underline{\mathrm{M}} \mathrm{Na}^{+}$and the GGRF resin. They evaluated two phase ratios (10 and $100 \mathrm{~mL} / \mathrm{g}$ ), two equilibration times (72 and 120 hours), constant $25^{\circ} \mathrm{C}$, and varied total $\mathrm{Cs}^{+}$content by spiking solutions with nonradioactive ${ }^{133} \mathrm{Cs}$ to determine isotherm data and report $\mathrm{Cs}^{+} \mathrm{K}_{d} \mathrm{~s}$ between 174 and $645 \mathrm{~mL} / \mathrm{g}$. Kurath et al. (1999, 2000a, 200b) reported similar experiments for the SuperLig ${ }^{\mathrm{TM}} 644$ resin $(15 \mathrm{~mL}$ lead/lag columns and actual AW-101 diluted to $4.59 \underline{\mathrm{M} \mathrm{Na}}{ }^{+}, 0.39 \underline{\mathrm{M} \mathrm{K}}{ }^{+}$, and 6.14E-05 $\underline{\mathrm{M} \mathrm{Cs}}{ }^{+}$) which demonstrated significant volume changes $\left(\mathrm{Na}^{+}\right.$to $\mathrm{H}^{+}$form) and $143 \mathrm{BV}$ to $50 \% \mathrm{Cs}^{+} \mathrm{C} / \mathrm{C}_{0}$ breakthrough. King et al. (2000), Hassan et al. (2000a, 200b), and Fiskum et al. (2005) reported on similar experiments with SuperLig ${ }^{\mathrm{TM}} 644$ resin and simulated AN-105 or actual AN-102 waste. Although not for the SRF resin and therefore outside the scope of the current review, they reported chemical and radionuclide results for a wide suite of analytes.

\subsection{Pilot-Scale Testing}

A number of pilot-scale tests have been reported for the SRF resin. Evaluating nearly two dozen hydraulic/chemical cycles, Adamson et al. (2006) and Adamson $(2007,2009)$ reported that the SRF resin permeability remained essentially constant $\left(\sim 3.3 \mathrm{E}-06 \mathrm{~cm}^{2}\right)$ during $1 / 4$ - and $1 / 2$-scale cycling and was 2.5 times greater than the full-scale WTP CIX design requirement. The hydraulic results were summarized previously in Section 3.5. The experiment used an AP-101 simulant with a density of $1.25 \mathrm{~g} / \mathrm{mL}$ and a viscosity of $3.0 \mathrm{cP}$ containing $5.00 \underline{\mathrm{M} \mathrm{Na}}{ }^{+}, 0.73 \underline{\mathrm{M}} \mathrm{K}^{+}$and $5.0 \mathrm{E}-05 \underline{\mathrm{M}} \mathrm{Cs}^{+}$. In the three $\mathrm{Cs}^{+}$loading tests the effluent never exceeded the method detection limit of $1.9 \mathrm{E}-08 \underline{\mathrm{M}} \mathrm{Cs}^{+}$ $\left(\mathrm{C} / \mathrm{C}_{0}=3.8 \mathrm{E}-04\right)$. Thus, no measurable degradation was observed in $\mathrm{Cs}^{+}$removal performance after 13 cycles. In addition, analysis of $\mathrm{Rb}^{+}$impurities during the tests suggested that $\mathrm{Rb}^{+}$is not retained on the SRF resin. There was no observable formation of fines, changes in SRF particle size, tendency to form fissures, or pack more densely even after multiple (16) cycles. Due to upflow regeneration, there was negligible radial pressure to the column walls during resin swelling and high permeability. Downflow regeneration was also evaluated and produced slightly lower permeability $\left(\sim 2.5 \mathrm{E}-06 \mathrm{~cm}^{2}\right)$. The pilot-scale testing did not optimize the conversion to $\mathrm{Na}^{+}$-form during the regeneration step (e.g., between 1.04 and 1.54 mole_Na ${ }^{+}$per liter of resin), but did confirm that lower $\mathrm{Na}^{+}$consumption may be possible by recirculating the $\mathrm{NaOH}$ solution. The test solutions remained clear through all 16 cycles and indicated minimal chemical degradation of the SRF resin, in contrast to previous tests with SuperLig ${ }^{\mathrm{TM}} 644$ (Fowley et al. 2004). Furthermore, these reports indicated that upflow regeneration and simulant loading produced negligible wall pressures and an ideal, level bed surface while downflow simulant loading produced an uneven bed.

\subsection{Near-Tank Cesium Ion Exchange}

NTCR by ion exchange is being evaluated at various DOE sites and locations as one of the supplemental pretreatment methods projected to shorten the overall duration of waste processing. Multiple embellishments have been described as near-tank treatment system, at-tank, or in-tank (e.g., SCIX). Nearly 20 years ago, the utility of such a system, termed the compact processing unit was evaluated for Hanford operations (Collins et al. 1994; Howden 1994). The current concept is to co-locate 
a filtration system (rotary micro filter or cross-flow filter) and the supplemental CIX column system (in-tank or skid-mounted) within the tank farm complex. Although outside the scope of this report, additional processes might include enhanced sludge washing or caustic leaching. Following filtration, the diluted and/or undiluted supernate and potentially dissolved salt cake would be passed through an appropriately sized ion exchange column containing either SRF resin (Hanford-preferred option) or the CST IONSIV $^{\mathrm{TM}}$ IE-911 material (SRS-preferred option). Where appropriate, the various reported works are described in previous sections. Spires et al. (2009) used the analytical hierarchy process for a systems engineering evaluation of the SRF and CST materials in the SCIX. Blanchard et al. (2009) summarized the skid-mounted NTCR process for removal of $\mathrm{Cs}^{+}$from 16,000 gal of simulant using downflow loading,

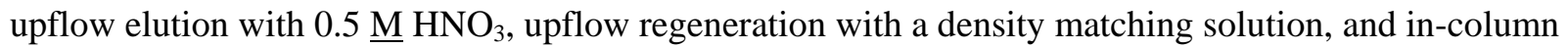
spent resin destruction. Josephson et al. (2010) provided a review of several CIX tests as applicable to a technology readiness assessment of the near-tank treatment system and included information about the pilot-scale NTCR system that had been designed by Parsons (Pasadena, CA). A brief summary of this system and operation can be found in Sams et al. (2009). The proposed system and process flowsheet appear to be simplified compared to the WTP flowsheet (e.g., fixed loading volume; reduced effluent process monitoring, concentrations, volumes, and elution temperature; and fewer valves, columns, and solutions).

King (2007) summarized a review of $\mathrm{Cs}^{+}$removal technologies to support material selection for SCIX operation within a HLW tank at the SRS as part of the modular salt processing technology development program. Two materials, SRF and CST, were evaluated. For the SRF resin, they evaluated manufacturability, production scale and reproducibility, resin physical properties, chemical cycling, radiolysis, chemical reactivity, sorption/desorption behavior, resin hydraulic properties, column loading and elution performance, testing with actual wastes, process safety, secondary waste implications, and exchanger disposal. Although primarily focused on the SCIX configuration, the report provides an excellent review of experimental and theoretical work done on the SRF resin through 2007.

Thorson and Gilbert (2007) and Ramsey and Thorson (2010) have provided technical assessments and justification for choosing SRF over CST at WTP. They report that the SRF resin is compatible with and qualified as the WTP baseline; may be operated at higher temperatures than CST; is less than 2\% of the cost of CST; and does not generate additional HLW solids and therefore does not require additional storage, grinding, or an alternative disposal path, prior to HLW vitrification start up. Spires et al. (2009) completed a systems engineering evaluation of various $\mathrm{Cs}^{+}$-removal technologies at SRS. The CST IE-911 was chosen over SRF resin primarily based on process compatibility with downstream processes, followed by life cycle cost, operational complexity, technology maturity, and schedule. 



\subsection{Resin Stability and Disposal}

This section summarizes cycling, chemical, radiolytic, and thermal degradation of the SRF resin as well as purposeful digestion and analysis of the resin for disposal.

\subsection{Resin Cycling Lifetime}

Thorson (2008a) completed a CIX process review and estimated the SRF resin cycling lifetime during proposed operations at the WTP. The 5-year average number of resin reuse cycles was estimated to vary from 33 to 46, far exceeding the 16-cycle experimental data reported by Adamson et al. (2006) and Adamson $(2007,2009)$ in Section 6.3. The assumption was that the SRF resin would be cycled to the point of significant performance degradation (e.g., until $\mathrm{Cs}^{+}$loading breakthrough occurred in the time required to complete the elution and rinsing process for the offline column). The cumulative radiation dose to the SRF resin was estimated to remain less than 80 MRad over the 46 cycles. Over $80 \%$ of the resin capacity degradation was estimated to come from exposure to dissolved oxygen.

\subsection{Chemical Degradation}

Fondeur et al. (2006) and King et al. (2006) investigated the chemical reactivity and degradation of the SRF resin at a variety of temperatures and $\mathrm{HNO}_{3}$ concentrations. They observed evidence of reactivity as low as $25^{\circ} \mathrm{C}$ with $3 \underline{\mathrm{M}} \mathrm{HNO}_{3}$ and at $66^{\circ} \mathrm{C}$ with $0.626 \underline{\mathrm{M}} \mathrm{HNO}_{3}$. The reaction rate and intensity increased with temperature and acid strength. Nearly complete destruction was reported with $3 \underline{\mathrm{M}} \mathrm{HNO}_{3}$ at $55^{\circ} \mathrm{C}$ and with $8 \underline{\mathrm{M}} \mathrm{HNO}_{3}$ at $25^{\circ} \mathrm{C}$. From mass uptake and elemental analysis of the SRF residue, $2 \underline{\mathrm{M}} \mathrm{HNO}_{3}$ at $25^{\circ} \mathrm{C}$ appears to be the threshold concentration for reaction. They also collected differential scanning calorimetry data for the SRF resin immediately after contact with $3 \underline{\mathrm{M}} \mathrm{HNO}_{3}$ and observed an exothermic reaction at an onset temperature less than $25^{\circ} \mathrm{C}$. A second reaction was observed at around $45^{\circ} \mathrm{C}$. Surface reflectance infrared analysis suggests the formation of ketone and organonitrate functionality (oxidation and nitration, respectively) after a 24-hour exposure of the SRF resin to $3 \underline{\mathrm{M}}$ $\mathrm{HNO}_{3}$. They also report a higher temperature exotherm $\left(225\right.$ to $\left.245^{\circ} \mathrm{C}\right)$ that suggests the nitrated SRF resin does contain energetic compounds, but that the density or localized concentration is sufficiently low that the material is not considered to have significant hazard potential with regard to rapid energetic decomposition. The investigators mention anecdotal information about SRF susceptibility to oxidation in caustic solutions but do not test or provide evidence.

Several investigators have reported that the SRF resin will react with dissolved oxygen that might be present during storage or use, resulting in a darkened surface (Adamson et al. 2006; Arm and Blanchard 2004; Fiskum et al. 2006a; Brown et al. 2011). This reaction can be reduced, if not eliminated, by storage under an inert gas (Fiskum et al. 2007) although some investigators specifically introduced air or oxygen to mimic WTP operations (Adamson et al. 2006; Arm et al. 2005, 2006) and evaluate resin degradation (Fiskum et al. 2006a). Adamson et al. (2006) quantified oxygen uptake from saturated solutions during a 16-cycle, pilot-scale test. From the oxygen content of the solutions, they calculated an expected maximum $\mathrm{Cs}^{+}$capacity reduction of $14 \%$. In contrast, the empirical data showed no degradation of the SRF resin's hydraulic or $\mathrm{Cs}^{+}$loading throughout the testing. 
Russell et al. (2012a, 2012b, 2014) reported on $\mathrm{Cs}^{+}$uptake by the SRF resin during extended solution flow at elevated temperatures $\left(45,50,55,60,65,75^{\circ} \mathrm{C}\right)$. They reported that the SRF resin loads less $\mathrm{Cs}^{+}$ above $45^{\circ} \mathrm{C}$, ceases to uptake $\mathrm{Cs}^{+}$above $60^{\circ} \mathrm{C}$, partially disintegrates at $65^{\circ} \mathrm{C}$, and disintegrates at $75^{\circ} \mathrm{C}$ in caustic waste simulant solutions as is shown in Figure 7.1. The results clearly demonstrate SRF resin degradation above $65^{\circ} \mathrm{C}$ and suggest a maximum operating temperature no greater than $60^{\circ} \mathrm{C}$, with reduced $\mathrm{Cs}^{+}$loading observed when temperatures exceeded $45^{\circ} \mathrm{C}$. Furthermore, column plugging was reported after 14 days for the 55 and $60^{\circ} \mathrm{C}$ tests and after 25 days for the $50^{\circ} \mathrm{C}$ test.

These tests were designed primarily to evaluate $\mathrm{Cs}^{+}$uptake kinetics, especially at $\mathrm{Na}^{+}$concentrations above $5 \underline{\mathrm{M}}$, using recirculated solutions and very small SRF columns. Extrapolation of the results to systems with large SRF columns and single pass load-elution cycles would be extremely difficult and speculative at best. Therefore, it is recommended that additional, multiple load-elute cycle testing with larger columns (e.g., >15 mL) be completed to fully evaluate SRF resin stability at temperatures exceeding $45^{\circ} \mathrm{C}$.

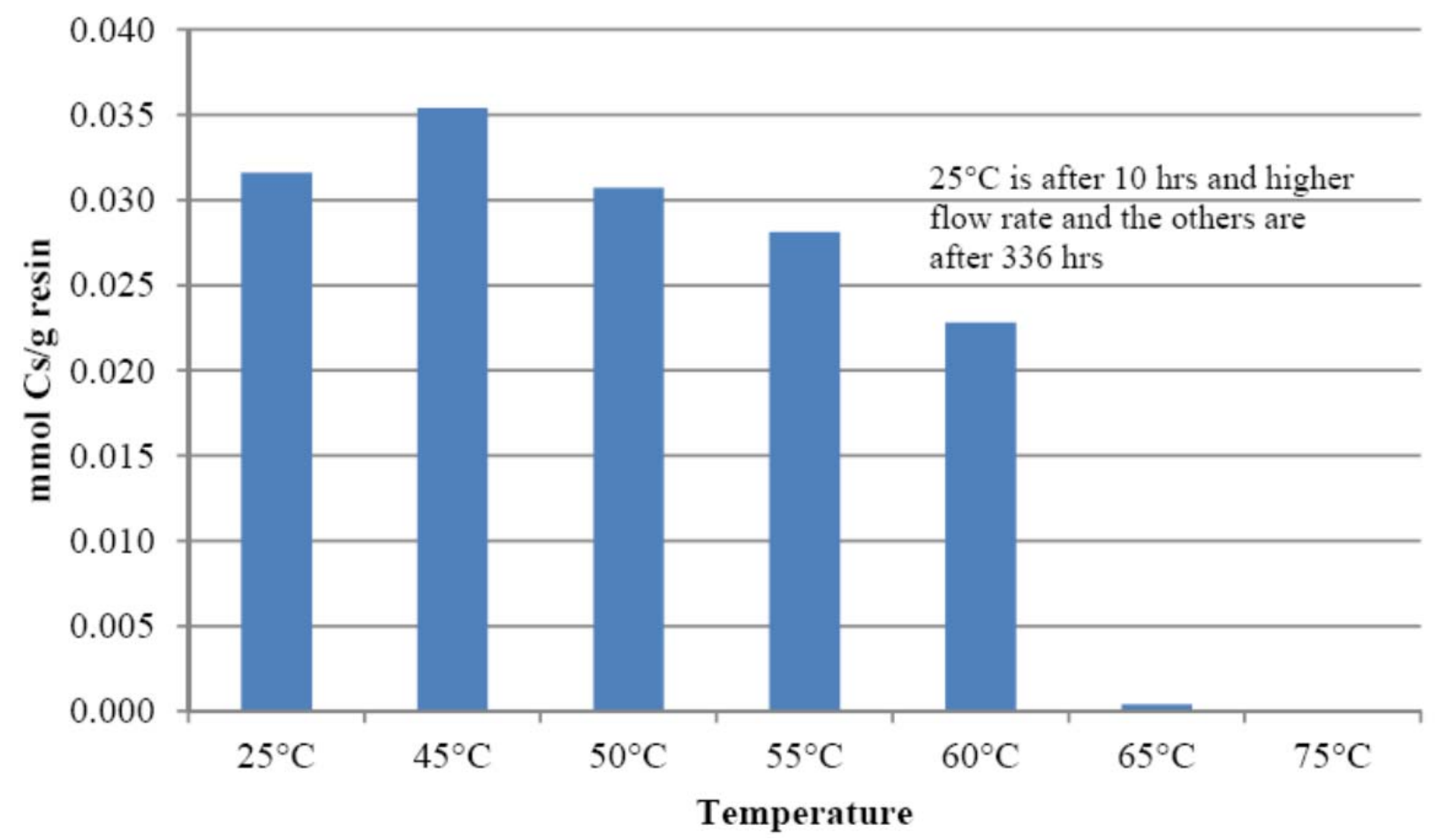

Figure 7.1. Cs+ Uptake by SRF Resin During Extended Flow Testing (Russell et al. 2002)

\subsection{Radiolytic Degradation}

Duffey and Walker (2006) completed a series of radiolytic, thermal, and physical degradation tests on the SRF resin in AP-101 simulant. They also reviewed and summarized historical irradiation experiments on the CS-100, GGRF, and SuperLig ${ }^{\mathrm{TM}} 644$ resins. They contacted the SRF resin with water, $0.5 \mathrm{M}$ $\mathrm{HNO}_{3}$, or AP-101 simulant at either 25 or $65^{\circ} \mathrm{C}$ with exposure to ${ }^{60} \mathrm{Co}$ gamma radiation doses of 0 , 34, or 100 MRad over the course of 10 days. They collected gas, liquid, and resin samples for further analysis. Gas analysis included $\mathrm{H}_{2}, \mathrm{O}_{2}, \mathrm{~N}_{2}, \mathrm{CO}, \mathrm{CO}_{2}, \mathrm{CH}_{4}$, and $\mathrm{N}_{2} \mathrm{O}$. They reported that radiolysis was responsible for the majority of the gas generation, although increasing temperature also increased the production of 
most gases, but did not significantly affect hydrogen formation. Batch distribution isotherms demonstrated that cesium uptake was reduced with increasing radiation exposure and temperature. Irradiation in the AP-101 simulant, followed by $0.5 \mathrm{M} \mathrm{HNO}_{3}$, and then water showed the largest reduction in $\mathrm{Cs}^{+}$uptake.

Birdwell et al. (2010) examined the effect of ${ }^{60} \mathrm{Co}$ irradiation (50 to $400 \mathrm{MRad}$ ) in water, $0.5 \underline{\mathrm{M}}$ $\mathrm{HNO}_{3}$, and tank waste simulants (Hanford AP-101 and SRS tanks 1, 2, 3) on gas generation and Cs adsorption performance of the SRF resin. Gases monitored during irradiation included $\mathrm{H}_{2}, \mathrm{O}_{2}, \mathrm{~N}_{2}$, and $\mathrm{CH}_{4}$. Chemical analyses of the liquids included total and volatile organic carbon and formaldehyde. In addition, the investigators reported batch distribution tests, including scoping studies (200 mL, 2 g, 25 and $45^{\circ} \mathrm{C}, 72$ hours) which are also described in Section 5.1. Significant reduction in $\mathrm{Cs}^{+}$uptake as a function of irradiation dose, and as compared to the control, was reported. In addition, a difference in $\mathrm{Cs}^{+}$ uptake observed for two different irradiation sources was attributed to uncontrolled temperature differences during irradiation. As described in Section 3.5, Taylor (2009) completed a series of tests to evaluate the hydraulic properties of the SRF resin under a variety of solutions conditions, including resin irradiation, and observed that irradiation reduced the void fraction and permeability of the resin bed.

\subsection{Thermal Degradation}

Dwivedi et al. (2012) reported TGA for granular RF particles, commercial XAD beads, and synthesized spherical RF-XAD beads. As discussed previously in this report, King et al. (2006) provided differential scanning calorimetry data for the SRF resin following contact with $\mathrm{HNO}_{3}$ at various temperatures. Kim et al. (2012a, 2012b) evaluated the thermal degradation of the SRF resin for a fire safety analysis with TGA and by measuring thermal conductivity, heat capacity, flash ignition temperature, and spontaneous ignition temperature in accordance with ASTM D5930-09, D5334-08, and D1929-96. They found endothermic weight loss associated with water at $102^{\circ} \mathrm{C}$, small exothermic transitions near 387 and $619^{\circ} \mathrm{C}$ linked to $\mathrm{CO}_{2}$ generation, and a large exothermic transition near $864^{\circ} \mathrm{C}$ also linked to $\mathrm{CO}_{2}$ generation with the corresponding weight losses of 25, 30, 5, and 20\%, respectively.

\subsection{Destruction of SRF Resin}

In support of the NTCR project, Tran et al. (2008) and Blanchard et al. (2009) demonstrated

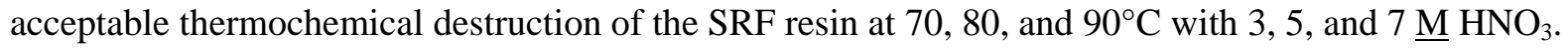
They measured total organic carbon, volatile organic carbon, and $\mathrm{NO} / \mathrm{NO}_{\mathrm{x}}$ to evaluate reaction kinetics. Higher temperatures and acid concentration increased the rate and extent of resin destruction, as did the addition of hydrogen peroxide. They also assessed the feasibility of using the caustic regeneration solution to neutralize the spent solution generated by the resin destruction process (e.g., residual organic and $\mathrm{HNO}_{3}$ ) to provide an initial assessment of disposal options for the residues from the acidic resin destruction process.

As described previously in Section 7.2, King et al. (2006) observed nearly complete destruction of the

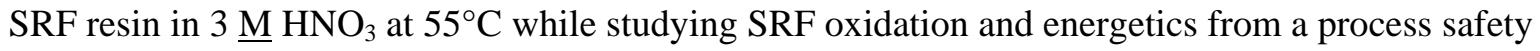
perspective. While not specifically studying resin destruction mechanisms, Russell et al. (2012a, 2012b, 2014) observed visual degradation and reduced $\mathrm{Cs}^{+}$uptake above $45^{\circ} \mathrm{C}$ during extended solution flow in caustic waste simulant solutions as was discussed in Section 7.2. 


\subsection{Spent Resin Disposal}

Chemical and radionuclide analysis of the spent SRF resin was completed by Fiskum et al. (2006d) after small column testing using simulated and actual AP-101 waste and actual AN-102 waste. Acid digestion of the spent SRF resin indicated $\sim 2 \mathrm{nCi} / \mathrm{g}$ TRU ( $<100 \mathrm{nCi} / \mathrm{g}$ TRU limit); $3.4 \mathrm{Ci} / \mathrm{m}^{3}{ }^{137} \mathrm{Cs}$; $340 \mathrm{mg} / \mathrm{kg} \mathrm{Cr}$; and $<10 \mathrm{mg} / \mathrm{kg} \mathrm{Ag}$, As, $\mathrm{Ba}, \mathrm{Cd}, \mathrm{Pb}$, and Se (Hg was not measured) after the resin had been eluted with $8 \mathrm{BV}$ of $0.5 \mathrm{M} \mathrm{HNO}_{3}$. Additional testing was suggested to confirm that no additional $\mathrm{Cr}$ leaching would occur during acetic acid elution (TCLP leaching). Based on the results, the authors indicated that there would be no concerns for SRF resin disposal.

Using simulated AP-101, AN-105, and AN-107 wastes, Nash et al. (2006) analyzed spent resin after small column loading and elution tests and found $<0.1 \% \mathrm{Cs}^{+}$was retained. In addition, they reported that the SRF resin has an affinity for $\mathrm{Ca}, \mathrm{Cd}, \mathrm{Cr}, \mathrm{Fe}, \mathrm{Pb}$, and $\mathrm{Sr}$. Of these materials, only $\mathrm{Cr}$ and Fe were found to be strongly retained on the spent SRF resin after elution, which is in agreement with results presented in Fiskum et al. (2006d).

Nash and Fowley (2007) completed a toxic leaching procedure and analysis of spent SRF resin after loading with AN-107 (envelope C) simulant that had been spiked with various regulated metals (Ag, Ba, $\mathrm{Cd}, \mathrm{Cr}, \mathrm{Ni}, \mathrm{Pb}, \mathrm{Zn}$ ) and organic compounds (see document for complete list). The simulant was pretreated with a Sr/TRU removal step (addition of 50\% $\mathrm{NaOH}, 1.5 \mathrm{M} \mathrm{Sr}\left(\mathrm{NO}_{3}\right)_{2}$, and $1.0 \mathrm{M} \mathrm{NaMnO}_{4}$ followed by filtration) prior to cesium ion exchange with the SRF resin. Full loading and elution cycles were completed. All resins pass the TCLP for RCRA metals and based on these results would not be characterized as hazardous waste.

McCabe (2000) presented a wide range of waste-treatment data related to the SuperLig ${ }^{\mathrm{TM}} 644$ resin. Kurath and Wagner (2000) and Kurath et al. (1999, 2000, 2007) reported on the analysis of SuperLig ${ }^{\mathrm{TM}}$ 644 and SuperLig ${ }^{\mathrm{TM}} 639$ (technetium selective resin) following a series of tests with AN-107 and AW-101 actual tank wastes. They reported that Cr, Co, and Zr concentrated on the SuperLig ${ }^{\mathrm{TM}} 644$ resin. They also reported that significant amounts of $\mathrm{Al}, \mathrm{Ca}, \mathrm{Cu}, \mathrm{Fe}, \mathrm{Na}, \mathrm{Ni}, \mathrm{Pb}, \mathrm{Sr}, \mathrm{Zn},{ }^{60} \mathrm{Co},{ }^{99} \mathrm{Tc},{ }^{137} \mathrm{Cs}$, and ${ }^{238} \mathrm{U}$ were observed on the SuperLig ${ }^{\mathrm{TM}} 644$ resin. There was no significant Hg found on either resin. Fiskum et al. (2004) reported on the analysis of SuperLig ${ }^{\mathrm{TM}} 644$ following a series of tests with various actual tank wastes contacted (AN-102, AP-101, AP-104, AW-101, AZ-101, AZ-102, and SY-101). They found concentrations, to some extent, of the following metals: $\mathrm{Ag}, \mathrm{As}, \mathrm{Ba}, \mathrm{Bi}, \mathrm{Ca}, \mathrm{Cd}, \mathrm{Co}, \mathrm{Cr}, \mathrm{Cu}, \mathrm{Fe}$, $\mathrm{Mn}, \mathrm{Ni}, \mathrm{Pb}, \mathrm{Se}, \mathrm{U}, \mathrm{Zr},{ }^{60} \mathrm{Co},{ }^{99} \mathrm{Tc},{ }^{241} \mathrm{Am}$, and ${ }^{239+240} \mathrm{Pu}$. Although not specifically for the SRF resin, the results described above may be of historical interest.

Nash and Duignan (2009, 2010) completed chemical and radionuclide analysis of spent SRF resin after processing with SRS tank 2F simulant and dissolved salt solution (tanks 25F and 41H) from the SRNL Shielded Facility. The two resins were loaded and eluted multiple times in both lead and lag positions. Following elution with $30 \mathrm{BV}$ of $0.5 \underline{\mathrm{M}} \mathrm{HNO}_{3}$ measureable quantities of $\mathrm{Al}, \mathrm{Am}, \mathrm{B}, \mathrm{Ba}, \mathrm{Cm}$, $\mathrm{Cr}, \mathrm{Cs}, \mathrm{Fe}, \mathrm{Hg}, \mathrm{Na}, \mathrm{Pu}, \mathrm{S}$, and Tc were found. Similar to previous experiments, $<4.5 \mu \mathrm{Ci} / \mathrm{g}{ }^{137} \mathrm{Cs}$ was measured in the spent SRF resin while nonradioactive ${ }^{133}$ Cs residue appeared to be "locked in" during simulant testing and was not fully removed during actual waste testing. They also reported approximately $10 \% \mathrm{Pu}$ retention after elution and nearly $30 \%$ of the $\mathrm{Pu}$ in the acid eluent, suggesting that $60 \%$ of the $\mathrm{Pu}$ passes through the SRF resin unretained. As the first credible data for $\mathrm{Hg}$, they reported that over $50 \%$ of the $\mathrm{Hg}$ in the feed solution was retained on the resin after elution. Finally, they provide a concise summary and comparison with four previously reported spent resin analyses. 


\subsection{Safety Basis}

Stability of the SRF resin with respect to cycling, chemical, radiolytic, and thermal degradation was described in Section 7.0. In general, the SRF resin was predicted to meet or exceed WTP specifications at ambient temperatures for up to 33 to 46 load and elute cycles (Thorson (2008a). Chemical degradation from dissolved oxygen was estimated to account for more than $80 \%$ of the capacity reduction.

Section 7.0 further details SRF resin reactivity in high acid $\left(3 \underline{\mathrm{M}} \mathrm{HNO}_{3}\right)$ at ambient temperature as well as lower acid with higher temperatures $\left(0.626 \underline{\mathrm{M}} \mathrm{HNO}_{3}\right.$ at $\left.66^{\circ} \mathrm{C}\right)$. These data suggest that safe elution

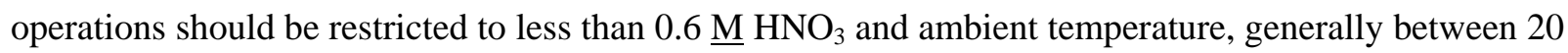
and $30^{\circ} \mathrm{C}$.

Operational conditions that load $\mathrm{Cs}^{+}$onto the SRF resin will also impact cycle performance and resin degradation. As detailed previously (Sections 6.0 and 7.0) most data have been collected near $25^{\circ} \mathrm{C}$ and demonstrate performance that exceeds WTP specifications. Relatively few experiments have been completed at $45^{\circ} \mathrm{C}$ (Nash et al. 2006; Brown et al. 2011; Russell et al. 2012a, 2012b, 2014), with the latter researchers evaluating temperatures above $45^{\circ} \mathrm{C}$. These data demonstrate reduced $\mathrm{Cs}^{+}$loading above $40^{\circ} \mathrm{C}$ when compared to ambient temperature. Furthermore, small (10 to $15 \mathrm{~mL}$ ) column loading tests have not been completed above $45^{\circ} \mathrm{C}$. For this reason, additional $\mathrm{Cs}^{+}$loading testing above $45^{\circ} \mathrm{C}$ is needed to further clarify the safe operating conditions of the SRF resin. 



\subsection{Modeling}

This section summarizes computer modeling of SRF resin loading and elution column performance and expected thermal profiles associated with worst-case $\mathrm{Cs}^{+}$loading.

\subsection{Computer Modeling}

Computer modeling of CIX loading and elution for the SRF resin has been reported by a number of investigators. The reader is directed to the cited references because it is beyond the scope of this report to describe these numerous studies in detail. Hardy et al. (2004), Smith (2007), and Aleman et al. (2007, 2011) reported using VERSE-LC to model multiple small column SRF loading curves while Hamm et al. (2000a, 2004) reported similar results for the SuperLig ${ }^{\text {TM }} 644$ resin. QA verification of the VERSE-LC software is described in Hamm et al. (2000b). They developed the simple algebraic four-component (i.e., $\mathrm{Cs}^{+}, \mathrm{K}^{+}, \mathrm{Na}^{+}$, and $\mathrm{H}^{+}$) cation exchange isotherm model based on laboratory batch equilibrium, column, and kinetic data from actual and simulated tank wastes. Much of the early SRF work focused primarily on loading and various Hanford-related waste streams (Aleman et al. 2007).

Smith (2007) and Smith et al. (2007, 2008a, 2008b) compared the non-elutable CST and the elutable SRF resins in the proposed SCIX configuration for in-tank $\mathrm{Cs}^{+}$removal at SRS. The nominal packed bed was assumed to be 432 gal (28 in. outer diameter by $15 \mathrm{ft}$ height with an internal 6 in. diameter cooling tube). Equilibrium $\mathrm{Cs}^{+}$loading was predicted from isotherm data and column breakthrough profiles were generated using VERSE-LC code and a $6 \underline{\mathrm{M}} \mathrm{Na}^{+}$SRS simulant composition. Column flow rates of 5, 10, and 15 gpm were evaluated and steady-state volumes processed for CST and SRF materials were 903 and $595 \mathrm{BV}$, respectively. Further, the $\mathrm{Cs}^{+}$adsorption capacity of the SRF resin was reported to decrease by approximately $50 \%$ when the operating temperature was increased from $25^{\circ} \mathrm{C}$ to $45^{\circ} \mathrm{C}$. Furthermore, they modeled chemical and radiolytic degradation of the SRF resin and the effect of sorption kinetics:

The cesium mass transfer zone extends across a distance slightly greater than one column length (15 feet) for CST and is largely contained in the lag column. The lead column is nearly saturated with cesium ions. In contrast, the cesium mass transfer zone length for RF is significantly shorter and is contained within approximately one quarter of one column length. This is a consequence of the larger effective porosity and loading kinetics of packed RF beds. Loading kinetics differences for the two media are further exemplified by separate modeling efforts at 10 and $20 \mathrm{gpm}$ (not shown) which show negligible impacts of increasing the flow rate for RF on the supernate volume processed while a 14\% decrease in volume processed was observed for CST.

Smith et al. (2008a, 2008b) also reported that depending upon the flow rate, radiation degradation limited the SRF resin to between 2 and 5 cycles at 10 and 20 gpm, respectively. They concluded that processing at even higher flow rates had minimal impact upon $\mathrm{Cs}^{+}$breakthrough profiles, presumably due to the faster kinetics, but decreased radiation exposure time by $50 \%$. Alternative processing strategies were evaluated including single column, lead-lag columns, and earlier column changes. In addition, heat loads and temperature profiles were reported under variety of bounding operational and accident scenarios.

In conjunction with a multi-site deprotonation concept, Aleman et al. (2011) summarized several methods for modeling CIX loading and elution behavior of the SRF resin including: 1) a multicomponent Freundlich/Langmuir isotherm, 2) a pH dependent separation factor isotherm, and 3) a multicomponent 
mass-action isotherm. All of the isotherms were able to predict column loading behavior with reasonable accuracy. To some extent, all of the isotherms were also able to show expected aspects of column elution behavior. However, it was concluded that the mass-action model provided the best method for accurately capturing column performance over the complete range of operating conditions.

Using Freundlich/Langmuir isotherms, Hang et al. (2010) modeled SCIX operations for SRF and a hypothetical spherical SuperLig ${ }^{\mathrm{TM}} 644$ resin using two SRS waste compositions (tank 3 and tank 37) and three Hanford waste compositions (hot commissioning, envelope B, and subsequent operations) at nominal, low, and high flow rates. For high $\mathrm{K}^{+}$solutions, the SuperLig ${ }^{\mathrm{TM}} 644$ resin was predicted to have superior performance, while with low $\mathrm{K}^{+}$solutions both resins were predicted to perform equally well.

Smith et al. (2009) updated their previously reported modeling efforts to include Hanford-specific wastes (i.e., AP-101, AP-102, AP-103, AP-104, AP-105, AP-107, AP-108, and AN-104) at $6 \underline{\mathrm{M}} \mathrm{Na}^{+}$and operations. The column was modeled as 36-in. diameter and 340 gal loaded at $2 \mathrm{BV} / \mathrm{hr}$ and $25^{\circ} \mathrm{C}$. Sensitivity analyses included additional diameters (30 and $42 \mathrm{in}$.), flow rates (1 and $3 \mathrm{BV} / \mathrm{hr}$ ), and an additional temperature $\left(15^{\circ} \mathrm{C}\right)$. The results of the sensitivity analysis were as expected. Results were relatively insensitive to column diameter. Higher flow rates broadened breakthrough curves and shortened operating times while the opposite occurred with lower flow rates. Furthermore, increasing temperature decreased resin capacity.

Smith et al. (2009) also reported that "lowering the flow rate from $2 \mathrm{BV} / \mathrm{h}$ (Case 2) to $1 \mathrm{BV} / \mathrm{h}$ (Case 4) increases the amount of waste that can be treated in a single ion-exchange cycle by about $16 \%$. However, the loading time is increased by $130 \%$. Increasing the flow rate to 3 BV/h (Case 5) decreases the volume of waste processed by about $11 \%$ and decreases the processing time by about $40 \%$. Faster processing times will also reduce $R F$ resin exposure to chemical and radioactive degradation. The results indicate that the relatively small gain in waste volume processed at the lower flow rate is probably not worth the increased loading time and resin exposure. However, faster processing rates will reduce both the operating time and the resin exposure with a relatively small penalty in column usage." Interestingly, the report predicted that waste compositions predicted to have relatively high $\mathrm{Cs}^{+}$ diffusivities (e.g., AN-104 and AP-107) would exhibit much steeper breakthrough curves such that both lead and lag columns would be almost completely loaded at the end of the process cycle.

Recently, Hang et al. (2013) reported an updated VERSE-LC modeling evaluation of a hypothetical spherical SuperLig ${ }^{\mathrm{TM}} 644$ resin and the SRF resin for SCIX operations. The results confirmed improved relative performance of SuperLig ${ }^{\mathrm{TM}} 644$ over the SRF resin for solutions that contain high $\mathrm{K}^{+}$levels. Relative performance of the two resins was comparable at low $\mathrm{K}^{+}$levels. The report described the evaluation of the standard lead-lag column configuration with low, nominal, and high flow rates (0.7 to 2.8 BV/hr) and five waste envelopes (envelope B, hot commissioning, subsequent operations, tank 3 , and tank 37). It has been suggested that improved resin performance will reduce the number of loading and elution cycles and reduce chemical degradation, thereby reducing life cycle operating costs. Furthermore, the model assessment suggested that the $\mathrm{Cs}^{+}$-leakage mechanism was isotherm controlled, and not mass transfer controlled, which could be used to predict overall $\mathrm{Cs}^{+}$leakage.

Russell et al. (2012a, 2012b, 2014) evaluated the kinetics of high $\mathrm{Na}^{+}$(8 $\underline{\mathrm{M}}$ ) simulants and concluded that although increased $\mathrm{Na}^{+}$content (above $2 \underline{\mathrm{M}}$ ) may slow down the adsorption/desorption as $\mathrm{Na}^{+}$ competes with $\mathrm{Cs}^{+}$for resin active sites, the modeling simulations indicated that 5 and $8 \underline{\mathrm{M}} \mathrm{Na}^{+}$have very similar adsorption/desorption rates. Temperature did not strongly impact adsorption/desorption rate 
constants. Contrary to expectation, the superficial velocity had a strong effect on the adsorption/desorption rate constants outside usual mass transfer mechanisms. This was speculated to arise from channeling in the column, convectively-enhanced pore diffusion of $\mathrm{Cs}^{+}$, or some other unknown mechanism not currently modeled. Above $1 \underline{\mathrm{M}}$, the hydroxide concentration had little or no effect on adsorption and desorption.

\subsection{Thermal Modeling}

Lee (2007), Lee and King (2009), and Lee and Smith (2009) used a two-dimensional model to calculate temperature distributions, including maximum and centerline temperature, for the SRF resin under a variety of SCIX configurations, processing conditions, and accident scenarios. Using a feed composition known to promote maximum $\mathrm{Cs}^{+}$loading, they determined that, as opposed to the CST material, the SRF resin did not necessarily require a central cooling tube to maintain adequate centerline temperatures as long as the column remained filled with liquid. The SRF resin loaded with a maximum worst case amount of ${ }^{137} \mathrm{Cs}$ could be kept at $25^{\circ} \mathrm{C}$ indefinitely using external wall jacketing and active coolant flow. In a previously unevaluated accident scenario, if liquid were removed from a 28-in. diameter $\mathrm{Cs}^{+}$-loaded SRF column, within 2 days centerline temperatures could exceed $250^{\circ} \mathrm{C}$. In contrast, temperatures would not exceed $100^{\circ} \mathrm{C}$ for a 12 -in. diameter column. 



\subsection{Conclusions}

Numerous studies have been completed throughout the DOE complex and scientific community to evaluate SRF resin: resin synthesis, characterization, use, properties, flowsheet development, column load/elution, equilibrium batch contacts, kinetics, modeling, spent resin characterization, and testing with actual and simulated wastes. King (2007) completed a similar literature review in support of material selection for the SCIX project and Thorson (2008a) documented the basis for recommending SRF over SuperLig $^{\mathrm{TM}} 644$ as the primary CIX resin in the WTP. The current review expands on previous work, summarizes the additional work completed to date, and provides a broad summary of the literature without focusing on a specific column system. Although the focus of the current review is the SRF resin, many cited references included multiple materials such as the non-spherical GGRF and SuperLig ${ }^{\mathrm{TM}} 644$ resins and the CST IONSIV ${ }^{\mathrm{TM}}$ 911, a non-elutable material.

The major conclusions from this review are as follows:

- Numerous batches of the SRF resin have been synthesized and evaluated for $\mathrm{Cs}^{+}$uptake, including batch sizes ranging from the gram scale up to 100-gal production lots. Lot number 5E-370/641 manufactured by Microbeads AS (Skedsmokorset, Norway) was chosen as the representative batch and was the most widely tested material. The resin has been shown to be stable for several years when stored in water under an inert gas.

- Batch distribution, kinetics, and column testing of the SRF resin was completed over a range of loading ( 0.5 to $8 \underline{\mathrm{M}} \mathrm{Na}^{+}, 0$ to $0.8 \underline{\mathrm{M}} \mathrm{K}^{+}, 5 \mathrm{E}-09$ to $\left.5 \mathrm{E}-02 \underline{\mathrm{M}} \mathrm{Cs}^{+}\right)$, and elution (0.07 to $\left.0.5 \underline{\mathrm{M}} \mathrm{HNO}_{3}\right)$ conditions. The SRF resin met existing WTP performance requirements.

- Minimal column loading tests at temperatures above $45^{\circ} \mathrm{C}$ have been completed and additional tests are recommended, including multiple loading and elution cycles with columns larger than $10 \mathrm{~mL}$. The SRF resin appears to be stable during column elution at temperatures up to at least $30^{\circ} \mathrm{C}$.

- The SRF resin pre-conditioning and process flowsheet requirements were optimized and the material was shown to meet WTP requirements for chemical, radiolytic, and thermal degradation and spent resin disposal.

- Hydraulic testing of the SRF resin over 16 load-elute cycles at ambient temperature demonstrated nearly constant permeability $\left(3.40 \mathrm{E}-06 \mathrm{~cm}^{2}\right)$ that was 2.5 times greater than the WTP design requirements. No degradation in $\mathrm{Cs}^{+}$uptake from the AP-101 test solution was observed in the SRF resin.

- Improved computer models of the SRF resin performance and column thermal profiles were developed based on an advancing understanding of the ion exchange process and experimental data collected. The models have been used to evaluate system-wide performance, including ion exchange loading and elution under a variety of solution compositions, temperatures, and column thermal profiles during routine operations and upset conditions. 



\subsection{References}

Adamson DJ. 2007. Pilot-Scale Hydraulic Testing of Resorcinol Formaldehyde Ion Exchange Resin. Presented at the Waste Management 2007, February 25-March 1, 2007, Tucson, AZ. WSRC-MS-2006-00421, Savannah River National Laboratory, Aiken, South Carolina.

Adamson DJ. 2009. Pilot-Scale Hydraulic Testing of Resorcinol Formaldehyde Ion Exchange Resin. Presented at the ASME 2009 Fluids Engineering Division Summer Meeting. FEDSM2009-78040, SRNL-STI-2009-00203, Savannah River National Laboratory, Aiken, South Carolina.

Adamson DJ, MD Fowley, JL Steimke, TJ Steeper, MR Williams, CE Duffey, and F Fondeur. 2006. Testing of Resorcinol Formaldehyde Ion Exchange Resin. WSRC-TR-2005-00570, SRNL-RPP-2006-00013, Savannah River National Laboratory, Aiken, South Carolina.

Adu-Wusu K and FM Pennebaker. 2009. Literature Review on Non-Acid Elution of Cesium from Resorcinol-Formaldehyde Resin in Small Column Ion Exchange Units. SRNL-STI-2009-00455, Savannah River National Laboratory, Aiken, South Carolina.

Adu-Wusu K and FM Pennebaker. 2010. Preliminary Report on Evaluation of Potential Eluants for Non-Acid Elution of Cesium from Resorcinol-Formaldehyde Resin. SRNL-STI-2010-00563, Savannah River National Laboratory, Aiken, South Carolina.

Adu-Wusu K, CA Nash, and FM Pennebaker. 2010. Alternative Non-Acid Eluants for Resorcinol-Formaldehyde Resin. Presented at the EM Waste Processing Technical Exchange, November 16, 2010. SRNL-STI-2010-00671, Savannah River National Laboratory, Aiken, South Carolina.

Adu-Wusu K, CA Nash, and FM Pennebaker. 2011. Evaluation of Potential Eluants for Non-Acid Elution of Cesium from Spherical Resorcinol-Formaldehyde Resin. SRNL-STI-2011-00628, Savannah River National Laboratory, Aiken, South Carolina.

Adu-Wusu K, CA Nash, and FM Pennebaker. 2012. "Evaluation of Potential Eluants for Non-Acid Elution of Cesium from Spherical Resorcinol-Formaldehyde Resin.” Separation Science and Technology, 2012, 47:14-15, pp. 2136-2144.

Aleman SE, LL Hamm, and FG Smith. 2007. Ion Exchange Modeling of Cesium Removal from Hanford Waste Using Spherical Resorcinol-Formaldehyde Resin. WSRC-STI-2007-0030, SRT-RPP-2007-00004, Westinghouse Savannah River Company, Savannah River Site, Aiken, South Carolina.

Aleman SE, LL Hamm, and FG Smith. 2011. Development of an Approach to Modeling Loading and Elution of Spherical Resorcinol Formaldehyde Ion- Exchange Resin. SRNL-STI-2011-00594, Savannah River National Laboratory, Aiken, South Carolina.

Arm ST and DL Blanchard Jr. 2004. Pre-Conditioning and Regeneration Requirements of Ground Gel Resorcinol Formaldehyde Ion Exchange Resin. PNWD-3390, WTP-RPT-104, Battelle-Pacific Northwest Division, Richland, Washington. 
Arm ST, DL Blanchard Jr, KP Brooks, BJ Cook, JM Cuta, SK Fiskum, Z Hontz, C Isackson, AA Schepmoes, DE Wallace. 2005. Progress Report on Laboratory Scale Hydraulic Testing of Spherical Resorcinol Formaldehyde Ion Exchange Resins. WTP-RPT-138, Battelle-Pacific Northwest Division, Richland, Washington.

Arm ST, DL Blanchard Jr, KP Brooks, WC Buchmiller, BJ Cook, JM Cuta, SK Fiskum, Z Hontz, C Isackson, AA Schepmoes, and DE Wallace. 2006. Laboratory Scale Hydraulic Testing of Spherical Resorcinol Formaldehyde Ion Exchange Resins. PNWD-3763, WTP-RPT-142, Battelle-Pacific Northwest Division, Richland, Washington.

Banerjee D, RA Rao, and PK Wattal. 2013. "Separation and Recovery of Cs from High Activity Waste Simulant using Resorcinol Formaldehyde Polycondensate Resin: Batch and Column Studies.” Separation Science and Technology, 2013, 48:1, pp. 133-139.

Berge A, T Nilsen, and J Ugelstad. 1997. Process for Preparing a Dispersion and for Preparing Polymer Particles. U.S. Patent \#5,677,373 (October 14, 1997).

Bibler JP and RM Wallace. 1995. Cesium-Specific Phenolic Ion Exchange Resin. U.S. Patent \#5,441,991 (August 15, 1995).

Bibler JP, RM Wallace, and LA Bray. 1989. Testing a New Cesium-Specific Ion Exchange Resin for Decontamination of Alkaline High-Activity Waste. WSRC-RP-89-682, Westinghouse Savannah River Company, Savannah River Laboratory, Aiken, South Carolina.

Birdwel J, D Schuh, PA Taylor, R Collins, and R Hunt. 2010. An Engineering Evaluation of Spherical Resorcinol Formaldehyde Resin. ORNL/TM-2010/200, Oak Ridge National Laboratory, Oak Ridge, Tennessee.

Blanchard Jr DL, SK Fiskum, JM Peterson, AF Farawila, and DE Kurath. 2008. Small Column Ion Exchange Testing for the Near Tank Cesium Removal Project. PNWD-3985, Battelle-Pacific Northwest Division, Richland, Washington.

Blanchard Jr DL, DT Tran, DE Kurath, and TL Sams. 2009. "Development and Testing of a Near Tank Cesium Removal Process-9222.” PNWD-SA-8626, In Proceedings of the Waste Management 2009 Conference, Phoenix, Arizona.

Bray LA, RJ Elovich, and KJ Carson. 1990. Cesium Recovery Using Savannah River Laboratory Resorcinol-Formaldehyde Ion Exchange Resin. PNL-7273, Pacific Northwest Laboratory, Richland, Washington.

Bray LA, CD Carlson, KJ Carson, JR DesChane, RJ Elovich, and DE Kurath. 1996a. Initial Evaluation of Two Organic Resins and Their Ion Exchange Column Performance for the Recovery of Cesium from Hanford Alkaline Wastes. PNNL-11124, Pacific Northwest National Laboratory, Richland, Washington.

Bray LA, KJ Carson, RJ Elovich, and DE Kurath. 1996b. Equilibrium Data for Cesium Ion Exchange of Hanford CC and NCAW Tank Waste. PNNL-11123, Pacific Northwest National Laboratory, Richland, Washington. 
Brooks KP, BS Augspurger; DL Blanchard Jr, JM Cuta, SK Fiskum, and MR Thorson. 2006. "Hydraulic Testing of Ion Exchange Resins for Cesium Removal from Hanford Tank Waste.” Separation Science and Technology, 2006, 41(11), pp. 2391-2408.

Brown GN, RJ Elovich, and LA Bray. 1995. Evaluations and Comparison of SuperLig ${ }^{\circledR ~ 644, ~}$ Resorcinol-Formaldehyde and CS-100 Ion Exchange Materials for the Removal of Cesium from Simulated Alkaline Supernate. PNL-10486, Pacific Northwest Laboratory, Richland Washington.

Brown GN, RL Russell, and RA Peterson. 2011. Small-Column Cesium Ion Exchange Elution Testing with Spherical Resorcinol-Formaldehyde. PNNL-20603, WTP-RPT-210, Pacific Northwest National Laboratory, Richland, Washington.

Burgeson IE, DL Blanchard Jr, BJ Cook, and JR DesChane. 2004. Elution Testing of Resorcinol Formaldehyde Resins with AN-105 Simulant. PNWD-3388, WTP-RPT-105, Battelle-Pacific Northwest Division, Richland, Washington.

Burgeson IE, JR DesChane, BJ Cook, DL Blanchard Jr, and DR Weier. 2006. “Evaluation of Elution Parameters for Cesium Ion Exchange Resins.” Separation Science and Technology, 2006, 41(11), pp. 2373-2390.

Collins ED, JE Bigelow, DO Campbell, LJ King, and JB Knauer. 1980. Flowsheet Development Studies for the Decontamination of High-Activity-Level Water at Three Mile Island Unit 2. Presented at the $89^{\text {th }}$ National Meeting of the American Institute of Chemical Engineers, Portland, Oregon, August 17-20, 1980.

Collins ED, WD Bond, DO Campbell, FE Harrington, DW Malkemus, FL Peishel, and OO Yarbro. 1994. Feasibility Study and Concepts for Use of Compact Process Units to Treat Hanford Tank Wastes. ORNL/TM-12714, Oak Ridge National Laboratory, Oak Ridge, Tennessee.

Duffey CE and DD Walker. 2006. Radiolytic, Thermal, and Physical Degradation Testing of Spherical Resorcinol-Formaldehyde (RF) Resin. WSRC-TR-2005-00075, Savannah River National Laboratory, Savannah River Site, Aiken, South Carolina.

Duignan MR and CA Nash. 2009. Removal of Cesium from Savannah River Site Waste with Spherical Resorcinol Formaldehyde Ion Exchange Resin: Experimental Tests. SRNL-STI-2009-00367, Rev. 0, Savannah River National Laboratory, Aiken, South Carolina.

Duignan MR and CA Nash. 2010a. "Resorcinol-Formaldehyde Ion Exchange Resin Chemistry for High Level Waste Treatment - 10161.” SRNL-STI-2009-00508, In Proceedings of the Waste Management 2005 Conference, Phoenix, Arizona.

Duignan MR and CA Nash. 2010b. "Removal of Cesium from Savannah River Site Waste with Spherical Resorcinol Formaldehyde Ion Exchange Resin: Experimental Tests.” Separation Science and Technology, 2010, 45(12), pp. 1828-1840.

Duignan MR, CA Nash, and TM Punch. 2007. High Aspect Ratio Ion Exchange Resin Bed - Hydraulic Results for Spherical Resin Beads. SRNL-STI-2007-00390, Savannah River National Laboratory, Aiken, South Carolina. 
Duignan MR, CA Nash, and TM Punch. 2008. "High Aspect Ratio Ion Exchange Resin Bed - Hydraulic Results for Spherical Resin Beads.” Separation Science and Technology, 2008, 43 (9-10), pp. 2943-2979.

Dwivedi C, A Kumar, JK Ajish, KK Singh, M Kumar, PK Wattal and PN Bajaja. 2012. Resorcinol-Formaldehyde Coated XAD Resin Beads for Removal of Cesium Ions from Radioactive Waste: Synthesis, Sorption and Kinetic Studies. RSC Advances, 2012, 2, 5557-5564.

Ebra MA and RM Wallace. 1983. Phenolic cation exchange resin material for recovery of cesium and strontium. U.S. Patent 4,423,159 (December 27, 1983).

Eibling RE and CA Nash. 2001. Hanford Waste Simulants Created to Support the Research and Development on the River Protection Project - Waste Treatment Plant. WSRC-TR-2000-00338, SRT-RPP-2000-00017, Savannah River National Laboratory, Aiken, South Carolina.

Ernest MV, JP Bibler, RD Whitley, and NHL Wang. 1997. "Development of a Carousel Ion-Exchange Process for Removal of Cesium-137 from Alkaline Nuclear Waste.” Ind. Eng. Chem. Res. 1997, 36, pp. 2775-2788.

Favre-Réguillon A, B Dunjic, M Lemaire, and R Chomel. 2001. "Synthesis and Evaluation of Resorcinol Based Ion-Exchange Resins for the Selective Removal of Cesium.” Solvent Extraction and Ion Exchange, 2001, 19:1, pp. 181-191.

Fiskum SK, ST Arm, WC Buchmiller, T Trang-Le, JE Martinez, J Matyas, MJ Steele, KK Thomas, and DL Blanchard Jr. 2006a. Comparison Testing of Multiple Spherical Resorcinol-Formaldehyde Resins the River Protection Project-Waste Treatment Plant. PNWD-3785, WTP-RPT-143, Battelle-Pacific Northwest Division, Richland, Washington.

Fiskum SK, ST Arm, MS Fountain, MJ Steele, and DL Blanchard Jr. 2006b. Spherical Resorcinol Formaldehyde Resin Testing for Cs-137 Removal from Simulated and Actual Hanford Waste Tank 241-AP-101 Diluted Feed (Envelope A) Using Small Column Ion Exchange. PNWD-3697, WTP-RPT-134, Battelle-Pacific Northwest Division, Richland, Washington.

Fiskum SK, BS Augspurger, KP Brooks, WC Buchmiller, RL Russell, MJ Schweiger, LA Snow, MJ Steele, KK Thomas, DE Wallace, NH Wong, JD Yeager, and DL Blanchard Jr. 2004. Comparison Testing of Multiple Resorcinol-Formaldehyde Resins for the River Protection Project - Waste Treatment Plant. PNWD-3387, WTP-RPT-103, Battelle-Pacific Northwest Division, Richland, Washington.

Fiskum SK, DL Blanchard Jr, ST Arm, and RA Peterson. 2005. “Cesium Removal from Simulated and Actual Hanford Tank Waste using Ion Exchange.” Separation Science and Technology, 40(1-3), pp. 51-67.

Fiskum SK, DL Blanchard Jr, MJ Steele, KK Thomas, T Trang-Le, and MR Thorson. 2006c. "Spherical Resorcinol-Formaldehyde Resin Testing for Cesium Removal from Hanford Tank Waste Simulant." Separation Science and Technology, 2006, 41:11, pp. 2461-2474.

Fiskum SK, IE Burgeson, OT Farmer III, LR Greenwood, CZ Soderquist, MJ Steele, and MP Thomas. 2006d. Spherical Resorcinol-Formaldehyde Resin Analysis Following Actual Hanford Tank Waste Processing. PNWD-3752, WTP-RPT-144, Battelle-Pacific Northwest Division, Richland, Washington. 
Fiskum SK, MJ Steele, and DL Blanchard Jr. 2006e. Small Column Ion Exchange Testing of Spherical Resorcinol Formaldehyde Resin for Cs-137 Removal from Pre-treated Hanford Tank 241-AN-102 Waste (Envelope C). PNWD-3751, WTP-RPT-135, Battelle-Pacific Northwest Division, Richland, Washington.

Fiskum SK, ST Arm, MK Edwards, MJ Steele, and KK Thomas. 2007. Storage and Aging Effects on Spherical Resorcinol Formaldehyde Resin Ion Exchange Performance. PNNL-16832, WTP-RPT-148, Pacific Northwest National Laboratory, Richland, Washington.

Fiskum SK, ST Arm, MJ Steele, and MR Thorson. 2008. "Spherical Resorcinol-Formaldehyde Performance Testing with Hanford Tank Waste.” Solvent Extraction and Ion Exchange, 2008, 26, pp. 435-452.

Fondeur FF, WD King, SW McCollum, and MA Pettis. 2006. Spherical Resorcinol- Formaldehyde Resin Reactivity with Nitric Acid and Other Hanford RPP-WTP Process Solutions.

WSRC-TR-2005-00228, Savannah River National Laboratory, Aiken, South Carolina.

Fowley MD, JL Steimke, DJ Adamson, LL Hamm, CA Nash, ML Restivo, MA Shadday, TJ Steeper, SE Aleman, and WD King. 2004. Ion Exchange Testing with SuperLig ${ }^{\circledR} 644$ Resin.

WSRC-TR-2003-00514, SRT-RPP-2003-00233, Westinghouse Savannah River Company, Aiken, South Carolina.

Hamm LL,SE Aleman, BJ Hardy, WD King, and CE Duffey. 2004. Ion Exchange Modeling for Removal of Cesium from Hanford Waste Using SuperLig ${ }^{\circledR} 644$ Resin. WSRC-TR-2003-00555, SRT-RPP-2003-00242, Westinghouse Savannah River Company, Aiken, South Carolina.

Hamm LL,FG Smith, and DJ McCabe. 2000a. Preliminary Ion Exchange Modeling for Removal of Cesium from Hanford Waste Using SuperLig® 644 Resin. BNF-003-98-0220, Westinghouse Savannah River Company, Aiken, South Carolina.

Hamm LL, FG Smith, and Ma Shadday. 2000b. QA Verification Package for VERSE-LC Version7.80. WSRC-TR-99-00238, Westinghouse Savannah River Company, Aiken, South Carolina.

Hang T, CA Nash, and SE Aleman. 2010. "Modeling Results from Cesium Ion Exchange with Spherical Resins - 11228.” SRNL-STI-2010-00494, In Proceedings of the Waste Management 2011 Conference. Phoenix, Arizona.

Hang T, CA Nash, and SE Aleman. 2013. "Modeling Ion Exchange with Spherical Resins for Cesium Removal.” Separation Science and Technology, 2013, 48, pp. 2090-2098.

Hardy BJ, SE Aleman, and LL Hamm. 2004. Ion Exchange Modeling for Removal of Cesium from Hanford Waste Using Resorcinol-Formaldehyde Resin. WSRC-TR-2004-00100, SRT-RPP-2004-00019, Westinghouse Savannah River Company, Savannah River Laboratory, Aiken, South Carolina.

Hassan NM and K Adu-Wusu. 2003. Cesium Removal from Hanford Tank 241-AW-101 Supernate using Resorcinol-Formaldehyde Resin. SRT-RPP-2003-00224, WSRC-TR-2003-00433, Savannah River National Laboratory, Aiken, South Carolina. 
Hassan NM and K Adu-Wusu. 2005. "Cesium Removal from Hanford Tank Waste Solution Using Resorcinol-Formaldehyde Resin.” Solvent Extraction and Ion Exchange, 23:3, pp. 375-389.

Hassan NM, K Adu-Wusu, and JC Marra. 2004a. Resorcinol-Formaldehyde Adsorption of Cesium (Cs ${ }^{+}$) from Hanford Waste Solutions_Part I: Batch Equilibrium Study. WSRC-MS-2004-00250, Savannah River National Laboratory, Aiken, South Carolina.

Hassan NM, K Adu-Wusu, and JC Marra. 2004b. "Resorcinol-Formaldehyde Adsorption of Cesium from Hanford Waste Solutions_-Part I: Batch Equilibrium Study.” Journal of Radioanalytical and Nuclear Chemistry, 2004, 262(3), pp. 579-586.

Hassan NM, K Adu-Wusu, and CA Nash. 2003. Multiple Ion Exchange Column Runs for Cesium and Technetium Removal from AW-101 Waste Sample. WSRC-TR-2003-00098, SRT-RPP-2003-00026, Westinghouse Savannah River Company, Aiken, South Carolina.

Hassan NM, DJ McCabe, WD King. 2000a. Small-Scale Ion Exchange Removal of Cesium and Technetium from Hanford Tank 241-AN-103, Revision 1. BNF-003-98-0146, Savannah River Technology Center, Westinghouse Savannah River Co. Aiken, South Carolina.

Hassan NM, DJ McCabe, WD King, and ML Crowder. 2000b. Small-Scale Ion Exchange Removal of Cesium and Technetium from Hanford Tank 241-AN-102. BNF-003-98-0219, Westinghouse Savannah River Company, Aiken, South Carolina.

Hendrickson DW, RK Biyani, and MA Beck. 1996. Hanford Tank Waste Supernatant Cesium Removal Test Report. WHC-SD-RE-TRP-018, Rev. OA, Westinghouse Hanford Company, Richland, Washington.

Howden GF. 1994. Functions and Requirements for a Cesium Demonstration Unit. WHC-SD-W236B-FRD-001, Westinghouse Hanford Company, Richland, Washington.

Hubler TL, JA Franz, WJ Shaw, SA Bryan, RT Hallen, GN Brown, LA Bray, and JC Linehan. 1995. Synthesis, Structural Characterization, and Performance Evaluation of Resorcinol-Formaldehyde (R-F) Ion-Exchange Resin. PNNL-10744, Pacific Northwest National Laboratory, Richland, Washington.

Hubler TL, JA Franz, WJ Shaw, MO Hogan, RT Hallen, GN Brown, and JC Linehan. 1996. Structure/Function Studies of Resorcinol-Formaldehyde (R-F) and Phenol-Formaldehyde Copolymer Ion-Exchange Resins. PNNL-11347, Pacific Northwest National Laboratory, Richland, Washington.

Jenkins KD, RC Chen, R Gimpel, Y Deng, MR Gross, and C Peredo. 2013 Flowsheet Bases, Assumptions, and Requirements. 24590-WTP-RPT-PT-02-005, Rev. 7, Waste Treatment Plant, Bechtel National, Inc., Richland, Washington.

Josephson GB, GJ Lumetta, H Harmon, JD Young, B Knutson. 2010. Technology Readiness Assessment for the Near-Tank Treatment System. PNWD-4190, Battelle-Pacific Northwest Division, Richland, Washington. 
Kim D, MJ Schweiger, RA Peterson. 2012a. Fire Safety Tests for Cesium-Loaded Spherical Resorcinol Formaldehyde Resin: Data Summary Report. PNNL-21321, Pacific Northwest National Laboratory, Richland, Washington.

Kim D, MJ Schweiger, RA Peterson. 2012b. Fire Safety Tests for Cesium-Loaded Spherical Resorcinol Formaldehyde Resin: Data Summary Report. PNNL-21490, Pacific Northwest National Laboratory, Richland, Washington.

King WD. 2007. Literature Reviews to Support Ion Exchange Technology Selection for Modular Salt Processing. WSRC-STI-2007-00609, Westinghouse Savannah River Company, Savannah River Laboratory, Aiken, South Carolina.

King WD, CE Duffey, and SH Malene. 2004. Determination of Cesium $\left(\mathrm{Cs}^{+}\right)$Adsorption Kinetics and Equilibrium Isotherms from Hanford Waste Simulants using Resorcinol-Formaldehyde Resins. WSRC-TR-2003-00574, SRT-RPP-2003-00252, Rev. 0, Westinghouse Savannah River Company, Aiken, South Carolina.

King WD, FF Fondeur, WR Wilmarth, ME Pettis, and SW McCollum. 2006. "Reactivity of Resorcinol Formaldehyde Resin with Nitric Acid.” Separation Science and Technology, 2006, 41, pp. 2475-2486.

King WD, DJ McCabe, and NM Hassan. 2000. Optimization of Cesium Removal from Hanford Envelope A Simulant with SuperLig® 644 Ion Exchange Resin. BNF-003-98-0169, Westinghouse Savannah River Company, Aiken, South Carolina.

Kurath DE, DL Blanchard Jr, and JR Bontha. 1999. Ion Exchange Distribution Coefficients for ${ }^{137}$ Cs and ${ }^{99}$ Tc Removal from Hanford Tank Supernatants AW-101 (Envelope A) and AN-107 (Envelope C). PNWD-2467, BNFL-RPT-009, Battelle-Pacific Northwest Division, Richland, Washington.

Kurath DE, DL Blanchard Jr, and JR Bontha. 2000a. Small Column Ion Exchange Testing of Superlig 644 for Removal of ${ }^{137}$ Cs from Hanford Tank Waste Envelope A (Tank 241-AW-101). PNWD-3001, BNFL-RPT-014, Battelle-Pacific Northwest Division, Richland, Washington.

Kurath DE, DL Blanchard Jr, and JR Bontha. 2000b. Small Column Ion Exchange Testing of Superlig 644 for Removal of ${ }^{137}$ Cs from Hanford Tank Waste Envelope C (Tank 241-AN-107). PNWD-3039, BNFL-RPT-024, Battelle-Pacific Northwest Division, Richland, Washington.

Kurath DE, LA Bray, KP Brooks, GN Brown, SA Bryan, CD Carlson, KJ Carson, JR DesChane, RJ Elovich, and AY Kim. 1994. Experimental Data and Analysis to Support the Design of an Ion-Exchange Process for the Treatment of Hanford Tank Waste Supernatant Liquids. PNL-10187, Pacific Northwest Laboratory, Richland, Washington.

Kurath DE, LA Bray, KP Brooks, CD Carlson, and AY Kim. 1996. Analysis of Equilibrium Data for Cesium Ion-Exchange of Hanford CC and NCAW Supernatant Liquid - Status Report. PNL-11117, Pacific Northwest Laboratory, Richland, Washington.

Kurath DE and JJ Wagner. 2000. Analysis of Spent Ion Exchange Media: Superlig 639 and Superlig 644. PNWD-3037, BNFL-RPT-028, Battelle-Pacific Northwest Division, Richland, Washington. 
Lehrman S. 2010. RF Resin Cesium Removal with Expanded Load and Elution Conditions. WTP Project Doc. No. 24590-PTF-TSP-RT-09-002, Rev. 0, Bechtel National Inc., Richland, Washington.

Lee DD, JR Travis, and MR Gibson. 1998. Hot Demonstration of Proposed Commercial Cesium Removal Technology. ORNL/TM-13169, Oak Ridge National Laboratory, Oak Ridge, Tennessee.

Lee SY. 2007. Heat Transfer Analysis for Fixed CST and RF Columns. WSRC-STI-2007-00345, Westinghouse Savannah River Company, Savannah River Laboratory, Aiken, South Carolina.

Lee SY and WD King. 2009. Thermal Modeling of Ion Exchange Columns with Spherical RF Resin. SRNL-STI-2009-00680, Savannah River National Laboratory, Aiken, South Carolina.

Lee SY and FG Smith. 2009. Thermal Analysis for In-tank Ion-Exchange Column Process. SRNL-STI-2009-00004, Savannah River National Laboratory, Aiken, South Carolina.

McCabe DJ. 2000. BNFL River Protection Project Cesium, Technetium, and Sulfate Ion Exchange Research. WSRC-MS-2000-00383, BNF-003-98-0283, Westinghouse Savannah River Company, Aiken, South Carolina.

Nash CA. 2004. Hanford RPP-WTP Alternate Resin Program - Protocol P1-RF: Spherical Resin Sampling from Containers, Resin Pretreatment, F-Factor, and Resin Loading to Column. SRNL-RPP-2004-00058, Savannah River National Laboratory, Aiken, South Carolina.

Nash CA and MD Fowley. 2007. Toxic Leaching Procedure and Totals Analyses of Spherical Resorcinol-Formaldehyde Resin. WSRC-STI-2007-00213, SRT-RPP-2006-00026, Westinghouse Savannah River Company, Savannah River Laboratory, Aiken, South Carolina.

Nash CA and MR Duignan. 2009. Real Waste Testing of Spherical Resorcinol-Formaldehyde Ion Exchange Resin. SRNL-STI-2009-00594, Savannah River National Laboratory, Aiken, South Carolina.

Nash CA and MR Duignan. 2010. Characterization of Cycled Spherical Resorcinol-Formaldehyde Ion Exchange Resin. SRNL-STI-2009-00605, Savannah River National Laboratory, Aiken, South Carolina.

Nash CA and ST Isom. 2010. "Characterization of Spherical Resorcinol-Formaldehyde Resin Cesium Adsorption with Batch Contact Tests.” Separation Science and Technology, 2010, 45:12-13, pp. 1822-1827.

Nash CA, WR Wilmarth, DD Walker, CE Duffey, WD King, MR Thorson, JM Meehan, DJ Sherwood, SK Fiskum, KP Brooks, IE Burgeson, ST Arm, and DL Blanchard, Jr. 2004. Cesium Ion Exchange Program at the Hanford River Protection Project Waste Treatment Plant \#5343. In Proceedings of the Waste Management 2005 Conference, Feb 27-March 3, 2005, Tucson, Arizona.

Nash CA, MR Duignan, and CE Duffey. 2006. Batch, Kinetics, and Column Data from Spherical Resorcinol-Formaldehyde Resin. WSRC-STI-2006-00071, SRNL-RPP-2006-00024, Savannah River National Laboratory, Aiken, South Carolina. 
Nash CA, SE Aleman, CE Duffey, and MR Thorson. 2007. Cesium Removal Performance of Resorcinol-Formaldehyde Resin. WSRC-STI-2007-00205-S, Westinghouse Savannah River Company, Savannah River Laboratory, Aiken, South Carolina.

Peterson RA, SK Fiskum, ST Arm, and DL Blanchard, Jr. 2006. "Cesium Removal Demonstration Using Selected Actual Waste Samples from the Hanford Reservation Tank Farm.” Separation Science and Technology, 41:11, pp. 2361-2371.

Ramsey AA and MR Thorson. 2010. Technical Comparison of Candidate Ion Exchange Media for Small Column Ion Exchange (SCIX) Applications in Support of Supplemental LAW Pretreatment. RPP-47630, Washington River Protection Solutions, Richland, Washington.

Ray RJ, WA Scrivens, and CA Nash. 2005. Spherical Resorcinol-Formaldehyde Synthesis by Inverse Suspension Polymerization. WSRC-MS-2005-00628, Westinghouse Savannah River Company, Savannah River Laboratory, Aiken, South Carolina.

Russell RL, SK Fiskum, LK Jagoda, and AP Poloski. 2003. AP-101 Diluted Feed (Envelope A) Simulant Development Report. PNWD-3248, WTP-RPT-057, Battelle, Pacific Northwest Division, Richland, Washington.

Russell RA, DE Rinehart, GN Brown, PP Schonewill, and RA Peterson. 2012a. Ion Exchange Kinetics Testing with SRF Resin. PNNL-21109, WTP-RPT-214, Pacific Northwest National Laboratory, Richland, Washington.

Russell RL, DE Rinehart, GN Brown, RA Peterson. 2012b. Cesium Ion Exchange Loading Kinetics Testing with SRF Resin. Separation Science and Technology, 2012, 47(14-15), pp. 2129-2135.

Russell RL, DE Rinehart, and RA Peterson. 2014. Ion Exchange Testing with SRF Resin FY 2012. PNNL-21645, WTP-RPT-223, Pacific Northwest National Laboratory, Richland, Washington.

Samanta SK; M Ramaswamy; and BM Misra. 1992. Studies on Cesium Uptake by Phenolic Resins. Separation Science and Technology, 1992, 27(2), pp. 255-267.

Sams TL, CE Miller, DE Kurath, and DL Blanchard Jr. 2009. Technical Approach for the Development of a Near Tank Cesium Removal Process-9143. In Proceedings of the Waste Management 2009 Conference, Phoenix, Arizona.

Smith FG. 2007. Modeling of Ion-Exchange for Cesium Removal from Dissolved Saltcake in SRS Tanks 1-3, 37 and 41. WSRC-STI-2007-00315, Westinghouse Savannah River Company, Savannah River National Laboratory, Aiken, South Carolina.

Smith FG, SY Lee, WD King, and DJ McCabe. 2007. Comparisons of Crystalline Silicotitanate and Resorcinol Formaldehyde Media for Cesium Removal by In-tank Column Processing.

WSRC-STI-2007-00638, Westinghouse Savannah River Company, Aiken, South Carolina.

Smith FG, LL Hamm, SE Aleman, ME Johnson. 2008a. Modeling an Ion-Exchange Process for Cesium Removal from Alkaline Radioactive Waste Solutions. SRNS-STI-2008-00061, Westinghouse Savannah River Company, Savannah River National Laboratory, Aiken, South Carolina. 
Smith FG, SY Lee, WD King, and DJ McCabe. 2008b. "Comparisons of Crystalline Silicotitanate and Resorcinol Formaldehyde Media for Cesium Removal by In-tank Column Processing.” Separation Science and Technology, 2008, 43, pp. 2929-2942.

Smith FG, LL Hamm, SE Aleman, and ME Johnson. 2009. "Modeling Ion-Exchange for Cesium Removal from Alkaline Radioactive Waste Solutions.” Separation Science and Technology, 2009, 44, pp. 2983-3012.

Spires RH, T Punch, DJ McCabe, and PA Taylor. 2009. "Salt Processing through Ion Exchange at the Savannah River Site Selection of Exchange Media and Column Configuration - 9198.” In Proceedings of the Waste Management 2009 Conference, Phoenix, Arizona.

Taylor PA. 2009. Hydraulic Permeability of Resorcinol Formaldehyde Resin. ORNL/TM-2009/293, Oak Ridge National Laboratory, Oak Ridge, Tennessee.

Taylor PA and HL Johnson. 2009a. Alternate Methods for Eluting Cesium From Spherical Resorcinol-Formaldehyde Resin. ORNL/TM-2008/194, Oak Ridge National Laboratory, Oak Ridge, Tennessee.

Taylor PA and HL Johnson. 2009b. “Alternate Methods for Eluting Cesium from Spherical Resorcinol-Formaldehyde Resin - 9160.” In Proceedings of the Waste Management 2009 Conference, Phoenix, Arizona.

Thorson MR. 2007. Required CNP Decontamination Factor with RF Resin. CCN-157932, Memo to DA Bruce, Waste Treatment Plant, Bechtel National, Inc., Richland, Washington.

Thorson MR. 2008a. Basis of Recommendation for Use of Spherical Resorcinol Formaldehyde Resin as the Primary Cesium Ion Exchange Resin in the WTP. 24590-WTP-RPT-RT-07-005, Rev. 0, Waste Treatment Plant, Bechtel National, Inc., Richland, Washington.

Thorson MR. 2008b. Resorcinol Formaldehyde Synthesis Summary. 24590-PTF-RPT-RT-08-005, Rev. 0, Waste Treatment Plant, Bechtel National, Inc., Richland, Washington.

Thorson MR and RA Gilbert. 2007. Issue Response Plan to Mature WTP Radioactive Cesium Removal to Technical Readiness Level 6. 24590-WTP-PL-PET-07-0003, Rev. 0, Waste Treatment Plant, Bechtel National, Inc., Richland, Washington.

Tran DT, DE Kurath, DL Blanchard Jr, JM Peterson, and TL Sams. 2008. Near Tank Cesium Removal - Phase II Resin Dissolution and Destruction. PNWD-4011, Battelle-Pacific Northwest Division, Richland, Washington.

Ugelstad J. 1984. Monodisperse Polymer Particles and Dispersions Thereof. U.S. Patent \#4,459,378 (July 10, 1984). 
Appendix A

Literature Reviewed but Not Cited 



\section{Appendix A}

\section{Literature Reviewed but Not Cited}

Adu-Wusu K and NM Hassan. 2003. Cesium Ion Exchange Using Tank 241-AN-104 Supernate (U). WSRC-TR-2003-00311, Westinghouse Savannah River Company, Aiken, South Carolina.

Aleman SE and LL Hamm. 2004. 3-Dimensional Flow Modeling of a Proposed Hanford Waste Treatment Plant Ion Exchange Column Design. WSRC-TR-2002-00309, SRT-RPP-2002-00154, Westinghouse Savannah River Company, Aiken, South Carolina.

Arm ST, DL Blanchard Jr, and SK Fiskum. 2001. Progress Report on the SuperLig ${ }^{\circledR} 644$ and SuperLig ${ }^{\circledR} 639$ Ion Exchange Resin Chemical Degradation Study. WTP-RPT-023, Battelle-Pacific Northwest Division, Richland, Washington.

Arm ST, DL Blanchard Jr, and SK Fiskum. 2002. Effect of Eluant Flow Direction on the Elution Characteristics of SuperLig ${ }^{\circledR} 644$ Ion Exchange Resin. PNWD-3202, WTP-RPT-032, Battelle-Pacific Northwest Division, Richland, Washington.

Arm ST, DL Blanchard Jr, SK Fiskum, and DR Weier. 2003. Chemical Degradation of SuperLig® 644 Ion Exchange Resin. PNWD-3315, WTP-RPT-046, Battelle-Pacific Northwest Division, Richland, Washington.

Arm ST, DL Blanchard Jr, and DR Weier. 2004. Aging Effects of Stored SuperLig® 644 Ion Exchange Resin. PNWD-3389, WTP-RPT-093, Battelle-Pacific Northwest Division, Richland, Washington.

Burgeson IE, DL Blanchard Jr, BJ Cook, JR DesChane, and DR Weier. 2004. Elution Testing of SuperLig® 644 with AN-105 Simulant. PNWD-3399, WTP-RPT-109, Battelle-Pacific Northwest Division, Richland, Washington.

Crooks WJ, CA Nash, DJ McCabe, and HH Saito. 2000. Studies of Ion Exchange Resin Integrity under Flowsheet Extremes: Part II. BNF-003-98-0225, Rev. 0, Westinghouse Savannah River Company, Aiken, South Carolina.

Duignan MR, DJ Adamson, TB Calloway, MD Fowley, ZH Qureshi, JL Steimke, MR Williams, and JR Zamecnik. 2005. Final Report: RPP-WTP Semi-Integrated Pilot Plant. WSRC-TR-2005-00105, SRNL-RPP-2005-00012, Savannah River National Laboratory, Aiken, South Carolina.

Fiskum SK, ST Arm, DL Blanchard Jr., and BM Rapko. 2002. Small Column Ion Exchange Testing of SuperLig ${ }^{\circledR} 644$ for Removal of ${ }^{137}$ Cs from Hanford Waste Tank 241-AP-101 Diluted Feed (Envelope A). PNWD-3198, WTP-RPT-016, Rev. 1, Battelle-Pacific Northwest Division, Richland, Washington.

Fiskum SK, ST Arm, and DL Blanchard Jr. 2003. Small Column Ion Exchange Testing of SuperLig® 644 for Removal of ${ }^{137}$ Cs from Hanford Waste Tank 241-AZ-102 Concentrate (Envelope B).

PNWD-3267, WTP-RPT-041, Battelle-Pacific Northwest Division, Richland, Washington. 
Fiskum SK, ST Arm, and DL Blanchard Jr. 2004. Small Column Ion Exchange Testing of SuperLig® 644 for Removing ${ }^{137}$ Cs from Hanford Waste Tank 241-AN-102 Supernate (Envelope C) Mixed with Tank 241-C-104 Solids (Envelope D) Wash and Permeate Solutions. PNWD-3266, WTP-RPT-053, Battelle--Pacific Northwest Division, Richland, Washington.

Fiskum SK, ST Arm, and DL Blanchard Jr. 2004. Small Column Ion Exchange Testing of SuperLig ${ }^{\circledR}$ 644 for Removal of ${ }^{137}$ Cs from Hanford Waste Tank 241-AZ-101 (Envelope B). PNWD-3240, WTP-RPT-033, Battelle-Pacific Northwest Division, Richland, Washington.

Fiskum SK, DL Blanchard Jr, and ST Arm. 2002. Aging Study and Small Column Ion Exchange Testing of SuperLig ${ }^{\circledR} 644$ for Removal of ${ }^{137}$ Cs from Simulated AW-101 Hanford Tank Waste. PNWD-3195, WTP-RPT-015, Battelle-Pacific Northwest Division, Richland, Washington.

Fiskum SK, DL Blanchard Jr, MJ Steele, and JJ Wagner. 2004. Analysis of SuperLig ${ }^{\circledR} 644$ Resin Used in Hanford Tank Waste Processing. PNWD-3353, WTP-RPT-089, Battelle-Pacific Northwest Division, Richland, Washington.

Fiskum SK, LA Snow, and DL Blanchard Jr. 2003. AP-101 Simulant Validation for Cesium Ion Exchange Processing Using SuperLig ${ }^{\circledR}$ 644. PNWD-3330, WTP-RPT-088, Battelle-Pacific Northwest Division, Richland, Washington.

Hassan NM, WD King, and DJ McCabe. 1999. SuperLig® Ion Exchange Resin Swelling and Buoyancy Study. BNF-003-98-0051, Westinghouse Savannah River Company, Aiken, South Carolina.

Hassan NM, WD King, DJ McCabe, ML Crowder. 2001. Small-Scale Ion Exchange Removal of Cesium and Technetium from Envelope B Hanford Tank 241-AZ-102. WSRC-TR-2000-00419,

SRT-RPP-2000-00036, Savannah River Technology Center, Westinghouse Savannah River Co. Aiken, South Carolina.

Hassan NM and CA Nash. 2001. Effect of Resin Particle Size and Solution Temperature on SuperLig ${ }^{\circledR}$ 644 Resin Performance with AN-105. WSRC-TR-2001-00606, SRT-RPP-2001-00233, Westinghouse Savannah River Company, Aiken, South Carolina.

King WD, NM Hassan, and DJ McCabe. 2001. Intermediate-Scale Ion Exchange Removal of Cesium and Technetium from Hanford Tanks 241-AN-102. WSRC-TR-2000-00420, SRT-RPP-2000-00014, Savannah River Technology Center, Westinghouse Savannah River Co. Aiken, South Carolina.

McCabe DJ, NM Hassan, WD King, JL Steimke, MA Norato, LL Hamm, and LN Oji. 2000. Comprehensive Scale Testing of the Ion Exchange Removal of Cesium and Technetium from Hanford Tank Wastes. WSRC-MS-2000-00499, Westinghouse Savannah River Company, Aiken, South Carolina.

Oji LN and DJ McCabe. 2000. Effects of Radiation on the Physical Properties of SuperLig® 644 Resin. WSRC-TR-2000-00422, SRT-RPP-2000-00015, Westinghouse Savannah River Company, Aiken, South Carolina.

Rapko BM, DL Blanchard Jr, KJ Carson, JR DesChane, RL Sell, and RG Swoboda. 2003. Batch Contact Testing of SuperLig ${ }^{\circledR}$ 644. PNWD-3265, WTP-RPT-037, Battelle-Pacific Northwest Division, Richland, Washington. 
Steimke JL, MA Norato, TJ Steeper, and DJ McCabe. 2000. Summary of Initial Testing of SuperLig ${ }^{\circledR}$ 644 at the TFL Ion Exchange Facility. WSRC-TR-2000-00505, Westinghouse Savannah River Company, Aiken, South Carolina.

Thorson MR. 2006. Basis for Recommendation of Spherical Resorcinol Formaldehyde Resin as the Approved Equivalent to SuperLig® 644. 24590-WTP-RPT-RT-06-001, Rev. 0, Waste Treatment Plant, Bechtel National, Inc., Richland, Washington. 

PNNL-23410

WTP-RPT-230 Rev 0

\section{Distribution*}

Bechtel National, Inc.

FW Damerow

JL Meehan

WTP R\&D Docs
Pacific Northwest National Laboratory

GN Brown

SK Fiskum

RA Peterson

RL Russell

Information Release (pdf)

Project File

*All distribution will be made electronically. 


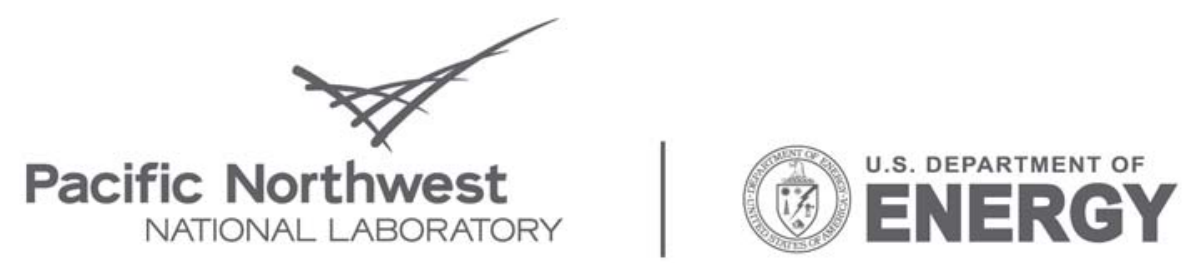

Proudly Operated by Battelle Since 1965

902 Battelle Boulevard

P.O. Box 999

Richland, WA 99352

1-888-375-PNNL (7665)

www.pnl.gov 